University of Louisville

ThinkIR: The University of Louisville's Institutional Repository

Electronic Theses and Dissertations

$5-2007$

\title{
Laboratories of democracy and state brownfield programs.
}

Jaclyn Susan Marie Opp

University of Louisville

Follow this and additional works at: https://ir.library.louisville.edu/etd

\section{Recommended Citation}

Opp, Jaclyn Susan Marie, "Laboratories of democracy and state brownfield programs." (2007). Electronic Theses and Dissertations. Paper 1082.

https://doi.org/10.18297/etd/1082

This Doctoral Dissertation is brought to you for free and open access by ThinkIR: The University of Louisville's Institutional Repository. It has been accepted for inclusion in Electronic Theses and Dissertations by an authorized administrator of ThinkIR: The University of Louisville's Institutional Repository. This title appears here courtesy of the author, who has retained all other copyrights. For more information, please contact thinkir@louisville.edu. 


\author{
By \\ Jaclyn Susan Marie Opp \\ B.A., University of Colorado- Boulder, 2001 \\ M.P.A., Western Kentucky University, 2003
}

\author{
A Dissertation \\ Submitted to the Faculty of the \\ Graduate School of the University of Louisville \\ in Partial Fulfillment of the Requirements \\ for the Degree of
}

Doctor of Philosophy

Department of Urban and Public Affairs

University of Louisville

Louisville, Kentucky

May 2007 
Copyright 2007 by Jaclyn Susan Marie Opp

All rights reserved 
“LABORATORIES OF DEMOCRACY” AND STATE BROWNFIELD PROGRAMS

By

Jaclyn Susan Marie Opp

B.A., University of Colorado-Boulder, 2001

M.P.A., Western Kentucky University, 2003

A Dissertation Approved on

April 9, 2007

(Date)

By the following Dissertation Committee

(Dissertation Director) 


\section{DEDICATION}

This dissertation is dedicated to my family

Christopher Patrick Opp

and

Victoria Lisa Opp

who have given me invaluable patience and unconditional love. 


\section{ACKNOWLEDGMENTS}

I would like to thank Dr. Peter Meyer for being the most patient, helpful, and valuable advisor any student could ask for. He has given me invaluable assistance, advice, opportunities, and guidance over the past several years. Working with him has truly been a pleasure and will be greatly missecl in the future. I also would like to thank all of my committee members. Dr. Cynthia Negrey, who introduced me to the beauty of qualitative research; Dr. David Imbroscio who has always helped me think outside of the box; Dr. Gennaro Vito, who has given me a very unique and valuable perspective; and Dr. Thomas Lyons who, in addition to a multitude of academic contributions, has graciously and routinely served on this dissertation from New York. Each has provided valuable input, guidance, and comments over the course of this research. Finally, I would like to express my thanks to my family. My husband and daughter are owed a deep debt of gratitude for so patiently waiting and encouraging me through this process. Also the deepest thanks and gratitude is owed to my grandmother, Louise Watkins, and my mother, Lisa Macner, the two strongest women I have ever known. 


\begin{abstract}
"LABORATORIES OF DEMOCRACY” AND STATE BROWNFIELD PROGRAMS

Jaclyn Susan Marie Opp
\end{abstract}

May 12,2007

Public investment and interest into brownfields has increased markedly in the past two decades. However, scholarship has not kept pace with this growth. Every state in the U.S. has created a brownfields program to deal with the presence of these properties in their state. However, the mechanisms offered in these state programs to facilitate brownfield remediation and redevelopment has gone untested and underresearched. This dissertation gathered data on all fifty state brownfield programs and the related Resource Conservation and Recovery Act (RCRA) enforcement and inspection data. The fifty state data was then supplemented with three state case studies using in-depth interviews with key participants and policymakers.

The findings of this dissertation demonstrate that a great diversity in mechanisms to facilitate brownfield remediation and redevelopment exists across these programs. The findings also illustration a level of disinterest by political officials in the monitoring of these programs. Furthermore, program officials indicate a significant connection and responsibility to the entity that gives them the most money- the EPA. Overall, the diversity across the states, lack of political interest, and influence of individual EPA Regions offers some insights into the potential for serious unanticipated consequences of 
the movement to protect liability from environmental contamination while offering public resources to redevelop brownfields. This dissertation also finds that the related RCRA program may offer an indicator for environmental protectiveness of a particular state. 


\section{TABLE OF CONTENTS}

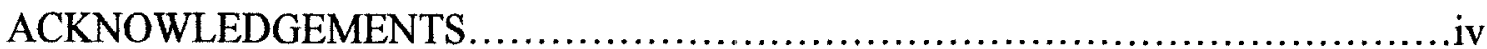

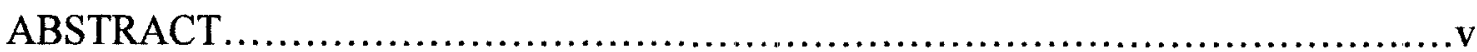

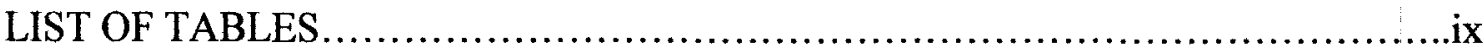

CHAPTER

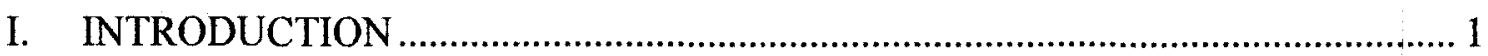

Research Objectives and Significance .............................................................. 4

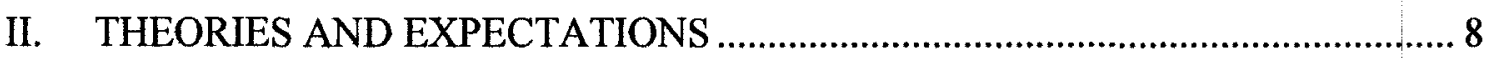

Environmental Federalism--- So why the states? ............................................... 9

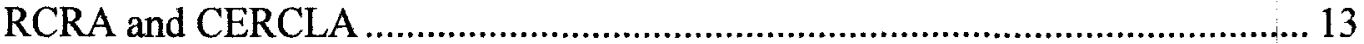

Political Control and Bureaucratic Discretion Theories ...................................... 22

Bureaucratic Discretion, Political Control, and State Brownfield Programs........ 30

III. DATA COLLECTION AND METHODS ……................................................ 32

Database Data Collection and Methods............................................................... 32

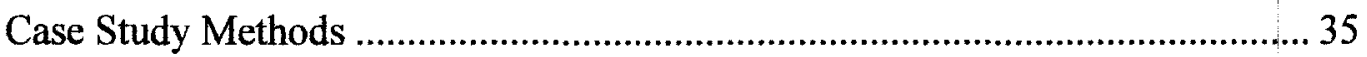

IV. EXPERIENCES OF THE LABORATORIES ….............................................. 42

Voluntary Cleanup Programs - a consistent overall approach by the States....... 44

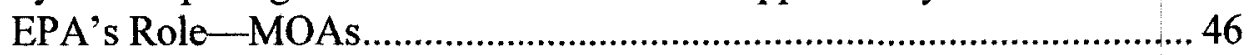

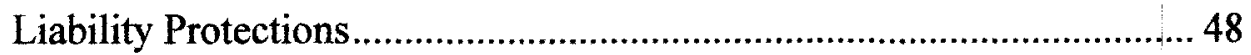

Responsible Party Participation ................................................................ 49

Financial Considerations, RBCA, and Land Use Controls..................................56

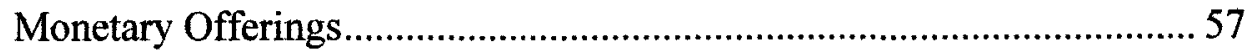

Assessment Grants ............................................................................. 58

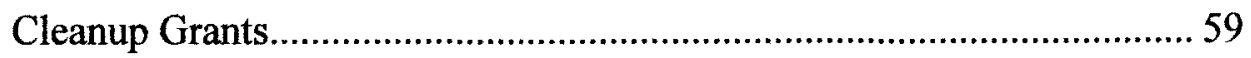

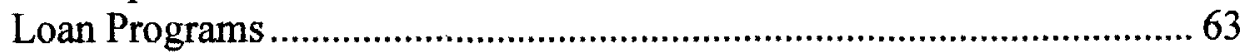

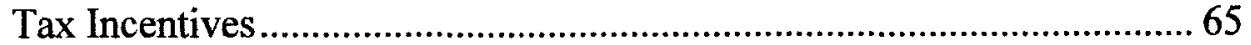

Income Tax Credits or Deductions for Cleanup Costs ............................. 65

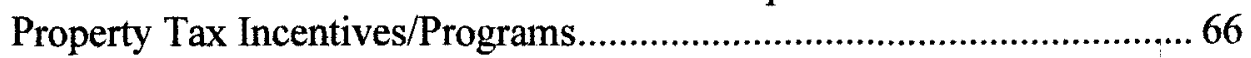

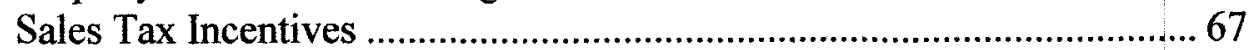

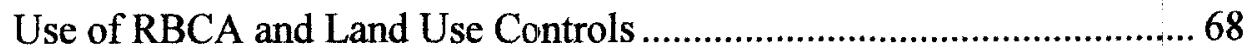

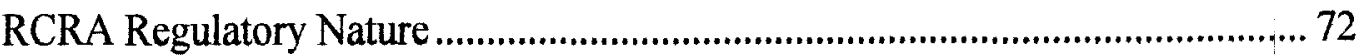

Case Study Selection Rationale ....................................................................... 84 
V. CASE STUDY PRESENTATION ……………......................................... 90

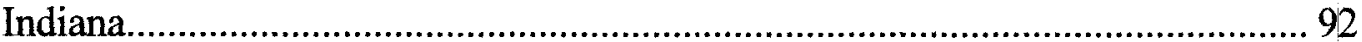

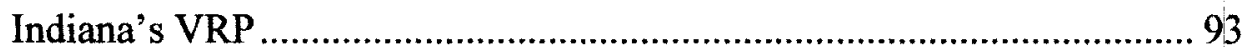

Indiana Brownfields Program ................................................................ 98

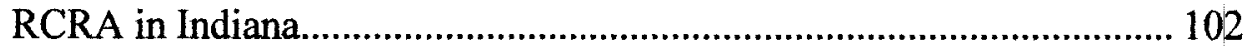

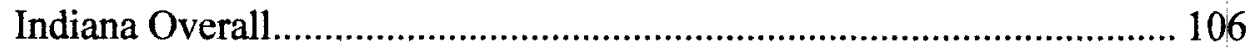

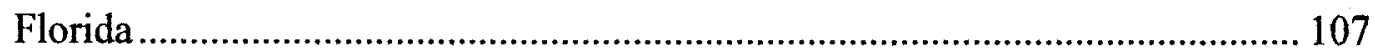

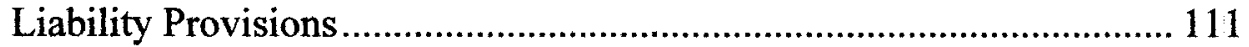

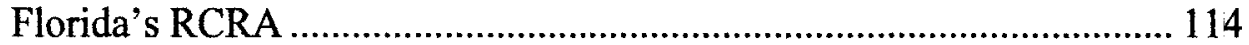

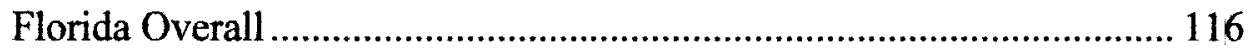

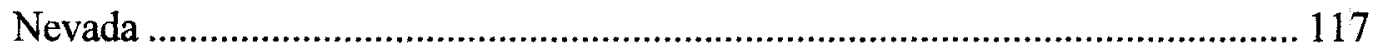

The Land Recycling Program/Brownfields Program ............................ 117

Nevada Voluntary Cleanup Program .................................................... 119

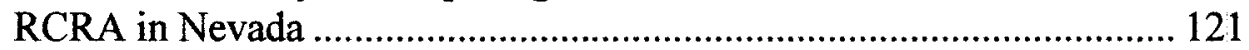

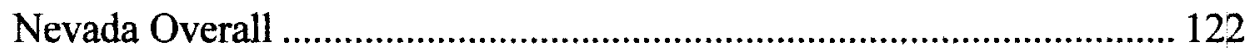

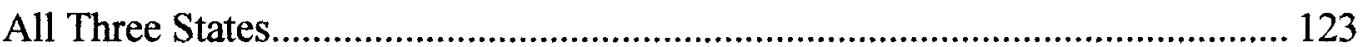

VI. CONCLUSIONS AND POLICY RECOMMENDATIONS............................... 125

What have the "laboratories of democracy" taught us?...................................... 126

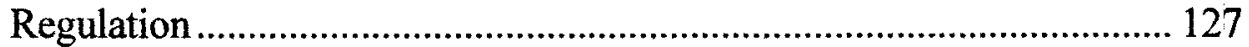

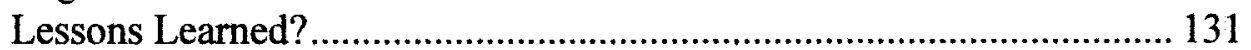

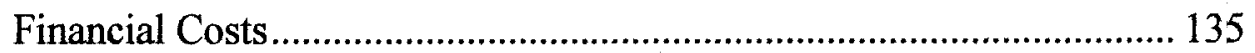

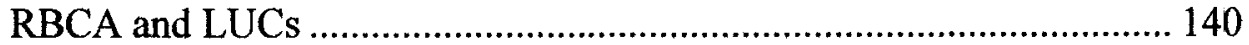

Discretion and Control of the programs? ........................................................ 144

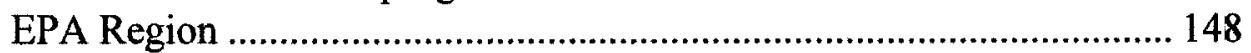

Lower Level Government Involvement.............................................. 149

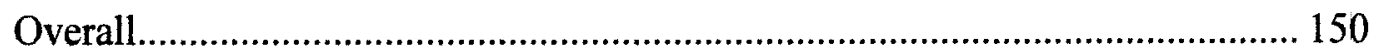

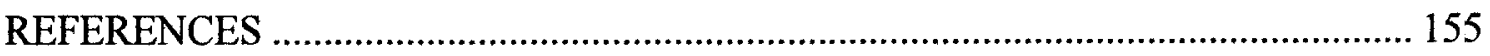

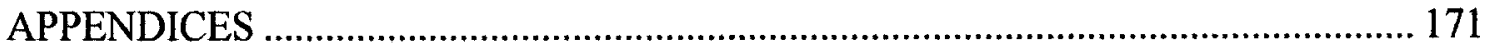

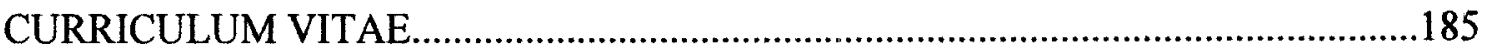




\section{LIST OF TABLES}

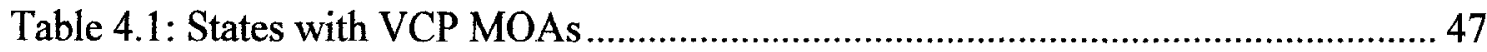

Table 4.2: Programmatic Constraints on RP Participation .............................................52

Table 4.3: Liability Details for States with $3^{\text {rd }}$ Party Protections ..................................... 54

Table 4.4: Adoption Status of Uniform Environmental Covenants Act............................ 71

Table 4.5: Highs and Lows Specific Type of RCRA Facilities Inspections...................... 78

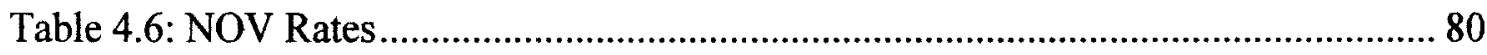

Table 4.7 Correlation of Inspections and Enforcements............................................... 81

Table 5.1: Indiana Industry Employment ............................................................. 92

Table 6.1: RCRA Inspections and BF Missions ...................................................... 127

Table 6.2: Highs and Lows TSD, Transporter Inspections.......................................... 129

Table 6.3: State Liability and Financial Abatement Methods ........................................ 132 


\section{CHAPTER I \\ INTRODUCTION}

Over the past several decades contaminated land issues have increasingly moved to the forefront of political, social, and economic debates in the United States and other western nations (see for example Barnett, 1994; Bartsch and Wells, 2005; Coleman, 1994; Dente, 1995; Meyer, Williams, and Yount, 1995; and Syms, 2004). Over 150 years of neglect and ignorance has contributed to an environmental crisis. Virtually every community in the United States is plagued by some form, and some level, of environmental contamination as a result of past decisions. One environmental problem that has steadily been increasing in recognition, and in corrective action, is that of brownfields.

Brownfields are defined by the Environmental Protection Agency (EPA) as, “... real property, the expansion, redevelopment, or reuse of which may be complicated by the presence or potential presence of a hazardous substance, pollutant, or contaminant" (US EPA, 2005). Estimates of the number of brownfields are generally accepted to be at least 450,000 nationwide (U.S. EPA, 2005; Northeast-Midwest Institute, n.d.). As local and state governments find themselves under pressure to provide more services to their constituents with fewer resources, brownfields become both an obstacle and an opportunity to them. Uremediated brownfields produce few jobs, provide little to no property tax revenue, and contribute to community blight. Communities that can 
redevelop their brownfields are in the position to reap real benefits- environmental, social, and economic.

The private sector has been slow in remediating and redeveloping brownfields for a variety of reasons. Concerns about potential legal liabilities, perceived and actual financial costs of cleanup, technical burden of dealing with contamination, the uncertainties associated with regulatory oversight, and the perceived stigma associated with brownfields all tend to make greenfields more attractive to prospective developers. For all of these reasons brownfield redevelopment is an issue in which the private sector has been unsuccessful in addressing quickly or routinely, even in exceptionally strong real estate markets. Having recognized both the benefits to be had, and the associated costs of brownfields, governments at all levels have taken a lead role in brownfield remediation and redevelopment.

The decision to pursue brownfield remediation and redevelopment has been a political choice that has been made and repeated at all levels of government in the United States. These political choices almost always entail creating a government program to deal with the issue. "A program consists of governmental action initiated in order to secure objectives whose attainment is problematical" (Pressman, 1984, p. xx).

Brownfield properties by virtue of their definition are problems for the local, state, and federal governments. Much like other political choices made in the twentieth century to address a perceived problem, administrative agencies are one of the most heavily relied upon means to achieve the brownfield-related goals of the local, state, and federal governments (Kettl and Fesler, 2005; Rosenbloom and Kravchuk and Rosenbloom, 2005). 
Although the administrative state in the United States has received significant criticism over the past century, it is still a primary means of carrying out the government's policy mandates (Huber and Shipan, 2002; Kettl et al, 2005; Rosenbloom et al, 2005). A Brownfield program, like any other government program, is faced with the same problems, constraints, and benefits that the American Administrative State presents to other areas of government intervention.

As Supreme Court Justice Louis Brandeis so eloquently stated, "It is one of the happy incidents of the federal system that a single courageous State may, if its citizens choose, serve as a laboratory; and try novel social and economic experiments without risk to the rest of the country" (New State Ice Co v. Liebmann, 1932). State experiments into brownfield programs can lend a great deal of information to citizens, government officials, and scholars. These state programs are largely under-researched and provide a valuable opportunity to investigate brownfield programs, program implementation, bureaucratic discretion, and political control of the bureaucracy. The problems that occur as a result of brownfields are of concern to many different groups of people including nearby residents and property owners, political officials, and businesses (both those owning brownfields and those who would benefit from facilitated remediation opportunities). Given this broad impact that brownfields have on society, understanding the government's intervention into this area will likely provide a benefit to a diverse and large group of individuals. To be sure, possessing a deeper, more complex understanding of the government intervention into brownfield remediation and redevelopment can enable and foster the pursuit of viable solutions to the problem of brownfields. 


\section{Research Objectives and Significance}

Brownfield research has been increasing in the past few years and most commonly includes descriptive studies, best examples of innovation in redevelopments, and manuals of resources for prospective developers. Although some research into the local and state government's role in brownfield remediation and redevelopment has been conducted over the last two decades the studies are very underdeveloped and the area remains largely under-researched (See for example, Northeast-Midwest Institute). As research is conducted it is becoming increasingly clear that across the fifty State Governments brownfield programs take a varied approach to facilitating remediation and redevelopment of these properties. Some states have comprehensive resources and opportunities for local governments and individuals to invest in brownfields, while others have minimal influence and resources. This variation provides an interesting and unique opportunity to better understand government intervention into brownfields.

“...Brandeis viewed the states as laboratories in which the Progressives could experiment with new solutions to social and economic problems. Those that worked could be applied nationally; those that failed could be discarded" (Osborne, 1990, p. 2). Brownfield programs offer a unique opportunity to research and record what the different laboratories are doing in respect to brownfield programs. By examining fifty unique programs that are all directed at solving a common problem it will be possible to gain a deeper understanding of the diversity of the mechanisms for government intervention into brownfields, details concerning the implementation and administration of these programs all while providing some insight into the use of public resources. Given the diversity of issues surrounding brownfield redevelopment and the government programs directed at addressing them, this dissertation takes an interdisciplinary, multifaceted look at state 
brownfield programs. This research seeks to further the knowledge of what states are doing in relation to their brownfield programs, how related regulations may impact the programs, and how the complex relationships between the bureaucracy and political officials exert control over these programs shaping them into what they are. In order to effectively understand all of these issues, this dissertation consists of two distinct research steps - with the second step building on, and stemming from, the first step. With little up to date data available on these brownfield programs, this research will require the use of multiple methodologies that are discussed further in Chapter Two. All Fifty State Programs

The first step of this research deals with the fifty state brownfield programs as a whole. Utilizing an annual survey (which is currently overdue for an update) conducted by the EPA this research adds to and expands upon this basic information into state brownfield programs in order to better understand some of the variations that exist in state programs across the fifty U.S. states. The end product of this data gathering is a fifty state database that allows for a deeper understanding and analysis of these programs. In essence the overarching research question in the database of the fifty states is: What are the fifty laboratories doing about their brownfields? Following from that large question several related questions are raised. These questions include: How, if at all, does the regulatory environment of a state influence their brownfield program? What can the states learn from each other? Are there any commonalities across the fifty states that are interesting to the quest for remediation and redevelopment of brownfields?

Although the database of the fifty states provides an expansive view of the variety of programs directed at brownfields-it does not provide a great level of depth on the 
specific day-to-day administration of any of the programs. The complex nature of intergovernmental relationships is particularly interesting to these programs and requires a smaller scale examination to untangle that web. In order to further provide the depth needed to understand the complex nature of these programs a second step of this dissertation involves three comparative case studies directed at further understanding these programs. The use of qualitative research enables this dissertation to better understand the contextual differences that exist in these programs. Drawing upon theories of political control and bureaucratic discretion, this research analyzes three states in depth to try and gain a better understanding of the real story of state brownfield programs. The usage of qualitative methodology to gain insights into these programs is, alone, a significant contribution to this topic. As will be discussed further in Chapter Two, these political control theories and bureaucratic discretion theories are concentrated at the federal level and in the usage of quantitative models-studying far more complex and interdependent state level provides an opportunity to expand on these theories while, at the same time, offering policy suggestions for brownfield programs. The basic research questions in this second step include among others: What are the experiences of the administrators in these programs? How do state political officials impact and monitor these programs? How does related regulation impact the operation and administration of the program? How does the EPA get involved in the administration and implementation of the programs? In the pursuit of these answers the dissertation is organized in the following manner.

Chapter Two provides the overarching theories and expectations for this research. Environmental federalism, regulation, and political control and bureaucratic discretion 
theories are discussed. This chapter provides the theoretical background and expectations required to understand and appreciate the complexities of the remaining chapters in this dissertation. Environmental policy and the shifts in relationships is a very complex subject, which requires an understanding of several pieces of environmental-related literature. Chapter Two provides the necessary information to understand the complex context this dissertation is working in. Chapter Three discusses the methodology used to gather and compile the database. This chapter also outlines the methodology and for the three case studies. Chapter Four presents the findings of the fifty-state database as well as the specific rationale for the selection of the three state case studies which emerges from the findings of the database. Related to Chapter Four is Appendix A and Appendix B which provides a detailed outline of what is included in the database created. This database will be placed online at http://cepm.louisville.edu. Chapter Five presents the findings of the three state case studies. Chapter Six analyzes the data compiled in the database as well as in the three case studies, offers some policy recommendations, and concludes the dissertation. 


\section{CHAPTER II \\ THEORIES AND EXPECTATIONS}

"Brownfields are real property, the expansion, redevelopment, or reuse of which may be complicated by the presence or potential presence of a hazardous substance, pollutant, or contaminant" (Small Business Liability Relief and Brownfields Revitalization Act, 2002). The presence, or potential presence, of contamination has led to reluctance to invest in brownfields on the part of many developers. Although, as pointed out in Chapter One, redeveloping brownfields can reap many rewards, a variety of liability, regulatory, and economic concerns prevent more widespread brownfield redevelopment. The remediation and redevelopment of brownfields has become an area where policymakers have become very interested. "Policy makers at all levels of government have sought ways to encourage the redevelopments in order to generate tax revenues and employment, curb urban sprawl, and remediate contamination that threatens public health and the environment" (Yount and Meyer, 1999, p. 179). Although it is recognized that the public sector has taken a keen interest in brownfields, little is known about the specific processes, successes, and potential lessons of this involvement.

The protection and regulation of the environment is an area where the fundamental tenets of the American government system are tested and are not always in concert with each other. Intergovernmental relations in this area pose some interesting circumstances under which the public brownfield programs operate. The relationships 
that exist across the states, localities, EPA Regions, and national EPA headquarters is a strong influencer on the outcomes and outputs of certain, particularly environmental, programs. "Congress cannot control every decision to be made in implementing a public program...Every policy contains the ability of implementers to make choices, and those choices are made by different people in any number of federal or state agencies..." (Scheberle, 1997, p. 10-11). Understanding the current and evolving context under which these programs operate is both necessary and important to an analysis of public brownfield programs. In order to begin to understand the government's intervention into the brownfield problem it is necessary to understand the history and context in which this intervention is working. This chapter of the dissertation will present the related literature and theories necessary to understand the problem of brownfields and the purpose of this dissertation. Specifically this chapter will start with an overview of environmental federalism and regulation highlighting the logic for studying state level programs. This chapter will then move on to discuss and outline theories concerning the administration of public programs illustrating the importance of understanding the influencers on brownfield program implementation; and will conclude with an overview of the current landscape of brownfield programs in the United States.

\section{Environmental Federalism- So why the states?}

The government at all levels in the United States intervenes in areas and issues considered to create environmental harms. Environmental harms represent a variety of “...physical, biological, and chemical threats to human health or the health of the ecosystems on which we depend..." (Etsy, 1996, p. 2). These environmental harms jeopardize social welfare because of both the damage to human health and because 
environmental resources are a fundamental component, or input, to production processes - be it land, water, or air (Etsy, 1996; Higgs and Close, 2004). Given the complexities of property rights, externalities, and transaction costs it is generally agreed upon that some form of public environmental regulation and intervention is necessary to protect social welfare (Farber, 2005; Higgs et al, 2004; Rosenbaum, 2005; Welborn, 1998).

With regard to personal liberties and property rights, most processes of production exhibit very blurry boundaries-something often referred to as spillovers in the literature (Stewart, 1977). "... the effects of local waste entail both local pollution and some external effects on other (most likely neighboring) jurisdictions" (Oates, 2001, p. 4). For example, if property owner A uses his property to dispose of toxic wastes which then travel to property owner B's property, whose property rights should be upheld? Does property owner A have the right to dispose on his own personal and private property? Or does property owner $\mathrm{B}$ have the right not to be subjected to the runoff from the neighboring parcel? "Cross-boundary pollution, like any interstate externality, is a valid concern in environmental policy" (Adler, 1998, p. 3). These are questions that have been subject to a number of high-profile and contentious court cases and requires government intervention to ensure a predictable and fair answer (Demsetz, 1967; Farber, 2005; Merrill, 1985; Revesz, 1992). Environmental harms tend to be too complex and complicated to be handled solely in the private market and as such the public sector has been involved for many years.

Although the public sector has been involved with regulating and controlling environmental harms for many years, the level of participation at the different levels of 
government has evolved over time. This changing and shifting roles over environmental protection and regulation is often referred to as Environmental Federalism. Much like the overarching arguments and shifts in responsibilities of the varying levels of government in the United States, Environmental Federalism has undergone similar shifts.

In the earliest years the protection of the environment tended to be highly decentralized (Percival et al, 2006; Melosi, 1981; Reitze, 1991). With origins in the 1880s and 1890s many large cities, like New York and Chicago, adopted nuisance laws to deal with garbage dumping and smoke (Melosi, 1981). It was generally believed that the protection from environmental harms was a power and duty of the local governments. It was not until much later that environmental protection became more centralized in nature.

As problems of pollution crossing political boundaries became more widespread or were recognized as such by evolving scientific analysis - the efforts to protect and regulate the environment grew more centralized (Stewart, 1977). "Although some states adopted air and water pollution laws as early as the end of the nineteenth century, state regulation of environmental problems did not begin in earnest until the post-World War II industrial boom. The state regulatory efforts of the 1950 s and $1960 \mathrm{~s}$, however, did little to stem the flow of pollution, and by the mid-60s, the demand for more centralized regulation was growing" (Etsy, 1996, p. 16). With Congress' passage of the Clean Air Act in 1963 and the Clean Water Act in 1965, environmental protection began to move in a more centralized direction with the federal government taking more responsibility for the protection and regulation of environmental related issues. These two federal acts were shortly succeeded by the passages of the Federal Environmental Pesticide Control 
Act of 1972, the 1974 Safe Drinking Water Act, the 1976 Resource Conservation and Recovery Act (RCRA), and the 1980 Comprehensive Environmental Response, Compensation, and Liability Act (CERCLA).

Many scholars have identified a variety of logical reasons that support a more centralized approach to environmental protection (see, for example, Etsy, 1996; Higgs et al, 2004; Oates, 2001; Scheberle, 2005; Stewart, 1977). One most widely touted and discussed idea is that of the 'race to the bottom' problem associated with a decentralized approach. Under the 'race to the bottom' premise a decentralized approach to environmental protection will ultimately fail as a result of the state and local governments that choose to neglect environmental protection in favor of economic development (Percival, Schroeder, Miller, and Leape, 2006; Sheldon, 2006).

Although many scholars believe the central government is the most logical place for environmental regulation and protection, the past several decades has seen a shift to a more decentralized environmental approach-that is the bulk of environmental protection and regulation responsibilities have been shifted down to the state level (Stewart, 1977; Rose-Ackerman, 1995). "Under the Reagan Administration several actions were taken that moved the responsibility for some environmental management back to the states. Indeed, one of Reagan's principles was to shift environmental responsibilities back to the states 'whenever feasible"' (Oates, 2001, p.15). The most recent public involvement into environmental protection and regulation continues to place the central government behind the state governments in terms of implementation and administration. "Since 1970, which marks the beginning of the first significant involvement of the national government in environmental protection, Congress has designed most federal 
environmental programs so that they could be administered at the state and local levels" (Sheberle, 1997, pg. 4). In fact, according to the Environmental Council of the States (ECOS), approximately $90 \%$ of all federal environmental programs are meant to be implemented and administered by the state governments (ECOS, 2006). Outside the normative views about the proper level of environmental regulation and protection, states have, indeed, become a pivotal and primary actor in the protection and regulation of the environment making this level of government intervention into brownfields logical to study. Although environmental protection and regulation takes on many different and varying types of environmental harms, of particular interest to this research are the laws and regulations contributing to and influencing brownfields. The Resource Conservation and Recovery Act (RCRA) and the Comprehensive Environmental Response, Compensation, and Liability Act (CERCLA) are the most salient federal acts for this purpose.

\section{RCRA and CERCLA}

Hazardous substances can be defined as ".... very large category of chemicals that exhibit corrosive, ignitive, reactive, or toxic characteristics" (Ringquist, 1993, p. 18). "Hazardous wastes pose a substantial threat to public health and the environment. When hazardous wastes are disposed of improperly, they contaminate soil, air, surface water, and ground water and threaten the well-being of humans and other organisms" (Barnett, 1994, p. 9). Prior to the enactment and implementation of the Resource Conservation and Recovery Act (RCRA) in 1976 only air and water were protected from hazardous disposal (Meyer, Williams, and Yount, 1995). With the passage of RCRA and the Toxic Substances Control Act (TSCA), both in 1976, and the Comprehensive Environmental 
Response, Compensation, and Liability Act (CERCLA) in 1980 contamination of land became an area where regulation intervened.

“...two federal statutes are most important in regulating the treatment and disposal of hazardous substances. These include CERCLA and the Resource Conservation and Recovery Act..." (Meyer et al, 1995, p. 60). While RCRA seeks to ensure hazardous waste is not disposed of improperly - thereby threatening the environment and human health; the original language of CERCLA sought to deal with the sites that were abandoned or where the person responsible can not be found or did not have the capacity to pay for the damages caused. CERCLA was subsequently amended in 2002 with the passage of the Small Business Liability Relief and Brownfields Revitalization Act which worked to shift the focus of CERCLA away from only orphaned sites. This change to CERCLA sought to eliminate some of the liability concerns associated with CERCLA and to promote the cleanup of brownfields. These two federal acts have instigated cleanup of contaminated sites and helped prevent future contamination - but at the same time may have discouraged their redevelopment. $R C R A$

RCRA was passed in order to closely monitor the utilization of toxic materials in production and the generation and disposal of hazardous waste. It was created initially as an amendment to the Solid Waste Disposal Act of 1965, which had no specific focus on toxics in the waste stream. In its current form RCRA has ten subtitles: A-J. Of these subtitles, three create programs while the remainder deals with provisions of oversight, duties, and other regulatory issues. The three regulatory programs established through 
RCRA deal with both land and water. These programs are Solid Waste, Hazardous Waste, and Underground Storage Tanks (USTs).

Subtitle C of RCRA deals with hazardous waste. This portion of RCRA is often referred to as a "cradle to grave" control mechanism since it regulates the entire life of hazardous materials. RCRA has two major parts to it as they related to hazardous waste. First, all treatment, storage, and disposal (TSD) facilities must obtain, and periodically renew, a permit. Permitted facilities are also required to demonstrate financial capacity to pay for the closure, cleanup, and post closure care of their site. This feature is particularly important in regards to the past creation of, and the avoidance of future, brownfields. A second major part to RCRA is the creation of a system of inspections and enforcement actions on facilities that generate or transport hazardous wastes. Unlike the TSD facilities, these entities are not required to demonstrate financial capacity to pay for cleanups, however, they are subject to corrective action orders as a result of violations of RCRA. An interesting component to RCRA that is worth noting is that “...EPA's regulations have long provided that a generator may accumulate its own hazardous wastes in tanks or containers for up to 90 days without triggering TSD status" (Percival et al, 2006, p. 358). This means that many generating facilities that are not subject to the financial assurance and permitting requirements of TSD's can continue being classified as a generator, even if they have continuously full containers or tanks of hazardous wastes. This can be achieved by storing wastes for 90 days, sending that waste to a TSD, and replacing that waste with new waste. This loophole in RCRA can potentially have significant implications for brownfields and brownfield programs. 
Intergovernmental relationships and interdependencies strongly influence the processes and administration of RCRA. The EPA sets basic minimums and requirements while states do much of the front line implementation and administration. "When RCRA was written, it was Congress' intent for the states to assume primary responsibility for implementing the hazardous waste regulations, with oversight from the federal government" (US EPA RCRA Orientation Manual, III-137). States may be granted the authority to carry out the duties of the EPA with regards to RCRA by enacting a similar hazardous waste program, so long as it is at least as comprehensive and strong as the federal guidelines. Currently 48 states operate their own base RCRA program authorized by the EPA, with Alaska and Iowa having no EPA authorizations (US EPA StATS database, 2006).

In most instances, State environmental agencies take the primary role in compliance assurance. This role includes educating the regulated community on the requirements, reviewing and approving necessary permits, inspecting for compliance with applicable laws and permit terms, detecting violations and taking appropriate enforcement response... (US EPA ECHO FAQ).

RCRA administration by the states is an example of how multiple levels of government can all be involved and impacting on the results and outputs of a government program. In addition to the minimum requirements outlined by the federal EPA, each state's program is also impacted by their EPA regional offices, state oversight, and state capacity to run the program. The state level administrative agencies capacity to properly and comprehensively regulate and inspect the population of regulated entities is something that has been called into question in the past (Barnett, 1994). The complex and interdependent relationships existing in the administration of RCRA poses interesting, and potentially harmful, questions for brownfields and the programs directed at cleaning 
and redeveloping them. In all of the RCRA authorized states, RCRA programs are administered through the same administrative agency that deals with Superfund and Brownfields. Although at this juncture brownfields and RCRA are not absolutely connected or reliant upon each other, a state's performance in RCRA may be a useful indicator for the regulatory nature of a state may be. More will be said on this in the following chapter.

\section{CERCLA}

"After 1980 , the history of RCRA became tightly intertwined with that of CERCLA... by and large, RCRA has become the locus of Congress's prevention concerns, while CERCLA tackles the problems of cleaning up past mistakes..." (Percival et al, 2006, p. 320). The act has direct implications for brownfield sites and has gained greater publicity than RCRA. CERCLA established prohibitions and requirements for dealing with brownfields, provided for liability or financial responsibility for contamination, and established a trust fund (Superfund) to finance cleanup when no responsible party could be identified.

After the EPA began seriously enforcing CERCLA, courts broadly interpreted the Act with regard to strict 'joint and several liability'. This meant that each of the responsible parties at a site can be liable for the entire cost of cleanup, so long as the harm caused by each party is indivisible from harm that other parties caused (Grayson, 1995). Under the original CERCLA regulations new owners- sometimes not even knowing the contamination existed-could be, and sometimes were, held liable (Coffin and Shepherd, 1998; Ellerbusch, 2006; Hodge, 1996; Ryan 1998; Schwab, 1997). 
Of particular concern are the principles of "strict" and "joint and several" liability. "Strict" liability does not require the demonstration of any wrong-doing. This means that even if the contamination actions taken were legal at the time they were done, a party may still be held accountable for the costs of clean-up and environmental damages. This liability is also retroactive, meaning that even if the pollution occurred prior to the passage of CERCLA in 1980, one may still be held accountable. "Joint and several" liability comes into play when there are several PRPs, and means that any one or all of the parties who might be even remotely associated with the pollution may be held responsible for the entire cost of clean-up (Meyer and Van Landingham, 2000, p. 4).

The aftermath of the liability concerns associated with CERCLA resulted in a negative stigma and a widespread reluctance by the private sector to deal with brownfields. In fact even financial institutions were reluctant to lend money for brownfield projects for fear of becoming liable themselves under broad court interpretations of liability under CERCLA. "Large cleanup expenses combined with a lack of legal finality leads potential developers and investors to choose uncontaminated suburban land (greenfields) over the more risky brownfields" (Eisinger, 2001, $\llbracket 1$ ).

CERCLA underwent several amendments attempting to ease liability concerns. Some of the most notable amendments occurred in 1996 with the passage of the Asset Conversion, Lender Liability, and Deposit Insurance Protection Act to offer lenders liability protection against being held liable for contamination on properties that they may have provided financing for. Additionally and more recently, CERCLA was amended in 2002 with the previously mentioned Small Business Liability Relief and Brownfields Revitalization Act. Regardless of these amendments, stigma over brownfields has remained. “...CERCLA liability has significantly retarded efforts to renovate brownfield lands and buildings through its impacts on perceived real estate investment returns is a belief widely promoted by policy analysts and practitioners" (Meyer et al, 1995, p.84-5). 
More than 25 years have passed since CERCLA was created and it has been extensively analyzed. The major complaints, as summarized by Percival et al (2006) are:

- Joint and Several Liability results in unfair allocations of financial responsibility

- A litigation-driven system funnels too much CERCLA money into transaction costs and too little into site cleanup

- The cleanup process is too slow and often ineffective

- Cleanup standards are too stringent; one size fits all health based standards are inappropriate and impair productive uses of land

- Where EPA does have discretion, remedies are uneven from site to site

An important difference exists between a Superfund site and a Brownfield site that must be understood. There are approximately 1300 Superfund sites out of an estimated 500,000 or more sites with contamination (brownfields). Superfund sites are listed on the NPL and undergo a federal cleanup. In addition to the federal Superfund sites there are also State Superfund sites. Each state determines their list in its own way, and some states do not even have one. Some of the state Superfund sites are the same as the federal sites; others are different. Many states have modeled their state program after the federal law or have tried to improve upon the federal law. Generally, the state programs have allowed the states to take emergency response activity, compel responsible parties to perform cleanup, develop its own state list and cleanup standards, and finance staff, studies, and remediation.

CERCLA and State Superfund lists have markedly become less active over the past several years with brownfield programs taking a much more upfront role in contaminated properties, a fact that many do not realize. 
In fact, because federal and state CERCLA programs are close to moribund with respect to the identification and remediation of new sites, brownfields programs are likely to be used to address even very seriously contaminated sites that are not already subject to a CERCLA cleanup. (Dana, 2006, p. 87)

CERCLA decline is often attributed to several factors. First, the Superfund Tax expired in 1995 and was never reauthorized, leaving Superfund cleanups fighting for an ever shrinking pool of discretionary funds at the federal level (Percival et al, 2006). Additionally, judges have become less inclined to enforce CERCLA as strictly as in the past (Dana, 2006). State brownfield remediation programs are increasingly taking on more of the extremely contaminated sites and most do not have provisions excluding properties based on level of contamination (Environmental Law Institute, 2002).

\section{RCRA, Superfund, and Brownfield Programs}

In principle, RCRA sites can become Superfund sites. A RCRA regulated facility that does not properly close or does not adequately protect the environment and human health can become a Superfund site. Given that the EPA provides authorizations to the state to administer the RCRA program, a state failure to properly oversee and enforce RCRA regulations can also transform a RCRA facility into a Superfund site. "State failure to adequately oversee existing facilities and to enforce compliance with regulatory requirements increases the likelihood of ground water and other environmental contamination" (Barnett, 1994, p. 88).

Given the fact that additions to the Superfund site lists have markedly decreased in the past several years, RCRA facilities that are not properly inspected, enforced, and closed will likely have an impact on a state's brownfield problem- not on its Superfund problem. More specifically, in addition to possibly becoming Superfund sites, RCRA facilities that contaminate land or ground water can become brownfields if the 
responsible party does not properly address the contamination through response actions, closure, or post closure care. Again, given that 48 states administer their own base RCRA program; wide differences often exist across the states in relation to RCRA inspections and enforcements. Significant differences in inspections and enforcements can contribute to a state's brownfield problem.

As Barnett (1994) points out "[t]he characteristics and strengths of state Resource Conservation and Recovery Act programs depend on the current activism and political power of affected interests as well as on historic patterns of environmental policy making and control" (p. 89). Inevitably variations across the fifty state's RCRA programs will result in impacts on a state's brownfield problem either through an increased inventory of brownfields or by jeopardizing the effectiveness of the public solution (program).

The public solution to a state's brownfield problem has been to create and administer state remediation and redevelopment programs. In public administration literature a great deal of scholarship exists concerning how and why policies get implemented as they do. Specifically, a stream of literature exists that deals with what influence political actors and non-elected administrators have on policies and programs. This literature is particularly important and salient to the study of brownfield programs. As brownfield programs take on more of the heavily contaminated properties, invest millions of dollars, and become more widespread it is an ideal time to explore how these programs facilitate brownfield remediation and redevelopment, as well as why they work the way they do. The following sections outline the theories associated with implementation variations as a result of elected and non-elected administrators' influences. 


\section{Political Control and Bureaucratic Discretion Theories}

In the last century Americans have demanded much more of and from their government. These demands have contributed to the wide expansion of what is often termed the American Administrative State (Kettl and Fesler, 2005; Rosenbloom et al, 2005). This expansion and growth of a fourth branch of government has spurred numerous debates and lengthy discourse over the relationships and the proper role of a non-elected administrative cadre in a democracy (Calvert, McCubbins, and Weingast, 1989; Davis, 1976; Gilmour and Halley, 1994; Huber, Shipan, and Pfahler, 2001; Huntington, 1952; Kingdon, 1995; Meier, 1993; Svara, 1994; Wilson, 1989; Wood and Waterman, 1994).

This immense growth in bureaucracy has not been without resistance and calls for change and reform. In fact, over the past two decades Americans have seen two largescale federal initiatives to fix the bureaucracy - reinforcing the widely held idea that the bureaucracy is broken. In 1993 the federal National Performance Review was initiated to deal with the bureaucracy and its inefficiencies. "... to change the culture of our national bureaucracy away from complacency and entitlement toward initiative and empowerment" (Clinton NPR Speech, 1993). Less than a decade later a new president and a new initiative surfaced, again to fix the bureaucracy. "The need for reform is urgent" (President's Management Agenda, 2002, p. 3). Although these two reform efforts are the most recent and notable, bureaucracy reform efforts span over the past century. In fact one prominent scholar aptly noted that, "No politician ever lost votes by denouncing the bureaucracy" (Wilson, 1989, p. 236). 
The bureaucracies that are charged with carrying out so many of America's programs, regulations, and policies are generally regarded in a less than favorable manner. "Citizens widely believe that bureaucracies are slow, lumbering giants that accomplish little and are generally unresponsive to public preferences" (Wood and Waterman, 1994, p. 2). The rhetoric that surrounds the ideas that bureaucracies are wasteful, inefficient, and incompetent is often connected to an idea that administrators or bureaucrats ignore or change the policy mandates given to them by the elected officials (Bawn, 1995; Huber, Shipan, and Pfahler, 2001). This presupposition, if true, is antithetical to the entire foundation of the American democracy. By constitutional design the democratic control of government relies upon the relationship between the elected representative and his or her constituents. The voters' ability to elect representatives and subsequently elect different representatives at their discretion provides some semblance of assurance that the citizens' wills are being expressed in the policies promulgated in the federal and state legislatures. As our society has grown increasingly more complex, the delegation of power to non elected administrators has grown immensely. It has been pointed out that many bureaucrats exercise managerial (executive), legislative, and judicial power as a result of elected officials' delegation of powers to them (Kettl and Fesler, 2005; Rosenbloom et al, 2005; Wood and Waterman, 1994). This delegation of power seemingly opens the door for the unelected bureaucrats to manipulate and shape policies without any accountability to the citizenry. Wood and Waterman (1994) point out that "[t]his extensive delegation of power to the bureaucracy also violates the principles of separation of powers and checks and balances" (p. 7). 
Interestingly enough, many of the current facets of bureaucracy that are perceived to be problems were deliberately created over a century ago. Still reeling from the corrupt and inefficient spoils system it was widely accepted that politics and administration should be separate—-the so called politics-administration dichotomy. "The proposed politics-administration dichotomy was a normative, not an empirical, debate" (Wood and Waterman, 1994, p. 15). Early public administration scholars viewed the proper role of administration as simply administering the policy mandates as dictated by the elected officials (Wilson, 1887; Goodnow, 1900). "The dichotomy was broadly accepted in American public administration until the mid-1900s, when Dwight Waldo and Herbert Simon challenged the dichotomy..." (Frederickson and Smith, 2003, p. 16). These first two scholars to recognize that administration is not, and cannot be, truly separate and insulated from politics came to this realization for different reasons.

Dwight Waldo, writing in 1946, believed all administrative acts were inherently political. Conversely, Herbert Simon, writing in 1947 , believed it was empirically difficult to separate politics from administration and administration from politics. Following from these initial two scholars, it became widely accepted that, in fact, no politics-administration dichotomy exists (Appleby, 1949; Long, 1949; Simon, 1947; Waldo, 1946). However, “...in the 1980s, the dichotomy reemerged and is now alive and well and found in control of bureaucracy theory" (Frederickson et al, 2003, p. 16). Control of bureaucracy theory has several assumptions and characteristics inherent with those who study it. First, bureaucracy theory allows for a distinction between political and administrative acts thereby allowing for valuable analysis of the interaction and relationships between the two. Secondly, the theories often rest upon an inherent distrust 
of administrative power. Finally, theorists studying the political control of the bureaucracy often subscribe to the belief that the elected officials should control the nonelected administrators. One prominent scholar explains the context of these theories well:

...different approaches to the study of administration usually come from one of two conflicting traditions in American politics-and each tradition leads to a very different perspective on the role of administration in American democracy. Some students of administration come to the subject with a fundamentally Hamiltonian bent. Like Alexander Hamilton they seek a vigorous state vested with a strong administrative apparatus. Other students of administration, however, are fundamentally Madisonians. Like Madison, they see a delicate balance of power the best protection against tyranny. The competitions of political interests, in their view, lessen the risk that bureaucracy can abuse individual liberty (Kettl, 1993, p. 407).

Although opinions on whether the bureaucracy can be controlled by elected officials or whether the bureaucracy influences policy in its own right are still extremely varied and as of yet unresolved, one thing tends to be agreed upon across relevant scholarship. That is, a general consensus exists across scholars that a variety of forces shape policy during implementation (Pressman and Wildavsky, 1984; Lipsky, 1980; Palumbo and Calista, 1990; Rosen, 1998; Wood and Waterman, 1994). Some scholars point to bureaucratic discretion (Handler, 1992; Hawkins, 1992). Other scholars point to legislative or political control mechanism's influence on implementation (Banks, 1989; Bendor, Taylor, and Van Gallen, 1987; Aberbach, 1990; Huber, Shipan and Pfahler, 2001).

Given the pervasiveness of bureaucratic activity, it is not surprising that political scientists long have sought to understand the relationship between legislatures and agencies. Understanding this relationship is essential to democratic theory, as it focuses attention on the legitimacy of the role played by unelected policymakers in a representative democracy. 
Furthermore, it sheds light on the actions, abilities, and motivations of legislators (Huber, Shipan, and Pfahler, 2001, p. 330).

In the quest to understand and deal with the relationship between bureaucracy and elected officials two distinct approaches have been taken in scholarship. The first is that of the traditional or bureaucratic dominance approach. The second is that of the political or legislative control approach.

\section{Traditional or Bureaucratic Dominance}

Under this approach to the study of administrative-political power views power delegation to administrative units and officials as creating a heavily insulated bureaucracy with a substantial principle-agent problem (Kaufman, 1981; Rourke, 1976; Wilson, 1980). In essence scholars taking this approach recognize that bureaucrats have information, time, and resources concerning their activities that elected officials do not have-leading many scholars to believe that the balance of power is tipped in favor of the bureaucrats (Mayhew, 1974; Fenno, 1978; Niskanen, 1971; Katzmann, 1980). Relevant literature has identified several related facets of bureaucracy that lend credence to this view of bureaucratic dominance. For example, lengthy career service is viewed as creating a close-knit community that often outlasts political appointees enabling them to capture even more power (Heclo, 1977; Kaufman, 1981).

Scholars writing about and in this approach to political-bureaucratic power dynamics tend to view the outlook in a very dismal manner for an effective political control of the bureaucracy. Bureaucrats are seen as power hungry and self interested with political officials having little means or even desire to control them (Cronin, 1980; Huber and Shipan, 2002; Noll 1971; Ogul, 1976). Several related and early streams of 
research also imply that political officials have little control over bureaucrats. Paramount to this research came from many early economic analyses of the bureaucracy which regarded the bureaucracy as a self-seeking individual in a market which seeks power and hides information (Buchanan and Tullock, 1965; Downs, 1967). Another notable example is that of capture theory which often pays close attention to regulatory agencies. Capture theorists emphasize the clientele relationships that develop between various agencies and their respective groups to demonstrate that bureaucracies are captured by these groups and therefore are even further insulated from political influences (Bernstein, 1955; Lowi 1969; Stigler 1971). Other arguments exist that expand upon individual's distastes and distrust of bureaucracy. For example, Kettl (1993) states:

Americans have long had a reverence for private markets to match their dislike of public power. Markets seek efficiency; government may not. Markets promote choice, in quality and price; government does not. Markets offer competition; government has a monopoly. The distinction between private liberty and public authority has always been a critical one in American society.

In addition to the scholarship on how elected officials can't control the bureaucracy, some scholars go so far as to state that the political officials voluntarily or strategically design policy so that administrators have discretion (Huber and Shipan, 2002). More specifically, in the face of divided political ideology or interests policymakers may develop policies that are deliberately vague so that the policy passes through the legislature. American distrust of bureaucracy is not likely to be easily changed; however, competing theories have emerged. 


\section{Political Control of the Bureaucracy}

In response to theories and research that indicated that political officials had little control or influence over bureaucratic affairs a competing approach emerged. This approach is sometimes termed congressional or legislative dominance, legislative control, or political control theories. Proponents and subscribers to political control theories argue that elected officials, in fact, have very powerful means by which to control the bureaucracy. Earlier examples tended to focus on ex post controls-that is reactive measures to get bureaucrats to cede to political officials wills. Common ex post controls include new legislation, oversight and monitoring arrangements, budget cuts, and new political appointees (Key, 1959; Meier 1993; West, 1997). Political dominance theorists often cite ex post controls as enabling the current legislatures to control bureaucrats now, that is the current elected officials are able to pressure the bureaucracy to cede to its' will.

The most recent and popular addition to this approach is often termed agency theory.

Agency theory explicitly assumed that elected officials (principles), such as the president and members of Congress, had political incentives to control the bureaucracy (agents). Unlike the earlier writings on bureaucracy, which were historical studies based on subjective assessments, most of the agency theory literature was based on hard quantitative evidence" (Wood and Waterman, 1994, p. 22).

Agency theorists tend to believe that political officials control the bureaucracy because they create/design the bureaucracy (McCubbins, Noll, and Weingast, 1987). That is, these theorists tend to believe political officials exercise powerful ex ante controls. "Studies of ex ante influence look at the ability of the current legislature to influence the future activities of agencies. These studies argue that through careful design of structures 
of bureaucracies and bureaucratic life shape and control policies and implementation. These aspects often include: administrative resources, agency values, public demand for services, and citizen ideology (Keiser and Soss, 1998).

\section{Bureaucratic Discretion, Political Control, and State Brownfield Programs}

Although, as evidenced by the scholarship outlined in this chapter, some interesting and powerful insights into the relationships between the elected legislators and the non-elected bureaucrats have been presented in past literature, this dissertation provides several valuable additions to this topic and is directed at expanding on current theories, not testing them. First, the majority of political control and bureaucratic discretion studies have been conducted at the federal level (Frederickson, 2003). Rather than study the federal government, this dissertation studies the state level bureaucracy and political actors. The state level provides a rich, complex set of actors to study in uncovering influences on brownfield programs. Secondly, it has been pointed out that most of the political control studies have involved complex quantitative models. Having a rich body of research on bureaucratic and political control issues at the federal level, this dissertation seeks to inform theory by analyzing state level bureaucracy where more complex relationships exist. Since an exploratory inquiry to state brownfield programs is a primary purpose of this dissertation, qualitative research methodology is used for this purpose. This research attempts to shed light on the complex nature of state brownfield programs in relation to bureaucratic discretion and political control coupled with the complexities of intergovernmental and inter-programmatic relationships which are germane to environmental programs and regulations. The following chapter of this 
dissertation provides details on how this dissertation will proceed methodologically to accomplish the goals of this dissertation which were outlined in Chapter One. 


\section{CHAPTER III}

\section{DATA COLLECTION AND METHODS}

In order to accomplish the goals of this dissertation this project involves two distinct data collection methods and outputs. First, as pointed out previously, this dissertation seeks to inform and add to theory, not test it. In order to accomplish this goal a two step data collection process was employed. First, in order to begin to understand how state governments are intervening in brownfield remediation and redevelopment, it is necessary to have a clear understanding of what exists across the fifty states. The first step in data collection for this dissertation involved creating an exhaustive database of key components of state brownfield program efforts. Following from the insights and lessons of the fifty-state database, three states were selected for in depth comparative case studies.

\section{Database Data Collection and Methods}

The database created in this dissertation drew initial and basic information from an annual EPA survey (State Brownfields and Voluntary Response Programs: An Update from the States, 2005). Although the EPA survey provided some valuable information, the survey is not completely accurate and lacks a number of important and relevant pieces of information. In order to properly and accurately record and expand on this survey, this dissertation undertook a multi-step process that was partially driven by the theories presented in the previous chapter of this dissertation. 
The first step of the data collection process included inputting all information from the EPA survey into a spreadsheet. The data contained in the survey was then checked across all fifty states using state statutes, administrative codes, web pages, news articles, and personal contacts. In the EPA survey the data is contingent upon the return of the survey by the individual state. With this reliance on personal survey responses, the data is not always answered by the most knowledgeable person. The survey lacks an effective check on this fault to determine whether it is accurate information. In a number of states the data was found to be inaccurate in the EPA survey. Additionally, a number of states were missing some of the most basic information fields. This dissertation checked and filled in all gaps in the basic information. Basic information included the year the program was created, number of programs, liability protections offered, financial assistance offered, and state statute references.

Given this dissertation in drawing upon intergovernmental relations, bureaucratic discretion, and political control theories, data was added to the database based upon the findings of previous scholarship. In order to properly encompass previous scholarship the key pieces of information that were added included: administrative organization, ideology measures of policy inception year, employees in agency, appointed or merit status of head of agency, formal name of the program(s), types of liability protections offered, $3^{\text {rd }}$ party liability information, financial assistance offered in minute detail, costs to enter the program, relationships with other administrative agencies in the state, CERLCA 128a Funding, and RCRA inspection and enforcement data. Most of this data was retrieved from statutes, web pages, documents from programs, and personal 
communications. However, the RCRA information was retrieved from an EPA database called ECHO or Enforcement and Compliance History Online.

The RCRA information was retrieved over several days in July 2006. In the online database only the previous three years of data are available. The information retrieved included all regulated industries in the state for the immediate three year period before July 2006. The following pieces of information were retrieved and calculated: Number of regulated facilities, number of inspections, number of informal enforcements, number of formal enforcements, number of EPA enforcements, and number of facilities in significant non-compliance (SNC) status. A second step of data collection was completed in this ECHO database. The specific facility type information was gathered in much the same way the entire universe was collected. RCRA regulates specific types of facilities: Large Quantity Generators (LQG) that produce more than $1000 \mathrm{~kg}$ of hazardous wastes a month; Small Quantity Generators (SQG) that produce less than 1000 $\mathrm{kg}$ but more than $100 \mathrm{~kg}$ of hazardous wastes a month; Conditionally Exempt Small Quantity Generators (CESQG) that produce less than $100 \mathrm{~kg}$ of hazardous wastes a month; Transporters that transport hazardous wastes between sites, to disposal facilities, and to storage locations; and Treatment, Storage, and Disposal (TSD) facilities that treat, store, or dispose of hazardous wastes. These specific facility types were examined for inspection rates across them. More will be said about the implications for specific facilities in the following chapters. After collecting this information on RCRA inspections and enforcements, all of the related percentages were calculated to enable comparison across the states. The RCRA data is used for two purposes in this dissertation. First, in order to ascertain the regulatory nature of the state the percentage 
inspection and enforcement rate is used to proxy how 'environmentally strict' that particular state is. Secondly, it is expected that RCRA programs and brownfield programs are interrelated and interconnected in many ways. This interconnectedness may prove to be an important factor in the in-depth case studies and analysis of the fifty state programs.

Upon the completion of the fifty state brownfield program database it is possible to answer the following question: What are the Laboratories of Democracy doing with their brownfields? This database enables a broad description and understanding of the variety of mechanisms, methods, and roles of the state brownfield programs. Although this database is a powerful tool in understanding what states are doing in their programs, it cannot answer some of the questions about why the programs function and look as they do. In order to provide a deeper level of analysis this dissertation utilizes a multiple case study approach to enable a better understanding of the variety of influencers on these programs---particularly bureaucratic and political control influences.

\section{Case Study Methods}

\section{Utility of Qualitative Research}

Phenomenological inquiry, or qualitative research, uses a naturalistic approach that seeks to understand phenomena in context-specific settings. Logical positivism, or quantitative research, uses experimental methods and quantitative measures to test hypothetical generalizations. Each represents a fundamentally different inquiry paradigm, and researcher actions are based on the underlying assumptions of each paradigm (Hoepfl, 1997, p. 1).

Rather than rely on numbers which often do not capture the real story, this part of the dissertation obtains in-depth information about these programs, political officials' and administrative officials' understanding and role in the program, and specific 
documents through in-depth open-ended interviews and document analyses. Anonymity was promised to all interviewees in return for their candid answers. In order to better protect identities, names and specific job titles are omitted. Job roles, as opposed to job titles, are used. This use of qualitative data allows for a richer understanding of what is truly going on within these programs (Patton, 2002).

Two key components of this dissertation make using a qualitative methodology logical and necessary. First, a key component of the dissertation involves understanding, learning, and potentially offering policy recommendations from an analysis of what the various states are doing in relation to their brownfield programs. The level of understanding required to provide potential policy recommendations for other states requires a qualitative methodology. "Generative research is concerned with producing new ideas either as a contribution to the development of social theory to or to the refinement or stimulus of policy solutions" (Ritchie and Lewis, 2003, p. 30). Secondly, this dissertation seeks to potentially add and expand theories of bureaucratic discretion and legislative control. Given that this part of the dissertation does not seek to test these theories, but add to and inform it through the study of state level programs with a high level of intergovernmental and inter-programmatic dependence, qualitative research provides the necessary depth of information required to do so. "It therefore has the potential to... determine actions that are needed to make programmes, policies or services more effective" (Ritchie and Lewis, 2003, p. 30-1).

It has been noted that a key strength of qualitative research is the ability to explore unanticipated issues (Ritchie and Lewis, 2003; Stake, 1995). This is an important aspect to this particular study as the variation across the states combined with the relative 
lack of research in these programs leaves a great deal of room for unanticipated issues. Statistical analysis of these programs would likely miss important facets of these programs which are of interest to this research. For example, in Indiana a portion of their brownfield program has recently (2005) broken off into a separate quasi-governmental organization. Statistical analysis of this program would not be ideal or even yield as deep of a level of understanding for this particular aspect and rationale for this change in this particular program. Furthermore, the complexities of these programs and the relationships each hold with the federal government, local governments, regional EPA offices, various other administrative units, various other regulatory and non-regulatory programs, and citizens of each respective states, make qualitative research methods both more appropriate and more fruitful than quantitative methods.

\section{Case Studies}

"Qualitative inquiry is not a single, monolithic approach to research and evaluation" (Patton, 2002, p. 76). As Cresswell (1998) points out, it is possible to distinguish five qualitative traditions: biography, phenomenology, grounded theory, ethnography, and case study. Case study methodology “...investigates a contemporary phenomenon within its real-life context" (Yin, 2003). This dissertation's subject is very appropriate to case study research. This dissertation specifically utilizes a comparative case study methodology. "Almost any observation, whether one makes it in academic research or real life, implies some form of comparative assessment, such as big-small or tall-short. Without comparison, one cannot tell whether an object is big or small" (Pierre, 2005, p. 454). Keeping with the view that comparison is essential to a deep

understanding in research, this part of the dissertation examines three specific state cases. 
In order to learn the most from these cases, these states were selected for their uniqueness using a purposive maximum variation sampling method stemming from data gathered in the fifty state database (Patton, 2002). This method of selecting cases is particularly important and logical for this dissertation as it allows for a selection of information-rich cases for study. "Studying information-rich cases yields insights and in-depth understanding rather than empirical generalizations" (Patton, 2002, p. 230).

"Qualitative research can contribute by: ...exploring how the manifestations of phenomena vary between groups, exploring how the reasons for, or explanations of, phenomena, or their different impacts and consequences vary between groups..." (Ritchie and Lewis, 2003, p. 50). As Patton points out, the first step in maximizing variation "involves identifying diverse characteristics or criteria for constructing the sample" (Patton, 2002, p. 235). Drawing upon existing scholarship on political control and bureaucratic discretion and this dissertation's fifty-state program database of characteristics of the brownfield programs and related RCRA programs, the following are selected key considerations to this research when selecting the three cases:

- Administrative Organization

- Given the interest in potential bureaucratic influence over these programs diversifying the administrative organization of the program is of interest. To provide the potential for rich analysis and information requires a diverse set of environments by which the programs operate. Key considerations here include how the program is structured in the administrative agency and the level of fragmentation that exists across the 
program. Data gathered and presented in Chapter Four will provide the basis for this classification.

- Regulatory Environment (agency values proxy)

- Drawing upon relevant scholarship in control and discretion theories, this dissertation posits that with all fifty state programs residing in the same administrative body as their RCRA program, it is useful to measure agency values with that state's stance on inspection and enforcement of RCRA. That is, a state with a more lax approach to inspection and enforcements indicates a certain value. That value may be expected to carry over to the brownfield program. Attention is also given to states with EPA Performance Partnership Agreements (PPA) concerning their RCRA programs (approximately $64 \%$ have PPA and the remaining $36 \%$ do not). In addition to the utility of a state's regulatory nature based upon RCRA performance, it is posited that RCRA is a program with a great deal of overlap and connection to brownfield programs, making the connection worth more inquiry.

- Ideology of Government

- Referring back to studies that use government ideology as an explanatory variable for proving political control over the bureaucracy, it is logical to factor ideology scores into the selection of cases. Using the Berry et al, measure of ideology, a range of political ideology scores from the most recent year and the year of the program's creation is an important consideration in selected the cases. 
- Age of Program

- This facet is less driven by theory and more driven by an interest in information rich cases. Attention is given to ensuring the selection of cases with enough history and time to provide this information rich potential.

This dissertation will draw from the details learned in the database and presented in Chapter Four concerning the fifty state brownfield programs to select the final cases for inquiry.

As with any research methodology a comparative case study has its own limitations. Specifically, case studies are not necessarily able to be generalized. What happens in one state may be a product of the uniqueness that is that state and the lessons learned there may only be applicable there. Individual states have unique contexts that hinder the ability to assume the lessons are applicable elsewhere. A common way of validating qualitative data is to see if other data sources seem to point to the same conclusion as gained from the interviewees. This dissertation reviewed thousands of pages of documents that included news articles, published reports, statutes, bill tracking reports, policy analysis documents, and personnel documents. By following the interviews with the other forms of research this dissertation is better able to be confident in the findings. In a number of cases the interviewee was contacted multiple times to discuss a new finding or to verify information.

The database of the fifty state programs is intended to provide a broad description of what is going on in the laboratories. Conversely the case studies are intended to provide a detailed story of what is going on and influencing the programs. These case 
studies provide a deep level of understanding concerning the roles, expectations, daily operation, and environment of these programs. Through discussions with front line administrators and political officials enables an understanding of the context under which each of these programs operate.

Although interviews and data collection were intense and inclusive, some limitations in this exist. Unfortunately, given both time constraints and reluctance on the part of certain individuals to participate in an interview, some potentially valuable individuals were not able to be included. Specifically, appointed officials in the three case study states were not available for this research. Although a number of front line administrators and higher up supervisors were interviewed, it is possible that the appointed officials would have added valuable insights. Furthermore, the Governors of the three states were not included in this research for much the same reasons. To be sure, administrative agencies are entities of the state's executive branch and as such, the head of the executive branch may have provided more valuable insights into a state's brownfield efforts.

A further limiting factor in this research has to do with the economic climate of the three states. Different levels of deindustrialization, economic capacity, and market structure may very well play important roles in determining a state's capacity and willingness to act upon brownfield remediation and redevelopment. This type of limitation must be taken into consideration when attempting to draw policy recommendations and lessons from the data. Although any research method is likely imperfect, this research, as designed, will certainly fill a gap in knowledge by providing a deeper, contextual understanding of the influences on state brownfield programs. 


\section{CHAPTER IV \\ EXPERIENCES OF THE LABORATORIES}

Academic and practitioner literature is dominated by liability issues surrounding and contributing to the problem of brownfields (Bartsch, Collaton, and Pepper, 1996;

Coffin and Shepard, 1998; Ennist, 2006; Whitney, 2003), financial concerns over cleanup costs (Connolly and Daddario, 1995; Depass, 2006; Schwab, 1997; Wernstedt et al, 2006; Meyer and Van Landingham, 2002), and stigma attached to brownfields (Roddewig, 1996; De Sousa, 2003). Recently scholars have turned to the role public brownfield programs take in aiding the remediation and redevelopment of these sites (Bartsch and Walls, 2005). In many ways the state governments' various brownfield programs can be seen as a creative mediatory working to level the playing field between brownfield and greenfield sites.

As discussed and outlined earlier in this dissertation a major part of this dissertation included collecting and organizing a database of details concerning the various fifty state brownfield programs. The final database covers a number of details concerning the scope and approach each state took to facilitate brownfield remediation and redevelopment and the related RCRA regulatory stance. The details in this database not only show the sheer diversity in programs across the fifty states, but it also enabled the educated selection of cases for the next stage of inquiry of this dissertation. The 
details covered in the database included a wide range of information intended to gain insights into the various participation requirements, administrative make-up, liability protections, financial incentives offered, ideology of government and citizens in year of program creation, RCRA facility inspections and enforcements, and any specific cleanup provisions of note. The final database contains over 4000 different pieces of information across the fifty states. Appendix A provides the template of the information gathered on each state in the U.S, while Appendix B offers the three case study states as examples of the complexity of this database. Unfortunately, due to the extensive size and scope of the database, it cannot be included in this printed dissertation, but will be available online at http://cepm.louisville.edu. Data pertaining to an average state can run well over ten pages in length.

A key to learning from other state's experiences is to have a clear understanding of what others are doing. Drawing from previous scholarship several facets of the brownfields problem, of which state programs are presumably attempting to remedy, are focused on in this database and chapter of this dissertation. As explained by the Northeast-Midwest Institute (2001):

Developers and investors, cautious of environmental liability, have shied away from brownfield sites. Contaminated properties, which are subject to many environmental regulations and procedures, also are vulnerable to costly construction delays. Pollution concerns have led developers to pass up opportunities in urban centers for ones in rural and suburban areas (a.k.a. greenfields) where land is perceived to be less expensive and free from unknown liability. If these barriers to brownfield reuse are to be overcome, site reusers need funds to perform site assessment, funds to develop a cleanup plan, and funds to do the cleanup (p. 2).

Drawing from the previous quotation, it can be inferred that among other things, the following components are important and integral to getting brownfields redeveloped: 
liability abatement concerns, regulatory process concerns, and minimizing the financial costs of cleanup and redevelopment. The overall findings of the diversity of the programs as recorded in the fifty state database are elaborated upon in the following sections not only using the three factors mentioned here but also by providing a description of the major aspects that exist across the fifty states. This chapter first details the most common brownfield program across the states-Voluntary Cleanup Programs including a discussion of liability issues; then moves on to a discussion of the variety of financial opportunities across the fifty states for brownfield remediation and redevelopment; next moves to a discussion of states' approaches to RCRA; and concludes with the detailed rationale for the case study selection to be discussed in the following chapter.

\section{Voluntary Cleanup Programs-a consistent overall approach by the States} Voluntary Programs-What are they?

As has been previously stated in this dissertation, all fifty states have some form of a brownfield program. Brownfield programs take a number of different forms across the fifty states. Some states have only one program while others have multiple programs. Forty seven of the 50 states have a standard voluntary cleanup program (VCP); sometimes called a Voluntary Response Program (VRP) or a Voluntary Remediation Program. Only Alaska, South Dakota, and North Dakota do not have the typical Voluntary Cleanup Program—although they do have some form of a brownfield remediation and redevelopment program. Regardless of the exact title of a state's voluntary cleanup program they all loosely follow the same procedure: upon the completion of an agreed upon cleanup the voluntary party receives some sort of liability 
protection such as Covenants Not to Sue (CNTS), Certificate of Closures (COC), or No

Further Action Letters (NFA). As the Environmental Protection Agency (1997) explains:

Many states have established voluntary cleanup programs. The key ingredients of a documented State voluntary cleanup program include established authority, investigative and remedial procedures, cleanup targets appropriate to sites, State sign-off conditions and procedures, and liability provisions. These voluntary cleanup programs allow volunteers, such as site owners and developers, to identify and clean up sites, to use less extensive administrative procedures, and to obtain some relief from future state liability for past contamination. These sites might otherwise not be cleaned up because of their relatively low priority, and because these sites are too numerous for other state or federal cleanup programs to address within a reasonable time frame (US EPA Guidance for Developing Superfund Memoranda of Agreement, 1997).

In many states Voluntary Cleanup Programs coexist with a variety of other programs directed at remediation or redevelopment of brownfields.

Almost all of the Voluntary Cleanup Programs require some fee for participation. These fees are most often used to facilitate the program's existence without relying solely upon appropriations from the state. Oftentimes the fees are required by state statute. For example in North Carolina, “...[t]here is a statutory fee of $\$ 2,000$ for obtaining a brownfields agreement" (North Carolina Program FAQ). At least two states, North and South Dakota who do not possess a formal VCP, do not charge for participation in their programs. Of the states with standard voluntary cleanup programs, only Florida does not charge a fee. However, Florida does charge for other brownfield programs separate from the VCP.

The VCP fees come in the form of oversight fees, sliding scale fees, and fixed fees. Some states require both a flat application fee and an oversight charge. For example New Mexico requires an upfront $\$ 1000$ application fee to apply to participate in 
their VCP as well as oversight charges of $\$ 65$ per hour (New Mexico Ground Water Quality Bureau- Voluntary Remediation Program).

EPA's Role-MOAs

Although the voluntary cleanup programs are both state instigated and state run, the EPA plays a role through a voluntary agreement—or a Memorandum of Agreement (M.O.A.). Any state in which the EPA grants an M.O.A. to is one where the EPA has determined the program meets minimum adequacy standards across six dimensions: minimum community involvement levels, protective of human health and environment, technical and financial resources, mechanisms for certification of response plan, oversight, and enforcement ability (US EPA Guidance for Developing Superfund Memoranda of Agreement, 1997). "The MOA gives the state VCP credibility and autonomy; EPA has stated, in agency guidance, that it will not investigate or "second guess" sites that have successfully completed the state's program unless there is a compelling reason to do so - like previously unknown contamination that presents an imminent threat to health and the environment" (Bartsch and Dorfman, 2000, p. 2).

Twenty-Three states currently have active voluntary cleanup program M.O.A.'s with the EPA. 


$\begin{array}{ll}\text { STATE } & \text { DATE SIGNED } \\ \text { Illinois, } & \text { April 1995 } \\ \text { Minnesota } & \text { May, 1995 } \\ \text { Wisconsin } & \text { October, 1995; Revised } \\ & \text { November 2006 } \\ \text { Indiana } & \text { December, 1995 } \\ \text { Colorado } & \text { April 1996 } \\ \text { Texas } & \text { May, 1996 } \\ \text { Michigan } & \text { July, 1996 } \\ \text { Missouri } & \text { September, 1996 } \\ \text { Maryland } & \text { February, 1997 } \\ \text { Rhode Island } & \text { February, 1997 } \\ \text { Delaware } & \text { August, 1997 } \\ \text { Oklahoma } & \text { April, 1999 } \\ \text { Florida } & \text { December, 1999; Revised } \\ & \text { November, 2005 } \\ \text { New Mexico } & \text { December, 1999 } \\ \text { Arkansas } & \text { December, 2000 } \\ \text { Kansas } & \text { March, 2001 } \\ \text { Ohio } & \text { July, 2001 } \\ \text { Virginia } & \text { January, 2002 } \\ \text { Wyoming } & \text { March, 2002 } \\ \text { Pennsylvania } & \text { April, 2004 } \\ \text { Iowa } & \text { June, 2004 } \\ \text { Louisiana } & \text { October, 2004 } \\ \text { Nebraska } & \text { November, 2006 } \\ & \\ & \end{array}$

Table 4.1: States possessing VCP Memorandum of Agreement's with the E.P.A.

Table 4.1 illustrates the range of states with MOA's for their VCPs. Of note are Florida and Wisconsin which have both revised their MOA's since the original agreement.

A state with an MOA will be able to extend greater certainty to the participants of their program that the EPA will not intervene and that the cleanup will not only suffice at the state level but also at the federal level. "The EPA added to the authority of states in 1995 when the Agency similarly began providing state memorandums of agreement 
("SMOA") that granted assurances that the EPA will not require subsequent liability after compliance with the state VCP had been achieved" (Collins, 2003, p. 304). This is of particular importance because, "CERCLA does not preempt state cleanup laws, and thus both the federal CERCLA and state's environmental laws must be applied in determining the requirements and the liabilities for remediation of a brownfield" (p. 304).

As previously stated in this chapter a key component to a state's brownfield remediation and redevelopment efforts is to provide liability protections. In the 47 states with VCP's, liability protections are provided within that program. However, in North and South Dakota no liability protections are apparent with their brownfield programs. Of additional note is Alaska, which offers a mechanism where a prospective purchaser of a property can receive a Prospective Purchaser Agreement (PPA) offering some liability protections to that party.

\section{Liability Protections}

One of the primary and most important components of state brownfield efforts, and more specifically their voluntary cleanup programs, are liability relief provisions. The various voluntary cleanup programs' liability provisions usually come in the form of a document issued by the overhead ${ }^{1}$ agency, governor, state attorney general, or state Department of Justice. In some cases more than one of these entities will issue a liability release document. These various liability relief documents range in names with the following being noted in this database: No Further Action Letters (NFA), Certificate of Closures (COC), Covenants Not to Sue (CNTS), Prospective Purchaser Agreements (PPA), No Further Remediation Required (NFR), Innocent Owner/Operator Certification (IOC), Innocent Party Agreements (IPA), Case Closure Letters, Letters of Concurrence,

\footnotetext{
${ }^{1}$ The Administrative Agency or Department in which the program is housed.
} 
Closure Letters, Site Status Letters, and Comfort Letters. In fact some states issue several different types and with a sometimes varying level of protection based upon the initial negotiated cleanup agreement. For example, in New Hampshire ...an eligible person can obtain a "Covenant Not to Sue" from the N.H. Department of Justice (DOJ) and a "Certificate of Completion" from the N.H. Department of Environmental Services (DES) when site investigations and remedial actions are performed in accordance with DES cleanup requirements (New Hampshire's Brownfields Covenant Program, 2005).

Comparing Wyoming to New Hampshire reveals how liability relief mechanisms can vary from state to state. Wyoming uses the same terms but issues the documents for different purposes and at different times.

DEQ expects that covenants not to sue will most often be issued while a cleanup is ongoing, rather than at the end of a cleanup, and that in many cases, covenants not to sue will be issued at the same time that a remedy agreement is signed. In general, a certificate of completion documents DEQ's opinion that all cleanup requirements for a site (or a portion of a site) have been successfully implemented or satisfied (Wyoming Fact Sheet \#5 Liability Assurances, 2003).

\section{Responsible Party Participation}

Regardless of the name and varying levels of liability protection offered, other aspects of a states liability relief are important. More specifically, a key liability relief component of state brownfield efforts is whether a party who is responsible for the contamination in whole or in part can participate in the various programs and receive benefits. Thirty three states offer the opportunity for the responsible party to participate. The remaining states with liability protection programs explicitly deny responsible party access to the program. For example, Maine has it written in statute that in order to participate in the Voluntary Response Action Program that person shall be: "Subject to the provisions of this section, a person may not be deemed a responsible party and that 
person is not subject to department orders or other enforcement proceedings or otherwise responsible" (Maine Voluntary Response Action Program, 1993).

Many of the states that allow participation by the responsible party place additional constraints that non-responsible parties do not face. In fact five states will not give the responsible party liability protection, but they are allowed to reap the benefits of oversight through the program. Other states place financial or cleanup standard restrictions on the responsible parties participating. For example Louisiana's Voluntary Remediation Program allows responsible parties to participate, but with additional constraints. The state notes that "All persons are eligible except that only nonresponsible persons (as defined in LAC 33:VI.903) are eligible to perform Partial Voluntary Remedial Actions" (Louisiana Voluntary Remediation Program Description).

Other states allow the responsible party to participate but explicitly do not allow a responsible party to utilize financial incentives associated with the program allowing them instead to receive the technical assistance and assurance they are performing an adequate response action. For example in New Jersey, “... in accordance with N.J.S.A. 58:10B-13.1, nothing in this Covenant [NJ Liability Protections] shall benefit any person who is liable, pursuant to the Spill Compensation and Control Act (Spill Act), N.J.S.A. 58:10-23.11, for cleanup and removal costs and the Department makes no representation by the issuance of this Covenant, either express or implied, as to the Spill Act liability of any person" (New Jersey Chapter 26C Department Oversight of Contaminated Sites, 2006).

A number of states do allow the responsible party to participate and allow them to receive liability protections and financial assistance. For example, in Oklahoma as long 
as the responsible party is not already under order by the EPA to perform a cleanup, they are allowed to participate fully in all aspects of the state VCP. One other variation on the allowance of responsible parties, however, that exists across the fifty states is that certain states will not allow responsible parties to use land use controls on sites they cleanup under the various brownfield programs even if they are allowed to receive liability protection and financial assistance-generally meaning that they will be required to do a complete cleanup as opposed to a risk based cleanup. Table 4.2 presented below shows the states with additional constraints on the responsible party participating in the state's brownfield program. Of particular note here are: Colorado, Delaware, Florida, Indiana, Kansas, Louisiana, Minnesota, Illinois, Missouri, New Mexico, Ohio, Oklahoma, Pennsylvania, Wisconsin, and Wyoming. These states both allow the responsible party to participate and to receive liability protections, while at the same time have a MOA with the EPA. These states are providing a route for responsible parties to receive liability protections from the state and the federal government by virtue of this aspect of their program. 
States

Alabama

Florida

Hawaii

Idaho

Louisiana

Maryland

Montana

New Jersey

Texas

Utah

Wyoming

\section{Liability Specifics}

Only relieves liability from future cleanup

The contamination must have occurred before 1997

No Liability Protections for RP

No Liability Protections for RP

Can't use department funding; Can't use Institutional Controls

RP cannot have knowingly violated any laws.

No Assessment Money Provided to RP

No CNTS awarded to RP

No liability relief for RP

No liability relief for RP

Contamination must have occurred before 2000; For post-2000 contamination the RP must have had a prevention plan in place (per department's rules) in order to participate fully.

Table 4.2: State Programmatic Constraints on Responsible Party Participation

What is actually covered in these liability documents and the relative level of liability protections offered through the various mechanisms is quite diverse across the states. Virtually all of the states with liability provisions provide that eligible recipient a liability assurance that the state will not instigate a lawsuit for further cleanup or for liability to the state. However, in a majority of states $3^{\text {rd }}$ Party lawsuits resulting from off-site migration of toxins or other related property or personal harms are not covered in the liability release documents. Whether $3^{\text {rd }}$ Party lawsuits are covered or not is very complex across the fifty states. In some states, such as Kentucky, 3rd Party rights to bring a lawsuit against an individual for harms resulting from brownfields are not allowed to be barred by the brownfield programs as a result of other aspects of state law. As was so eloquently detailed in an issue of the Brownfield News: 
"The bill [a 2006 bill expanding on liability relief for brownfields] also preserved the right of a third party or any person, other than the cabinet, to bring claims for injury to property or person resulting from contamination migrating onto an adjacent property. Such a provision is necessary due to Kentucky's "jural rights" doctrine imbedded in case law and Kentucky's Constitution. The jural rights doctrine restricts the authority of the General Assembly to limit common law rights of recovery (Manning, 2006).

Across the fifty states the most common states to have liability provisions against suits by $3^{\text {rd }}$ parties are those states that issue CNTS. States noting $3^{\text {rd }}$ Party liability protections include: Connecticut, Georgia, Indiana, Massachusetts, Michigan, New Jersey, New York, Oregon, Pennsylvania, South Carolina, and Tennessee. Only Pennsylvania leaves the potential open for $3^{\text {rd }}$ Party Liability Relief for responsible parties. In fact, this is written in statute:

Any person demonstrating compliance with the environmental remediation standards established in Chapter 3 shall be relieved of further liability for the remediation of the site under the statutes outlined in section 106 for any contamination identified in reports submitted to and approved by the department to demonstrate compliance with these standards and shall not be subject to citizen suits or other contribution actions brought by responsible persons. The cleanup liability protection provided by this chapter applies to the following persons: (1) The current or future owner of the identified property or any other person who participated in the remediation of the site. (2) A person who develops or otherwise occupies the identified site.... (Pennsylvania Land Recycling and Environmental Remediations Act, 1995).

Pennsylvania also possesses an MOA for its program, making these liability protections even more powerful for participants. The remaining states with $3^{\text {rd }}$ Party Protections explicitly do not allow the responsible party, even if that state allows responsible parties to participate in the overall program, to obtain $3^{\text {rd }}$ Party liability relief. Table 4.3 illustrates the liability specifics across these eleven states. 
States

Connecticut

Georgia

Indiana

Massachusetts

Michigan

New Jersey

New York

Oregon

Pennsylvania

South Carolina

Tennessee
Liability Details

CNTS, $3^{\text {rd }}$ Party, NRP

PPA, $3^{\text {td }}$ Party, Superfund Sites, NRP

CNTS, $3^{\text {rd }}$ Party only NRP, MOA

CNTS, $3^{\text {rd }}$ Party only NRP

CNTS, $3^{\text {rd }}$ Party only NRP, MOA

CNTS, PPA, NFA, $3^{\text {rd }}$ Party only NRP

CNTS, COC, $3^{\text {rd }}$ Party

NFA, PPA, $3^{\text {rd }}$ Party, NRP

CNTS, $3^{\text {rd }}$ Party, MOA

CNTS, $3^{\text {rd }}$ Party NRP Only

NFA, $3^{\text {rd }}$ Party NRP only

Table 4.3: Liability Details for States with $3^{\text {rd }}$ Party Protections

Additional states of note here are: Washington which is reviewing the ability to provide these waivers; and Rhode Island that deals with $3^{\text {rd }}$ Party Protections on a case by case basis. In Florida the only thing barred pertaining to $3^{\text {rd }}$ Party claims is that a $3^{\text {rd }}$ party cannot compel a participant with relief documents to cleanup the property any further.

Finally of note is Alaska which is able to offer some prospective purchaser liability relief documents that cover $3^{\text {rd }}$ Party claims.

In addition to the complexities of what is covered under the liability relief documents, differences exist concerning how far reaching into the future the liability protections are. For example, in some states liability protection documents do not allow for the voluntary party to be held responsible for any of the contamination formerly on the site both at the time of completion and any that may be discovered at a later date (with usual notable exclusions for fraud and illegal activities). However, most states, such as Massachusetts, New Jersey, Pennsylvania, and North Carolina do allow for what is termed reopeners. Reopeners are "[e]xpress exceptions to liability releases or agreements that reserve the government's right to require further cleanup under certain conditions. These conditions typically include fraud by parties responsible for the 
cleanup, discovery of previously unknown contamination, and discovery that contamination remaining on the site is significantly more toxic than originally believed" (Brownfields Center, 2006).

Across the 48 states with liability protection, all but Alaska have those protections embedded within their Voluntary Cleanup Program; Alaska offers the PPA in their general state cleanup process. However, one notable exception to this exists in Indiana. In Indiana the state offers both a Voluntary Remediation Program (VRP) and a Brownfields Program. Under the VRP participants receive both a Certificate of Closure and a Covenant Not to Sue. These are the state's most powerful liability protections. Alternatively, under the Indiana Brownfields Program participants can receive Comfort or Site Status Letters. These do not necessary protect participants from liabilities but provide them with assurances about the status of a particular site and is aimed more at facilitating a sale of a low-to-no contamination present on the property site. If a property is deemed to have more significant contamination present the property will likely be referred to the VRP (Brownfield Director, IFA).

A relevant related point worth mentioning here concerns liability protections for brownfield remediation and redevelopment and sovereign immunity. Although the courts interpretation of CERCLA initially indicated that States were potentially liable under the law, court cases since have reversed that finding based upon an interpretation of the $11^{\text {th }}$ Amendment (Percival et al, 2006). Under the U.S. Constitution local governments are not granted the same protections as states. However, across the fifty states exists a wide variation in whether States grant their instrumentalities (municipalities, redevelopment agencies, counties, etc) immunity from being sued by private parties. In fact Percival et 
al (2006) note that, “...counties and municipalities are sued for contribution most often" (p. 391). Whether instrumentalities of a state are granted sovereign immunity is a very complex and disputed topic in whole that often changes with new court rulings. Although it is not in the scope of this dissertation to examine the potential implications of sovereign immunity being granted to states' instrumentalities, it is worth noting in reference to liability protections. It is likely that some of the states in the U.S. offer sovereign immunity to their instrumentalities thereby potentially eliminating some of the liability concerns surrounding brownfields on the part of local governments and redevelopment agencies who find themselves in a position to remediate a brownfield.

One additional, but rare, liability relief provision that exists in a few states is that of state involvement in environmental insurance. At least four states have some form of environmental insurance assistance: Wisconsin, Massachusetts, New York, and Connecticut. Each of these states involvement in offering environmental insurance is varied from tax credits for the purchase of insurance (NY), to endorsement and a discount for insurance (WI), to actual state subsidized insurance (MA and CT).

\section{Financial Considerations, RBCA, and Land Use Controls}

In addition to liability concerns, the perceived and actual costs associated with the remediation aspect of brownfield properties is a major obstacle in getting them cleaned up and redeveloped. As a primary concern, the various state brownfield programs each offer a variety of financial incentives and avenues available in the remediation process for developers to help lessen the costs associated with the cleanup of brownfields. This is where other programs other than the voluntary cleanup programs are commonplace across the states. Some states will have incentives and methods for lessening the cleanup 
costs existing within their voluntary cleanup programs, while others will have their offered incentives in separate brownfield related programs which are called something different entirely and may have different rules for participation. The various programs have both real financial offerings in the form of grants, assessments, or loans as well as available and allowed cleanup methodologies for lessening the cleanup costs. The standard methodologies that exist are the use of risk based cleanup levels, often termed risk based corrective action or RBCA [pronounced Rebecca], and the ability of developers to use Land Use Controls on a property being cleaned up. More will be said about the cleanup methodologies in the following sections following a discussion of the monetary offerings across the states for brownfield remediation and redevelopment.

\section{Monetary Offerings}

The states have approached real financial incentives or offerings in a variety of ways. According to the data gathered all of the state programs offer some kind of financial consideration for brownfield remediation through their various programs. The financial incentives offered across the fifty states ranges from monies available as a result of a specific EPA grant to actual state supported granting programs. Several states exhibit a plethora of incentives while others will only have the barest incentives available based upon EPA support. In a few cases, the financial considerations are only offered to public entities. For example in Alaska the state's Contaminated Sites Program only offers, “... DEC, with support from EPA's Region 10, wishes to assist non-profits, municipalities, local governments, and their communities by conducting environmental site assessments at potential brownfield sites" (Alaska's Brownfields Program). The 
most common financial incentives offered across the states are assessment grants, cleanup grants, revolving loan funds, and tax incentives.

\section{Assessment Grants}

A majority of the states offer some form of assessment grants. Virtually all of these assessment granting programs actually stem from an EPA grant awarded to the states by their respective EPA region in the form of a Targeted Brownfield Assessments [TBA] grant. For example, Arizona offers assessment grants, "Through an EPA grant, the VRP will contract a consultant to perform an environmental site investigation for a qualifying brownfield property. The program is available to municipalities, prospective purchasers, and parties who would not be found liable for any existing contamination at the property" (Arizona Voluntary Cleanup: Brownfields Assistance). As the EPA points out: "The TBA selection process varies with each EPA Region and by state Voluntary Response Programs. Each Region is given an annual budget to spend on TBAs. State Voluntary Response Programs allocate TBA funding on a case-by-case basis" (US EPA Targeted Brownfield Assessments Fact Sheets, 2003).

A few states have internal assessment granting programs separate from the EPA TBA program. For example, Michigan once offered the Site Assessment Fund (SAF) grant to eligible public entities. The SAF is funded by the Michigan Environmental Protection Bond Fund of 1988. The Michigan Department of Environmental Quality currently notes that no funds are available under this program at this time- -however it is still noted as an available program with the hope that the state will be able to offer funding again under this program in the future. Assessment grants, although not necessarily pivotal to getting brownfields remediated, do enable states, localities, and 
developers to better understand what the status of a particular site is. Some sites thought of as brownfields turn out to be either uncontaminated or less contaminated than feared, and assessment grants can provide the necessary information to get that site cleaned up and successfully reused.

\section{Cleanup Grants}

Outside of assessment grants the other most common granting program offered across the states is cleanup grants. These cleanup granting programs are far rarer than the assessment granting programs and are most often targeted to public or non-profit entities. For the states offering actual cleanup money most have very specific restrictions on whom and what site can receive the grant money. For example Michigan offers a Clean Michigan Initiative (CMI) grant program that allows, "Any county, city, village, township, Brownfield Redevelopment Authority, or other authority or other public body created pursuant to state law may apply for a grant. Eligible activities include environmental investigations and assessments, interim response, and due care response activities necessary for the proposed development" (Michigan CMI Brownfield Redevelopment Grants, 2006). A few states offer cleanup grants to a wider audience that includes private entities. For example, in Delaware a brownfield granting program exists that "...authorizes the appropriation of $\$ 3,000,000.00$ annually from the Hazardous

Substance Cleanup Act Fund (HSCA Fund) for the purpose of reimbursing reasonable remedial costs..." (Delaware Hazardous Substance Cleanup Act Mixed Funding and Brownfields).

In addition to brownfield cleanup grants available within the brownfield programs some states have enabled and encouraged the use of granting mechanisms from other 
programs and administrative agencies. For example in Oklahoma in 2000 a seemingly unrelated grant program was amended to better allow redeveloped brownfield properties to access to the funds.

The Oklahoma Quality Jobs Act was amended to apply to basic industries that locate their principal business activities on contaminated properties of at least ten acres in size which qualify as 1) a federal Superfund removal site, 2) National Priorities List (NPL or Superfund) site, 3) a site formally deferred to the state in lieu of NPL listing, or 4) a site that was remediated pursuant to an order of the DEQ. These companies may be eligible for the Quality Jobs Program incentive payments irrespective of their actual gross payroll or the number of full-timeequivalent employees in new direct jobs [68 O.S. Supp. $2000 \S 3604(E-H)]$ (Oklahoma Brownfields Financial Incentives Fact Sheet).

Variations do exist on the specifics related to the use of other programs' financial mechanisms. For example, Ohio provides an example where one of their granting programs requires a fund match by the recipient.

Another interesting component of some state brownfield programs is the use of CERCLA 128a funds to public entities for cleanups, assessments, and other related expenses. "Section 128(a) of the Comprehensive Environmental Response, Compensation, and Liability Act (CERCLA), as amended, authorizes a noncompetitive $\$ 50$ million grant program to establish and enhance state and tribal response programs" (US EPA Funding Guidance for State and Tribal Response Programs, 2007). All fifty states get CERCLA 128a funds.

Grant applications are required by the states in order to receive funding under this program and states are granted considerable leeway in determining how to use these funds. Tracking down how much funding each state gets has proven to be a difficult endeavor. None of the EPA grant databases provides details on the amount of 128a funding awarded. The EPA allows the individual regions to handle that grant, and only 
Region 1 (CT, ME, NH, RI, VT) has made that data available in published form.

Requests for data from the EPA and other regions are met with guidance to ask individual states for that information. Calls and emails to the remaining states have provided spotty results of how much each state gets. Additionally, some states only provide cumulative totals, while others provide the most recent year. These programs have only been eligible to receive funding from this since 2003 , making the cumulative totals useful as well. The following charts outline the known CERCLA 128a Funding to states for the most recent year and cumulatively since the program's inception.

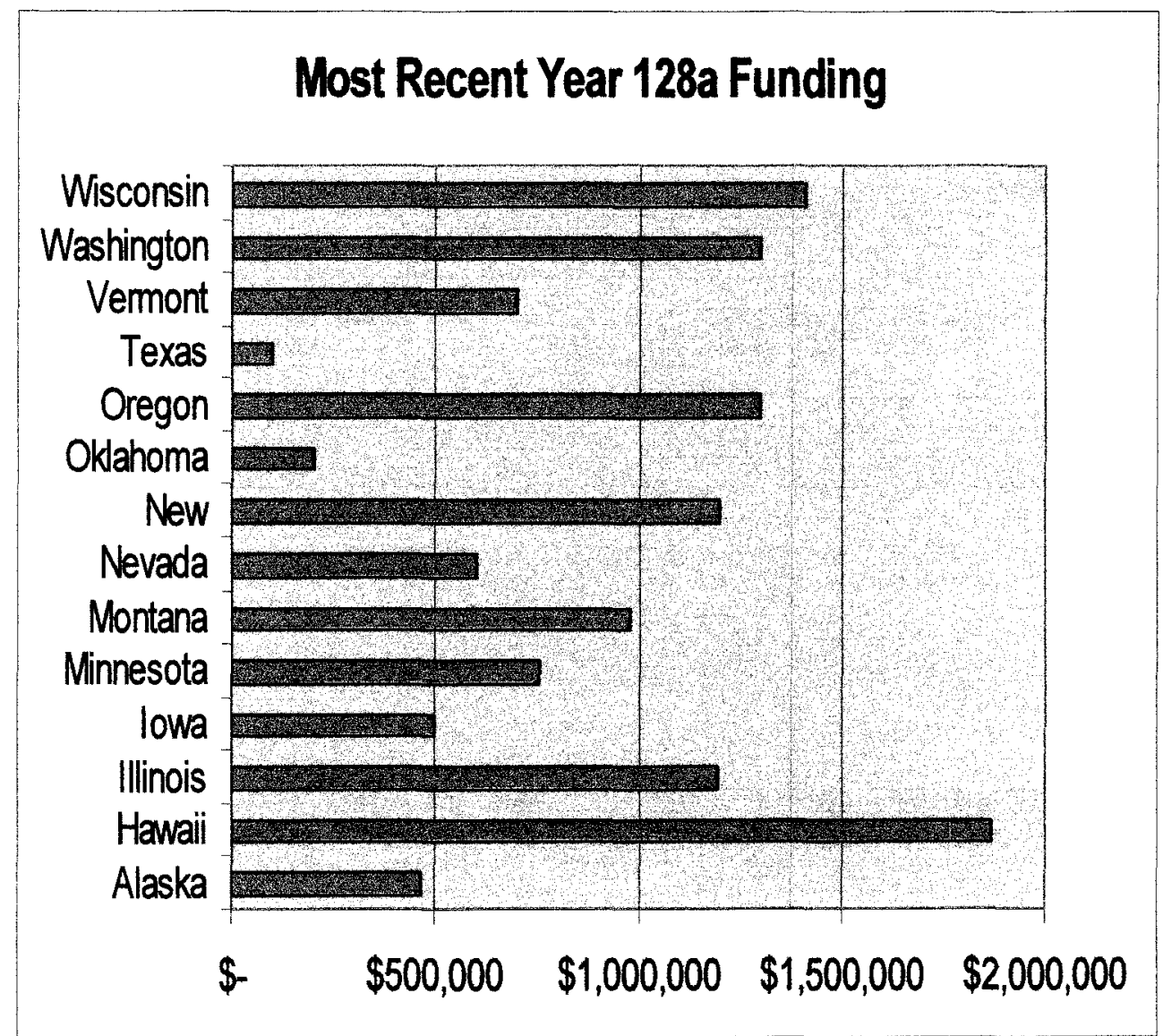

Figure 4.1: CERCLA 128a Funding for most recent Fiscal Year 


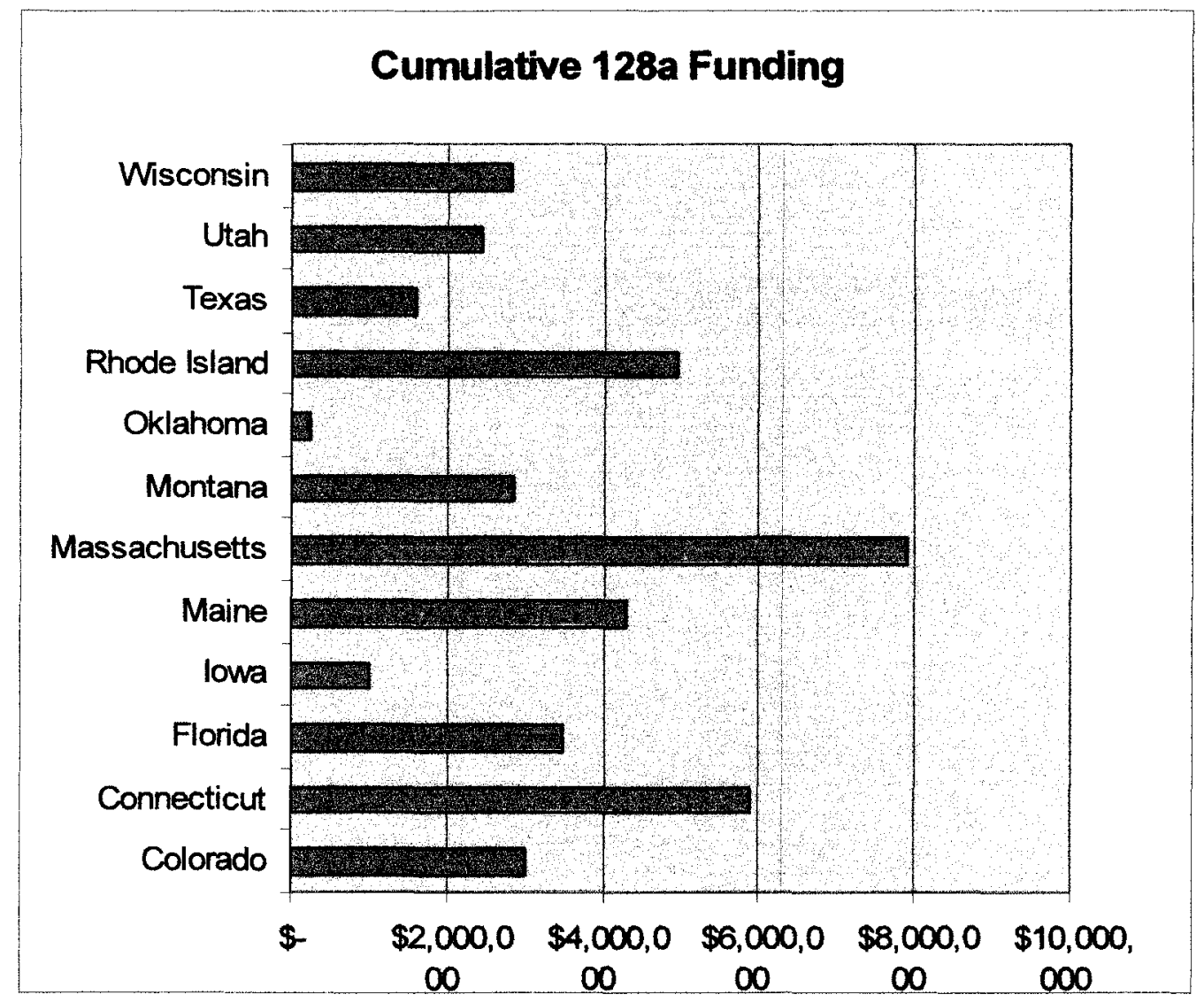

Figure 4.2: CERCLA 128a Funding, Cumulative over life of grant

As stated previously, some states use this 128 a funding to provide grants and assessments to participants in their programs. As with the actual funding amounts, it is not entirely clear how many states use their funding, or how much is used, for this purpose. However, Nevada and Florida are examples where they provide grants to the public sector with 128a funds; with Nevada using the entire amount for grants and administration of the Land Recycling Program (not the Voluntary Cleanup Program). Judging from the three case study states, some states use these funds primarily for providing grants, others use them for some combination of grants and administrative costs. 
Overall in terms of grants available-assessment grant programs, particularly EPA supported TBA's, are much more common than any state supported cleanup grant programs. Important and of particular educational value to other states is that, a number of states have started to make the connection from brownfield property needs to other state supported economic development grant programs, which often have many more grant opportunities than the brownfield programs do-but there exists a lot of room for improvement in this connection.

\section{Loan Programs}

Outside of assessment and cleanup grant programs, loan programs are the next most common form of financial assistance offered by states for brownfield remediation and redevelopment. The most common form of loan program is an EPA originated Revolving Loan Fund (RLF).

A major component of the Brownfields Economic Redevelopment Initiative is the award of pilot cooperative agreements to States (including U.S. territories), political subdivisions (including cities, towns, and counties), and Indian tribes to capitalize Brownfields Cleanup Revolving Loan Fund (BCRLF). The purpose of the pilots is to enable States, political subdivisions, and Indian tribes to make low interest loans to carryout cleanup activities at brownfields properties (US EPA Brownfields Cleanup Revolving Loan Fund Pilot Program).

Approximately twenty states have received EPA capitalized revolving loan funds.

Important to note here is that many cities and counties across the United States have also applied for and received funds from the EPA to capitalize revolving loan funds. So even in the thirty states without an EPA capitalized RLF, larger cities or counties may have actually received these funds enabling developers within that state access to revolving loan funds for brownfield redevelopments. 
In addition to the EPA capitalized RLF's a number of states have created loan programs of their own. Oftentimes these loan programs will involve a low-to-no interest loan program similar to the EPA capitalized RLF. For example, New Jersey provides a wide expanse of loan programs to a variety of individuals including private parties: "Loans are available to private entities for up to $100 \%$ of the funding needed to remediate a discharge of hazardous substances up to $\$ 1$ million per year. The interest rate is the Federal Discount Rate with a minimum of $5 \%$ and is determined by the NJEDA. The maximum term for any loan is 10 years" (New Jersey HSDRF Fact Sheet). Some states, such as Michigan, have created more than one loan fund.

Brownfield redevelopment loans provide funding to local units of government and other public bodies to investigate and remediate known sites of environmental contamination, which will be used for identified economic redevelopment projects... The Revitalization Revolving Loan (RRL) Program is designed to support local community efforts to redevelop brownfield properties by providing eligible entities with low-interest loans which may be used to evaluate contaminated or potentially contaminated properties, demolish dangerous or hazardous buildings that obstruct redevelopment, and to conduct interim response actions necessary to investigate a property or demolish a building (Michigan Department of Environmental Quality-Brownfields Grants and Loans).

In addition to the more common low-to-no interest loan programs, several states have loan guarantee programs directed at enabling investors to obtain outside financing in place in their brownfield programs. For example, in Oregon the state offers a program named the Capital Access Program (CAP). "Capital Access program offers loan portfolio insurance for environmental evaluations and brownfield redevelopment projects" (Oregon Brownfields Program: An Overview). Although CAP was initiated in 1991 for economic development purposes, the program has grown to include brownfields. This program does not provide loans, but it offers a state guarantee on the 
loan thereby increasing the likelihood that a bank will approve an applicant. Other states noting loan guarantee programs include Florida and Missouri.

\section{Tax Incentives}

In addition to upfront money programs such as the grants and loans available, many states offer a variety of tax incentives. According to data gathered at least 32 states offer some form of a tax incentive. The types of tax incentives offer vary widely with the following types being noted: credits and deductions for the cost of cleanup, tax reductions on increased property value for a length of time, tax credits for each new job created, sales tax exemptions, special provisions allowing the use of Tax Increment Financing (TIF), property tax abatements, various fees and tax exemptions, deductions for cost of environmental insurance, sliding scale tax rates on properties redeveloped, Fees in Lieu of Taxes, tax exemption on hazardous waste shipments, tax cancellations, and the ability to transfer-at no cost- tax delinquent properties to new owners willing to clean them up. Tax incentives vary widely across the states that offer them, with a variety of restrictions and eligibility rules across the states. Some of the more common and interesting of the various tax incentives available are elaborated on below.

\section{Income Tax Credits or Deductions for Cleanup Costs}

Several states offer deductions or credits on an individual or businesses' state income tax for the costs of cleanup. This is the most commonly available type of tax incentive across the states who offer tax incentives. Key examples include Colorado where tax credits are offered to offset the cleanup costs of brownfields: 
As part of Governor Owens' smart growth initiative, the Colorado General Assembly passed a Brownfields Tax Credit (this has been extended to the end of 2010) as an added incentive to develop formerly used and possibly contaminated properties (Brownfields). The bill provided an income tax credit of up to $\$ 100,000$ to offset cleanup costs and make the redevelopment of such properties more financially viable (Colorado Brownfields Tax Credit).

Florida also offers cleanup tax credits, but for corporations only:

The 1998 Florida Legislature created the Voluntary Cleanup Tax Credit (VCTC) to encourage voluntary cleanup of certain drycleaning solvent contaminated sites and sites in designated Brownfield areas. The 2006 Florida Legislature modified and expanded the VCTC. With the repeal of the Intangible Personal Property Tax, Section 199.1055, F.S, the VCTC is valid against Florida Corporate Income Tax only... (Florida Voluntary Cleanup Tax Credit).

Income tax credits or deductions are fairly common across the 32 states offering tax incentives, however the requirements, eligibility, and specifics vary widely. As is evidenced in the two examples above, some states allow both individuals and businesses to benefit from the tax incentives, while others only allow businesses. As is the case with the liability and participation rules, some states allow responsible parties to benefit, some explicitly do not, and some judge it on a case-by-case basis. Most commonly the income tax incentives allow the individual or business to deduct a certain percentage of the costs associated with the cleanup of brownfields from their personal and/or corporate tax liability. These tax credits and deductions usually have a maximum cap on the amount able to be claimed and some allow the costs to roll over to the following year, while others do not.

\section{Property Tax Incentives/Programs}

In addition to programs that allow individuals or businesses to deduct or receive a credit on income taxes for cleaning up and redeveloping brownfields, some states provide property tax incentives. The most common property tax incentive involves enabling the 
local or county governments to freeze or reduce property tax on a remediated and redeveloped brownfield. For example, in Georgia, "The Brownfields tax law allows property owners to apply to their local taxing authority for preferential assessment of the Brownfield property. The preferential assessment reduces taxes on the property for ten years, or until the certified assessment and cleanup costs are recouped, whichever occurs first" (Georgia Brownfield Redevelopment Incentives).

Other variations and examples exist as well. In Idaho a VCP participant is eligible to receive a seven year, up to a $50 \%$ reduction in property taxes on remediated brownfield properties (Idaho Statute Title 63 Chapter 6, Exemptions from Taxation). Although some states, like Georgia and Idaho, require that the local taxing authority participate if a request is made -other states do not require subdivisions to participate and leave the final discretion up to the local authority. Maryland is a key example of this where the local jurisdiction must elect to participate in the state Brownfields Revitalization Incentive Program (BRIP).

Maryland is also a good illustration of how a brownfield program's essential components can be distributed throughout a variety of administrative units. More specifically, in Maryland the liability relief and cleanup components of the VCP is located in the Department of Environment; however, this tax incentive is part of the Department of Business and Economic Development.

\section{Sales Tax Incentives}

Less frequently than the previously discussed tax incentives, a few states offer sales tax incentives. Most often these sales tax incentives involve exempting or refunding the sales taxes paid on brownfield cleanup equipment or machinery. At least 
three states provide clear guidance on sales tax incentives: Alabama, New Jersey, and Oklahoma. A good example of a common form of a sales tax incentive exists in Oklahoma. "The Oklahoma Sales Tax Code allows an exemption for machinery, equipment, fuels, and chemicals incorporated into the treatment process to substantially reduce the volume or harmful properties of hazardous waste at facilities approved by the DEQ for the cleanup of a site of contamination" (Oklahoma Brownfields Financial Incentives Fact Sheet).

\section{Use of RBCA and Land Use Controls}

In addition to the offering of grants, loans, and tax incentives to help lessen the financial burden of remediating a brownfield, many states offer alternative methodologies for cleaning up brownfields. More specifically, many states allow for risk based corrective action (RBCA) and land use controls on remediated properties. Although these are not actual money incentives they do work to lessen the financial burden by making the overall cleanup less cost prohibitive-theoretically enabling and encouraging more cleanups and redevelopments of brownfields.

RBCA is by far the most common alternative cleanup methodology allowed under the fifty state programs. RBCA is, "A streamlined approach in which exposure and risk assessment practices are integrated with traditional components of the corrective action process to ensure that appropriate and cost-effective remedies are selected, and that limited resources are properly allocated" (US EPA RBDM FAQ 6). Under traditional definitions the RBCA process is derived from ASTM (American Society for Testing and Materials) guidance which states, "The RBCA process ... us[es] a tiered approach that integrates site assessment and response actions with human health and ecological risk 
assessment to determine the need for remedial action and to tailor corrective action activities to site-specific conditions and risks" (ASTM Standard Guide for Risk Based Corrective Action, 2007).

At least 40 states allow some form of risk based corrective actions in their brownfield programs. However, the comprehensiveness, eligibility, and specifics of the usage of RBCA or RBCA-like processes vary widely across the states. For example in Utah one of the key benefits (as expressed by the agency) of their VCP's is the fact that "[v]oluntary cleanups can be tied to land use allowing for a risk-based approach to cleanup" (Utah Department of Environmental Quality Voluntary Cleanup Program). In many ways risk based cleanups are dependent upon some form of land use control and most of the states will include language in any liability relief document concerning any land use controls required and used by that property and developer. Land use controls, whether used in conjunction with risk based corrective action methods or not, is also a way for states to enable investors to clean brownfields at a lower cost.

Land Use Controls (LUCS) are “....also known as 'institutional controls', are defined broadly as legal measures that limit human exposure by restricting activity, use, and access to properties with residual contamination" (US EPA Land Use and Institutional Controls). Often LUCS will be a pivotal part of a state's risk based cleanup process. It has been pointed out that the array of terminology and definitions concerning risk based remediation across the states is complex and confusing (Land Use Control Site, 2007). For the sake of understanding and providing consistent human health and environmental protection the Uniform Environmental Covenants Act was proposed and 
offered across the fifty states by the National Conference of Commissioners on Uniform State Law (NCCUSL).

Land use controls, activity and use limitations, institutional controls, engineering controls, restrictive covenants, and deed restrictions, etc. all may provide the same legal remedy for risk-based cleanup but for differing sites. The Act attempts to encompass all of this terminology by connecting broadly defined activity and use limitations with the requirement that they are enacted in conjunction with an agency-authorized environmental response project (Land Use Controls Site, 2007).

Currently 14 states have adopted the Uniform Environmental Covenants Act with an additional 24 introducing the bill in 2007 (Uniform Environmental Covenants Act).

Table 4.4 illustrates the states' status in terms of the Uniform Environmental Covenants

Act. 


$\begin{array}{lll}\text { ENACTED } & \text { Introduce 2007 } & \text { Ongoing Study } \\ \text { Delaware } & \text { Alabama } & \text { North Carolina } \\ \text { Hawaii } & \text { Alaska } & \text { Oregon } \\ \text { Idaho } & \text { Arizona } & \\ \text { Iowa } & \text { Arkansas } & \\ \text { Kentucky } & \text { Connecticut } & \\ \text { Maine } & \text { Florida } & \\ \text { Maryland } & \text { Georgia } \\ \text { Nebraska } & \text { Indiana } \\ \text { Nevada } & \text { Michigan } \\ \text { Ohio } & \text { Minnesota } \\ \text { Oklahoma } & \text { Mississippi } \\ \text { South Dakota } & \text { Missouri } \\ \text { Utah } & \text { Montana } \\ \text { West Virginia } & \text { New Hampshire } \\ & \text { New Jersey } \\ & \text { New Mexico } \\ & \text { North Dakota } \\ & \text { Pennsylvania } \\ & \text { Rhode Island } \\ & \text { Texas } \\ & \text { Vermont } \\ & \text { Virginia } \\ & \text { Washington } \\ & \text { Wyoming }\end{array}$

Table 4.4: Adoption Status of Uniform Environmental Covenants Act

Understanding the lack of uniformity in definitions, tracking, and requirements for Land Use Controls is particularly important point for understanding brownfield programs. According to data gathered virtually all of the states allow for, some even require, land use controls on brownfield redevelopments. A lack of uniformity is an interesting component of state brownfield efforts and could be a point of improvement for many states. Some states provide an extensive and complex tracking system; others do not track the controls at all. Arkansas and Alabama are key examples of states that allow controls but currently do not track them. On the other side, some states (Florida in particular) have an extensive, publicly available tracking system for Land Use Controls. 
The ability of brownfield investors to use various land use controls is likely a valuable and effective way of reducing the cleanup costs associated with reusing brownfields. It seems that almost all of the states are allowing the use of these controls, but the tracking and long term control of these measures is not consistent across the states. Furthermore, a majority of the states are not party to the Uniform Environmental Covenant Act which would enable individuals, businesses, and concerned parties a clearer, more consistent understanding of terminology, control, and requirements for these land use controls across the fifty states. It would also provide a much needed consistency for the future of these land use controls.

\section{RCRA Regulatory Nature}

In addition to the details concerning the actual brownfield specific programs, the database also collected data concerning RCRA inspections and enforcements to use as a proxy for regulatory stance of a state as well as to explore any possible relationships between the two programs. Although both RCRA and CERCLA have contributed to the problem of brownfields, RCRA is the most logical area of inquiry to characterize a state's regulatory nature as it may impact its state brownfield program. As outlined in Chapter Two, RCRA is intended to be implemented and administered by the states. In fact, remembering that 48 of the fifty states have received base RCRA authorization from the EPA illustrates the widespread nature of the state-level participation in RCRA. A state's activity level in relation to RCRA may be able to enable a deeper level of understand of an overall state's perspective on brownfields. More specifically state performance under RCRA may be able to be used as a proxy for state commitments to environmental 
regulation and enforcement. The database included RCRA enforcement and inspection data.

In addition to providing a proxy for a state's environmental regulation and enforcement stance, another issue of concern to brownfields is that of RCRA failure. By RCRA failure, it is meant that a state who does not adequately inspect regulated facilities and enforce any violations discovered may lead to failure of the protection of the environment and human health. In addition to short term problems associated with it, RCRA failure also holds the likelihood of increasing the number of brownfield properties within a given state. A state that does not provide a high, or even adequate, level of RCRA inspections and RCRA enforcements relative to the number of establishments using, disposing, or treating toxic materials can be expected to not only have more brownfield properties (due to neglect of efforts to avoid them), but also have a lower motivation for state spending on remediation and redevelopment of those properties. Additionally it may be expected that this potentially could translate into a more liberal risk-based cleanup program. Conversely, a particularly strict regulatory stance on hazardous wastes may be expected to limit certain types of risk-based cleanups, institutional controls, and/or types of assistance provided under that state's brownfield program. That is, a state that inspects and enforces hazardous waste violations at a high level is logically more likely to regulate the hazardous wastes being remediated in their brownfield program. Across all 48 RCRA authorized states the program is operated under the same department, often even the same office, as the brownfield programs. The variations in inspections and enforcements of RCRA regulated facilities can be 
counterproductive to even the best state brownfield remediation and redevelopment efforts as well as are likely related to the efforts of the brownfield programs. RCRA PPA's

Before discussing specific inspection and enforcement rates it is necessary to understand that the EPA offers a mechanism for states to work more closely with them through a Performance Partnership Agreement (PPA). PPA's are negotiated agreements a state agency will enter into with the EPA in order to detail the working relationship between the two. "The scope and contents of PPA's varies. Individual PPA's can range from general statement about how the state and EPA will work together as partners (perhaps identifying joint priorities that will be addressed) to comprehensive, multiprogram documents that detail each party's roles and responsibilities" (US EPA About Performance Partnership Agreemetns). Of the 48 RCRA authorized states, 33 have PPA's. Under RCRA, and in some states, these PPAs can dictate how many inspections each state will conduct annually. When statistical tests are run on this data, interestingly enough, states with Performance Partnership Agreements (PPA) do not have statistically significant differences in rate of inspections as compared to the remaining states without PPA's.

\section{RCRA Inspections}

A pivotal part of the RCRA regulatory process is inspections. Every type of RCRA regulated facility is subject to inspection. The EPA Enforcement and Compliance History Online (ECHO) database tracks RCRA regulated facility inspections. Inspections are available in one, two, or three year increments for the past three years from the date of inquiry. EPA recognizes that it is not possible to inspect ever regulated 
facility every three years (US EPA ECHO Frequently Asked Questions). However, a state's commitment and commitment to inspecting facilities can be gained from an examination of this database. Additionally, with 48 states having their base RCRA program authorized by the EPA, and two being administered by the EPA, it is possible to compare states with state authorization to states where the EPA administers the RCRA program. Figure 4.3 demonstrates the percentages of facilities that received an inspection in the past three years in each of the fifty states, keeping in mind that two states receive their inspections directly from the EPA.

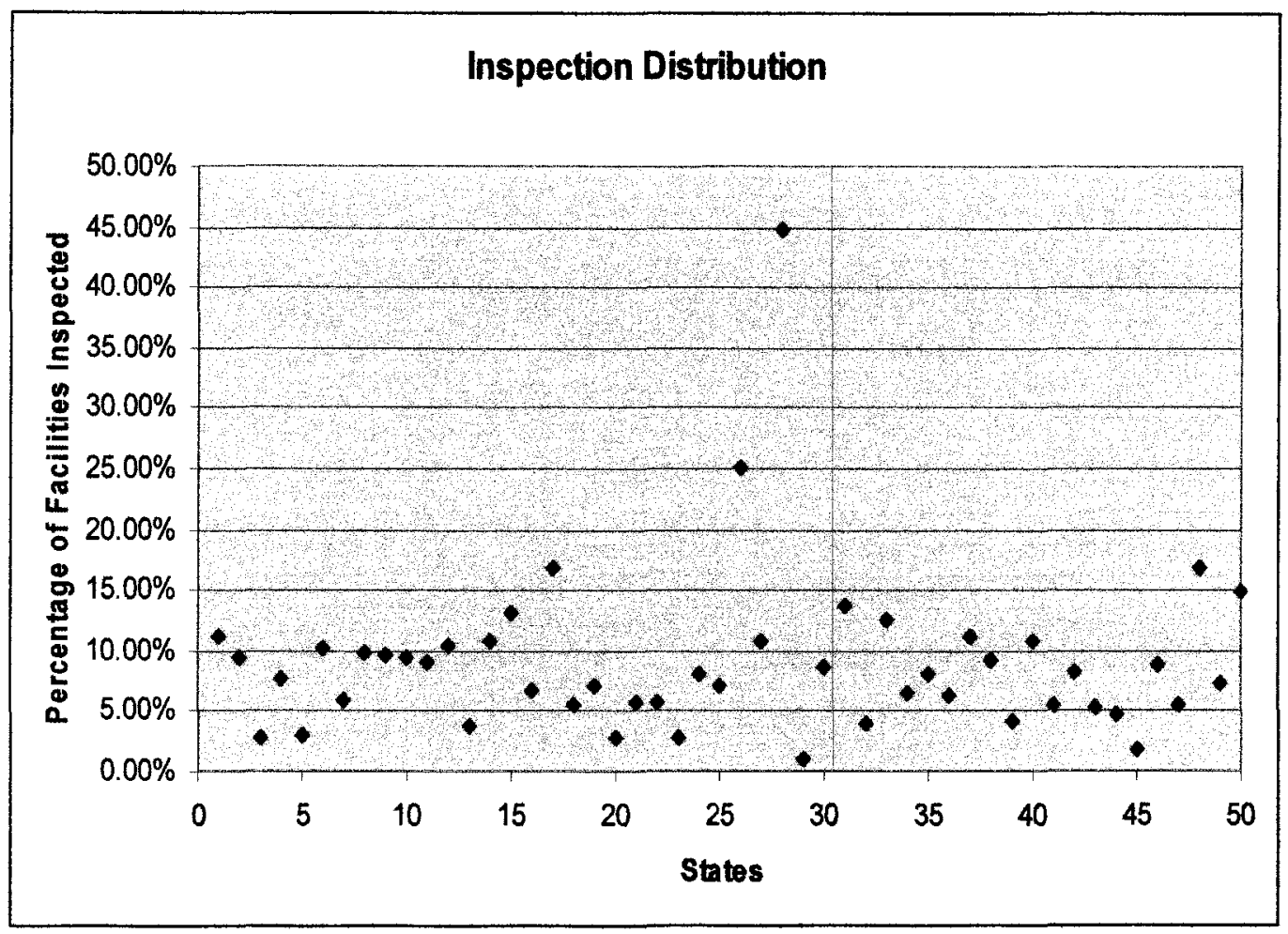

Figure 4.3: RCRA Facility Inspection in the past 3 years. States listed in Alphabetical Order

As would be expected with the varying capacities across the fifty states, Figure 4.3 illustrates a moderate level of variation existing across the fifty states in the percentage of regulated facilities that received an inspection in the last three years. 
As of July 2006 , ECHO reports a total of 653,720 RCRA currently regulated facilities across the United States. RCRA regulated facilities generally include things like furniture manufacturers, gas stations, chemical plants, and other activities that produce, transport, handle, or dispose of a hazardous waste as defined by the EPA. The average state inspected $7 \%$ of their facilities in the past three years. Nevada inspected the most, at $44.75 \%$ of their regulated facilities, and New Hampshire inspected the fewest, at just $1 \%$ of their facilities. Alaska and Iowa, the two EPA administered RCRA programs, inspected $9.37 \%$ and $13.06 \%$ of their regulated facilities respectively. The state and the EPA rely on self-reported data to assess compliance in the facilities that they have not inspected. "It is possible that facilities do have violations that have not yet been discovered, thus are shown as compliant in the system. EPA cannot positively state that facilities without violations shown in ECHO are necessarily fully compliant with environmental laws" (US EPA ECHO FAQ).

It has been pointed out that, “...by several orders of magnitude the system is much harsher on TSD facilities" (Percival et al, 2006, p. 357). Recognizing a difference exists in inspection rates at the different types of facilities, information was collected on specific facility types. Figure 4.4 illustrates this facility specific inspection rate across the states. 


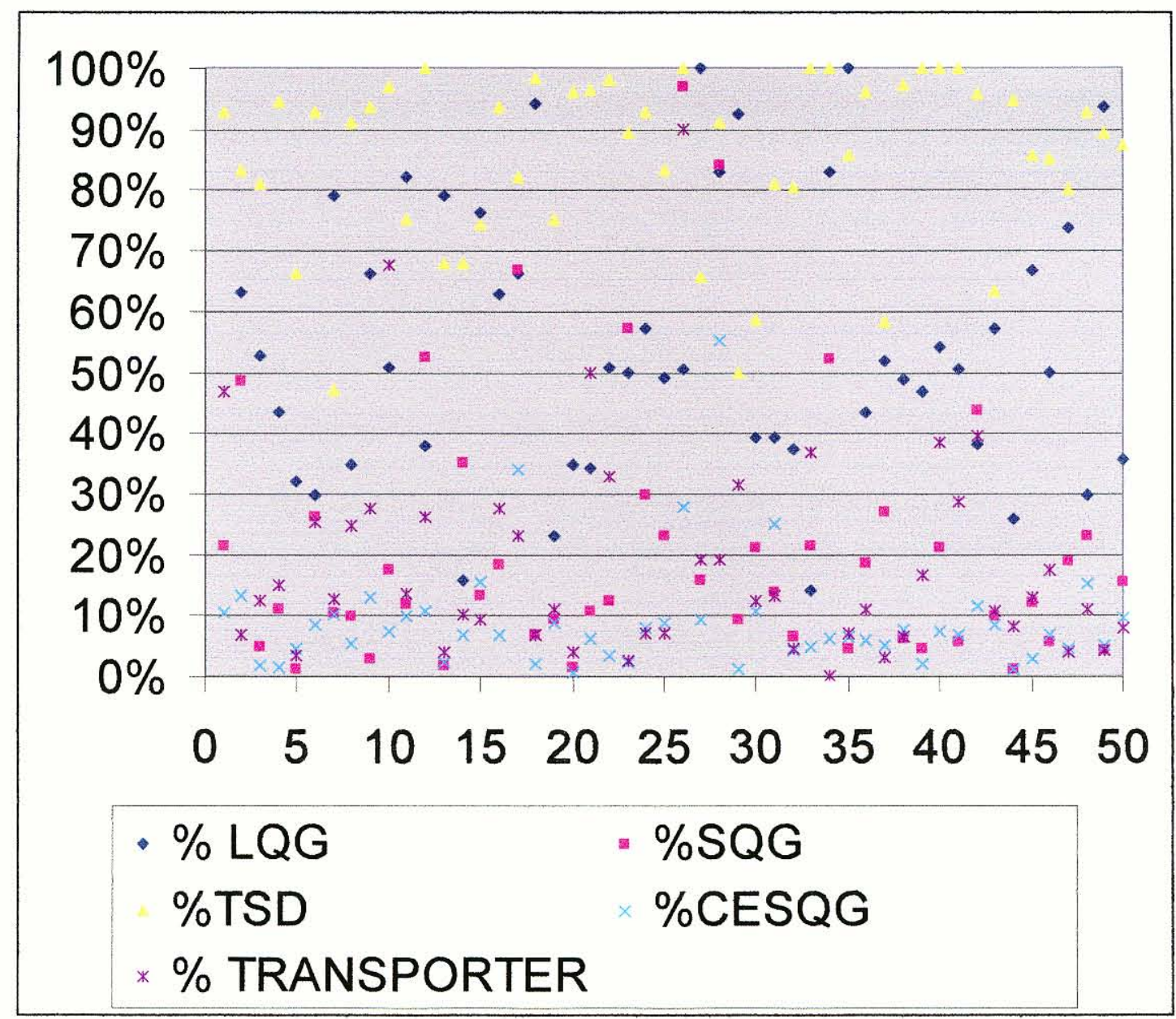

Figure 4.4: Inspection rates of specific types of RCRA regulated facilities. States in alphabetic order. Large Quantity Generators (LQG), Treatment Storage and Disposal Facilities (TSD), Small Quantity Generator (SQG), Conditionally Exempt Small Quantity Generators (CESQG) and Transporters. States are listed in alphabetical order.

RCRA regulated facilities are broken up into five separate classifications. These classifications are as follows: Large Quantity Generators (LQG) which produce more than $1,000 \mathrm{~kg}$ of hazardous waste in a month; Small Quantity Generators (SQG) which produce more than $100 \mathrm{~kg}$ but less than $1,000 \mathrm{~kg}$ of hazardous waste a month; treatment, storage and disposal facilities (TSD), Transporters of hazardous waste, and conditionally exempt small quantity generators (CESQG) which produce less than $100 \mathrm{~kg}$ of hazardous waste per month. Examining the breakdown of types of facilities, reveals that inspections 
across all states are performed most often at TSDs and least often at CESQG's. The high level of inspection at TSD's is consistent with previous scholarship indicating a harsher stance on these properties. What is interesting, however, is the incredibly varied inspection rate at the SQG and LQGs which is illustrated well in Figure 4.4.

Table 4.5 illustrates the highs and lows across the fifty states in terms of specific facility inspection rates.

\begin{tabular}{|c|c|c|c|c|c|}
\hline $\begin{array}{l}\text { Type of } \\
\text { Facility }\end{array}$ & LQG & SQG & TSD & CESQG & Transporter \\
\hline NTL Average & $54 \%$ & $21 \%$ & $75 \%$ & $9 \%$ & $19 \%$ \\
\hline Highest State & $\begin{array}{l}\text { MT, N.D. } \\
(100 \%)\end{array}$ & MT (97\%) & $\begin{array}{l}\text { MT, NC, } \\
\text { ND, RI, } \\
\text { SC, SD } \\
(100 \%)\end{array}$ & NV (55\%) & MT $(90 \%)$ \\
\hline Lowest State & $\begin{array}{l}\text { N.Y. } \\
(14 \%)\end{array}$ & $\begin{array}{l}\text { CA, MD, } \\
\text { and UT } \\
(1 \%)\end{array}$ & CТ (47\%) & $\mathrm{MD}(0 \%)$ & ND (0\%) \\
\hline $\begin{array}{l}\text { EPA } \\
\text { Administered } \\
\text { States }\end{array}$ & $\begin{array}{l}\text { AK }(53 \%) \\
\text { IA }(63 \%)\end{array}$ & $\begin{array}{l}\text { AK (48\%) } \\
\text { IA (13\%) }\end{array}$ & $\begin{array}{l}\text { AK }(83 \%) \\
\text { IA }(74 \%)\end{array}$ & $\begin{array}{l}\text { AK }(13 \%) \\
\text { IA }(15 \%)\end{array}$ & $\begin{array}{l}\text { AK }(7 \%) \\
\text { IA }(9 \%)\end{array}$ \\
\hline
\end{tabular}

Table 4.5: Highs, Lows, and National Averages of RCRA specific types of facility inspection rate

As can be seen in the table above, Montana holds four of the five highest rankings for inspection rates at specific types of facilities. This is a bit misleading. Montana has very few regulated facilities when compared to other states. In July 2006 Montana reported a total of 2003 facilities in their state. In fact in absolute numbers by type of facilities Montana only inspected a total of 292 facilities over the past three years. What is more important to be gathered from the scatter plot above (Figure 4.4), is that across the fifty states two things are fairly consistent: TSD's get the most inspections and CESQG's get the fewest. The remaining types of facilities are extremely varied across the fifty states. This variation may be an indication of discretion and political control influences at the 
state level. This variation may also have impacts on that state's brownfield program-as LQG, SQG, and Transporters are not insignificant in hazardous waste generation and handling. This data was also checked across the EPA regions and no significant statistical findings were found indicating a significant variation across the various EPA Regions. The next stage in RCRA compliance and enforcement for the database was the rate of informal enforcements.

\section{RCRA Informal Enforcements}

When a RCRA regulated facility has been identified as an alleged violator, the usual first step in the enforcement process involves the state or the EPA issuing a warning letter or notice of violation (NOV). These warning letters and NOVs are considered informal enforcements. This process generally serves as the notification to a facility that it is in violation of the law and that it should remedy the situation or face formal enforcement actions. Important to note here, is that a RCRA regulated facility may not even be subject to an informal enforcement if the inspector believes the violation to be insignificant enough not to warrant any enforcement. Informal enforcement measures are most often the result of discoveries made during standard inspections. “[Informal Enforcements]... reflect determinations made by EPA or States when conducting inspections or reviewing facility self-reports" (US EPA ECHO FAQ). Across the fifty states an average of $97.8 \%$ of informal enforcement measures occur in facilities that have been inspected. It is expected then that most of the remaining $2.2 \%$ of informal enforcement measures result from self reported or complaint information. 
Table 4.6 illustrates the distribution of the state's percentages of facilities receiving informal enforcements in the past three years as reported by ECHO. The national average for informal enforcement measures is $2 \%$.

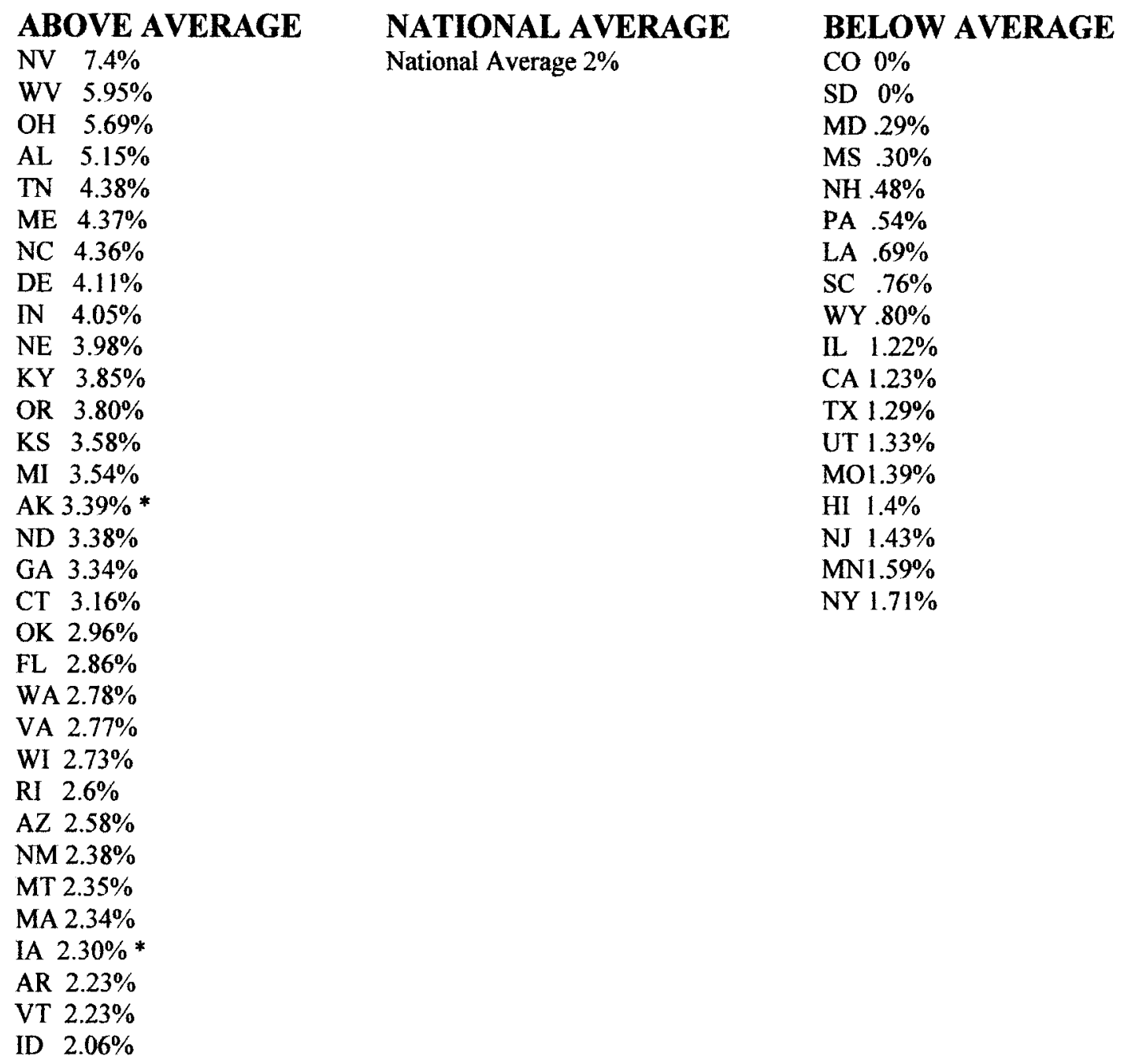

Table 4.6: Notice of Violation Rates for RCRA regulated Facilities

* EPA Administered RCRA programs

Alaska and Iowa, the two EPA administered RCRA programs, have informal enforcement measures of $3.39 \%$ and $2.30 \%$ respectively. As would be expected, the rate of inspections is positively correlated with the issuance of NOVs (see table 4.7). 


$\begin{array}{lrrr} & & \text { PERCINSP } & \text { PERCNOV } \\ \text { PERCINSP } & \begin{array}{r}\text { Pearson } \\ \text { Correlation } \\ \text { Sig. (2-tailed) }\end{array} & 1.000 & .516^{\star *} \\ \text { PERCNOV } & \mathrm{N} & 50 & .000 \\ & \begin{array}{r}\text { Pearson } \\ \text { Correlation } \\ \text { Sig. (2-tailed) }\end{array} & .516^{\star *} & 50 \\ & \mathrm{~N} & .000 & 1.000 \\ & & 50 & 50\end{array}$

** Correlation is significant at the $\mathbf{0 . 0 1}$ level (2-tailed).

Table 4.7: Correlation of Inspections to notice of violations

Referring back to Figure 4.3, it is logical to assume that states with low inspection rates will have less opportunity to identify regulated facility non-compliance. In fact the EPA recognizes this, "If ECHO shows a recent inspection and the facility is shown with no violations, user of the ECHO site can be more confident that the facility is in compliance with the programs..." (US EPA ECHO FAQ). In essence a state who conducts comparatively few inspections on regulated facilities is relying more heavily upon self reporting for compliance information. An unusually low inspection rate logically can contribute to RCRA failure, which in turn can contribute to an increase in brownfields and/or Superfund sites and also indicates a state's regulatory environment.

The fact that over $97 \%$ of NOVs are issued to facilities who received inspections seems to imply that a heavy reliance on self reporting does not ensure a high level of RCRA compliance. If, as more inspections are performed more violators are discovered, 
states with low inspection rates likely are exposing their citizens to a greater likelihood of exposure to toxins as a result of RCRA failure.

\section{RCRA Formal Enforcement and SNC Status}

The next step in the RCRA enforcement process is what is termed a Formal Enforcement procedure. "The next step, or in a number of cases, the first step in the enforcement process is the initiation of a civil administrative action or civil judicial action (in some serious cases, criminal enforcement actions may be taken)" (US EPA ECHO FAQ). The national average for formal enforcement measures is 65.28 formal enforcements over the past three years. The average state has $0.54 \%$ of their regulated facilities with a formal enforcement measure in the last three years. Hawaii has the highest percentage of formal enforcements at just over $2 \%$ of its RCRA regulated facilities. North and South Dakota possess the lowest level of formal enforcements: neither had any in the last three years.

A facility that is deemed to be in 'Significant Non-Compliance' or SNC status means that it has done one or more of the following: caused exposure or has a threatened exposure to hazardous waste; is a chronic violator; or it deviates substantially from the terms of a permit, order or agreement, or from RCRA statutory or regulatory requirements (US EPA ECHO FAQ). South Dakota, North Dakota, and New Hampshire have the fewest facilities in SNC with 0 facilities reported. As a percentage of total RCRA regulated facilities, Hawaii has the most SNC facilities at $0.76 \%$ of their RCRA regulated facilities falling into SNC status. Unlike informal enforcement measures, 
formal enforcement measures and SNC status are not uniformly correlated with a state's frequency of inspections. This lack of correlation is likely a result of the level of discretion a state RCRA inspector has in enforcement measures.

\section{Regulatory Nature and Expected Impacts}

Having reviewed state RCRA enforcement and compliance information it is possible to draw some broad conclusions about what the likely impacts are on a state's brownfield situation. Although further study of this issue will allow for a deeper understanding of this relationship, it is possible to draw some preliminary conclusions across the fifty states.

Important to reiterate here is that all $48 \mathrm{RCRA}$ authorized states house their RCRA program in the same department or agency as a main part of their brownfield or Voluntary Cleanup Program. In most situations, the same overhead administrator sets the budget, mission, and goals for both programs. Several states appear to be particularly strict in terms of its RCRA inspection and enforcement statistics. These stricter regulatory natures will likely reduce the likelihood of an increase in RCRA failure, thereby reducing the risk of an increased prevalence of RCRA brownfields.

Brownfield redevelopments are directly connected to regulations, although a brownfield sitting idle is not necessarily subject to regulatory action. The American Federalist system has created a myriad of political, regulatory, administrative, and social conditions across the fifty states. This variation is apparent in the regulatory nature of each state. Examining RCRA regulatory activity has shown that states are not consistent in their inspections or their enforcement measures. As state governments continue to 
spend increasingly scarce tax dollars on programs it is important to understand the connections, and sometimes the counterproductive nature, of other state programs. In this case a state's RCRA program may logically impact its brownfield problem and program - thereby making it essential to understand if one is concerned about the presence and correction of these properties.

Although the database created in the research for this dissertation enables a very broad and important look at state brownfield efforts and state regulation of hazardous waste, it does not speak about the specific nuisances of the programs. In order to gain a more in-depth look at these programs and better tell the story, it is necessary and worthwhile to take a look at three specific cases. The cases can be selected using information gathered in the database. The final section of this chapter outlines the rationale stemming from this database for the three cases to be studied in depth.

\section{Case Study Selection Rationale}

Drawing from the rationale outlined in Chapter Three, three state case studies were picked for maximum variation in several components. These states are Florida, Indiana, and Nevada. Each of the components used as a selection tool is outlined below providing justification for the selection of the three cases. The individual components were taken collectively before selecting the three cases and are presented individually below.

\section{Administrative Organization}

In gathering data about the fifty state programs it became apparent that certain states organize their programs in an administratively interesting manner. While many states clearly have their brownfield program located in one administrative unit, others 
have the various components of their brownfield program spread throughout a number of other administrative agencies. Of the states who exhibit an administrative fragmentation their programs the most common organization included having the economic incentive part of their program located in an Economic Development agency while the remediation aspect of their program located in the Environmental agency. To account for this variation, and keeping with the rationale of maximum variation sampling, this dissertation selected a case that was administratively fragmented (Indiana) and cases that were administratively unified (Florida and Nevada).

In addition to a level of fragmentation of the program one particular state exhibited an additional administrative aspect that was unique and potentially valuable to this research. Florida exhibits a very unique organization that seems to be echoed throughout its state. That is, Florida requires participation from the local government before anyone or any entity can participate in the liability protection or economic incentive aspects of their brownfield program. This devolution of responsibility is an interesting case study of how to organize a brownfield program and certainly provides an interesting and information rich case to analyze for this dissertation. With specific attention to the potential to offer policy guidance to other states, Florida is a potential gold mine of information.

\section{Regulatory Environment}

In order to learn about any connection between brownfields and RCRA, including a state's regulatory stance, it is logical to select cases that have variation in this aspect. The first consideration revolves around selecting at least one case that possesses and one state that does not possess an EPA Performance Partnership Agreement (PPA). Ensuring 
a case selection that includes variation in the presence or absence of a PPA is a logical consideration. Of the three selected cases for this dissertation, Nevada and Florida do not have PPAs and Indiana has one. Although this ratio is not consistent with the percentage of states with the PPA nationally, it does not jeopardize the validity of this selection. Recall that states with PPA's do not show a statistically significant difference in inspections from those states without a PPA. However, it is useful to take into consideration at least one state with a PPA so that any connections and impacts of PPA's not caught in the database can be potentially discovered in the case studies.

Further consideration in terms of regulatory environment centers on the inspection and enforcement levels of the state as recorded by EPA ECHO database and is evidenced in this chapter. The three states selected provide an interesting and information rich variation in terms of regulation and enforcement of RCRA. Specifically, Nevada has the highest level of inspections of all fifty states, with approximately $44.75 \%$ of their regulated facilities showing inspections over the other states. This will provide an interesting variation from Florida where approximately $9.5 \%$ of their facilities received an inspection over the last three years and Indiana where the PPA agreement spells out certain percentages which have been recorded as approximately $11 \%$ over the last three years. This variation in regulatory environment is particularly useful for this type of study.

\section{Ideology of Government}

In literature concerning bureaucratic discretion and legislative control theories, a common theme used to examine the influences of each revolves around operationalizing policy preferences of legislators and bureaucrats. Several authors have pointed to 
ideology as a mechanism for demonstrating and testing these policy preferences (Clark and Allen, 2004; Huber and Shipan, 2002). This dissertation also uses ideology as a proxy for policy preferences of government employees (bureaucrats) and political officials. Drawing on work done by William Berry in which he measures and records both citizen and state government ideology, this dissertation will use his ideology measures as a proxy for policy preferences of bureaucrats and political officials. "We construct dynamic measures of the ideology of a state's citizens and political leaders, using roll call voting scores of state congressional delegations, the outcomes of congressional elections, the partisan division of state legislatures, the party of the governor, and various assumptions regarding voters and state political elites" (Berry et al, 1998, p. 327). Berry's measure of ideology ranges from a 0 to a 100 . The closer the score is to 0 the more conservative it is; the closer the score is to 100 the more liberal it is. "One is state citizen ideology, generally conceived as the mean position on a liberalconservative continuum of the active electorate in a state. The other may be termed state government ideology---the mean position on the same continuum of the elected public officals in a state, weighted according to the power they have over public policy decisions" (Berry et al, 1998, 327-8). For the sake of maximum variation in cases this dissertation used ideology measures as a factor in determining the cases.

Of the three selected cases each show ideology variation. Florida has an approximate ideology measure of 55 for the state government (thought to represent the policymakers) and 45 for the citizens (thought to represent the bureaucrats) in the year of the creation of the brownfield program. For the most current year available Florida offers a government ideology score of 7 and a citizen ideology score of 46 . This compares to 
Indiana at 63 government and 46 citizens for the year the brownfield program was created and 57 government and 43 citizens for the most recent year available; Nevada at 47 government and 57 citizens for the year the brownfield program was created and 37 government and 46 citizen for the most recent year available. Although these particular states do not have the most extreme ideology scores across the fifty states, they offer variation on each side of the spectrum for citizen versus government. More simply stated, these cases represent both a more liberal government and conservative citizen (Indiana); a more conservative government and liberal citizen scores (Nevada); as well as a government that changed scores drastically from the year the program was created until the most current year (Florida). This variation will potentially enable more insights on the argument that political officals and bureaucrats would attempt to shape policy based upon individual policy preferences.

\section{Political Appointees}

All fifty states possess a political appointee at the top of the bureaucracy that administers the brownfield program. Without interviewing and studying each state in depth, understanding any small differences in changes in these political appointees as a way of selecting cases is not feasible. However, besides being an interesting component of the study of the cases individually, this aspect did enable and expand on the rationale for selecting Indiana. As will be elaborated on in the following chapters, Indiana has a very fragmented program where one large aspect of it falls into a quasi-governmental authority with reporting requirements to a completely politically appointed board. This will provide some interesting variation in this aspect. 


\section{CHAPTER V}

\section{CASE STUDY PRESENTATION}

The implementation and administration of state level brownfield programs are likely impacted by a multitude of things. Although this research cannot point to all the potential influencers some valuable and significant contributions can come from this research. As has been outlined in Chapter Four, state intervention into the remediation and redevelopment of brownfields is both complex and widely diverse. Although the overall database provides keen insights into this diversity, the in-depth interviews and document review has enabled this research to go one step further in detailing the specific complexities and the influences elected and non-elected officials can have on these programs.

Drawing on the theories of political control and bureaucratic discretion, this research is able to demonstrate some of the influences each have had on the implementation and administration of the various brownfield programs. In each of the case studies a number of key individuals were interviewed. Depending upon the state and organization, the number of interviews conducted in each state differed. In Indiana a total of seven interviews were conducted; in Nevada a total of five interviews were conducted; and in Florida a total of nine interviews were conducted. These interviews lasted anywhere from 45 minutes to two hours in length. In some cases interviews were conducted more than once with the same individual as a result of new information and 
questions. The individuals being interviewed ranged from brownfield program heads to political officials involved in the crafting of the enabling legislation. RCRA officials were also interviewed in each state. Unfortunately in no state was the appointed official in the overall department interviewed. These individuals were very reluctant to discuss their jobs and the programs. However, unfortunate this lack of interview opportunity is, the findings from these individuals are very worthwhile and significant. These appointed department heads change with each administration, are located many offices above the brownfield programs, and can likely provide little additional information on the programs that is not able to be gleaned from the individuals interviewed. The individuals in the administrative capacities of the programs provide keen insights concerning the impact, or lack of, by the appointed head of the overall department or agency.

As outlined in Chapter Four these cases were selected for their variation on the key components outlined in political control and bureaucratic discretion theories. These cases represent three different EPA regions, varied environmental and economic histories, and very different programs for their brownfields. This chapter records the findings and specific details discovered during the interviews and document reviews; the following chapter discusses these findings in relation to bureaucratic discretion, legislative control, regulatory environment, and intergovernmental relations. In all cases the names of the interviewees are intentionally omitted per an agreement of confidentiality in return for the candid answers received for the interview questions. Additionally, the job titles are omitted and replaced with job roles to provide more obscurity to the individuals participating in these interviews. The three cases are 
presented individually in preparation for a synthesis and analysis in Chapter Six. The following text outlines the findings for Indiana, Florida, and Nevada.

Recalling from the previous chapters, these states were selected for their variation on several key points. Both Florida and Nevada show administrative unity, while Indiana shows a greater level of fragmentation. All three states show a stark difference on their regulatory issues as they relate to RCRA. Indiana possesses a PPA with the EPA for their RCRA program, Nevada exhibits an extremely high level of RCRA inspections and enforcements, and Florida shows a lower than national average inspection rate. Ideology scores varied across the three states as well. Finally, all three states have been in existence for several years allowing for a richer set of experiences than if they were particularly new programs.

\section{$\underline{\text { Indiana }}$}

Indiana is a state that has dealt with significant deindustrialization over the past several decades. According to the United States Census Bureau the following reflects the change in percentage of employment in manufacturing over the past three decades.

\begin{tabular}{ll|l|l|}
\hline & $\begin{array}{l}\text { Total Wage \& } \\
\text { Salary } \\
\text { Employment }\end{array}$ & $\begin{array}{l}\text { Manufacturing } \\
\text { Employment }\end{array}$ & Percentage \\
\cline { 2 - 4 } 1970 & $1,965,281$ & 717,420 & $36 \%$ \\
1990 & $2,632,040$ & 648,151 & $25 \%$ \\
2000 & $3,118,980$ & 697,911 & $22 \%$
\end{tabular}

Table 5.1: Source: US Census Bureau. NOTE: Classifications of industry changed in 1997, discrepancy may exist in $\mathbf{2 0 0 0}$ data as a result.

As the table indicates, from 1970 to 1990 Indiana experienced a sharp decline in manufacturing. Employment in this industry dropped by over $36 \%$ in this thirty-year period. Logically, this may be indicative of prevalence in brownfields within the state of 
Indiana. That is, as deindustrialization occurs brownfield sites are potentially left behind. Over this same period Indiana experienced only a marginal growth in terms of population change. Overall from 1970 to 2000 Indiana's population grew by about $17 \%$. It is not easy to assess what Indiana's brownfield situation may actually be. Even the officials dealing with brownfields in the state admit: "A lot of people don't want it public that their site is a brownfield and as a result we may never know it exists" (VRP administrator, 11/9/2006).

Although making a clear and completely accurate statement surrounding the potential applicable population for the public brownfield programs in Indiana is nearly impossible, it is still fruitful to examine this program in this research. In response to the known presence and potential presence of additional contaminated sites in their state the policymakers created public programs directed at these properties. Indiana currently has two major brownfield programs - the Voluntary Remediation Program (VRP) and the Brownfields Program. The brownfield remediation and redevelopment efforts began in earnest in 1993 when the state passed legislation creating IC 13-25-5 forming the Voluntary Remediation Program (VRP) housed within the Indiana Department of Environmental Management's Office of Land Quality. Alternatively, the Brownfields Program as currently organized and functioning was created in 2005 with the passage of Senate Enrolled Act 578. Each of Indiana's two programs will be detailed in the following sections. The findings from the Indiana RCRA program will also be detailed. Indiana's VRP

The passage of the enabling legislation for the VRP made Indiana one of the first states in the country to have a voluntary cleanup program. According to one elected 
official in the state legislature at the time of the creation of this program the VRP was at least partially directed at the problems Indiana faced stemming from deindustrialization in the state (Policy Maker \#1,11/11/2006). The statutorily stated purpose of the Indiana VRP is to: "...provide an alternative procedure to assure compliance with the law and to encourage the voluntary remediation of hazardous substances and petroleum" (IC 13-25$5 \mathrm{Sec} 1 \mathrm{a})$. The statutes creating the VRP are very broad and offer guidance concerning the purpose of the program, eligibility for participation, appeal processes, fees, public comments and notices, and other broad details concerning the work plan creation and approval process. Although the statute allows for administrative rulemaking concerning the implementation of this program, none are noted in the Indiana Administrative Code and only guidance documents have been created, not formal rules.

This particular program is located in the Office of Land Quality in the Indiana Department of Environmental Management. The Office of Land Quality encompasses a variety of programs dealing with, “...waste management, site cleanup or spill prevention" (IDEM Office of Land Quality, 2007). Of note here is that the RCRA program is also operated out of this same group of programs. Although all the programs within this office have similar roles, the VRP administrator reports little overlap and day-to-day working relationships between the various programs with the slight exception of RCRA.

We don't really work with any other program. Well, we have some sites that overlap with RCRA the RCRA folks. There's a couple of different parts to RCRA. One part of RCRA is called RCRA corrective action and we have some RCRA corrective action sites that are completing their responsibilities to RCRA through the VRP. So we probably have a half a dozen of those or so. On those we will interact with RCRA staff pretty hard on those. But I would say in general outside of those we don't really have that much interaction with the RCRA program (VRP Administrator, 11/9/2006). 
The VRP program has eight project managers working in it. Like all the other voluntary cleanup programs across the United States, Indiana's VRP provides a mechanism for obtaining liability relief for completing a certain level of cleanup of a site. Specifically, participants receive a Certificate of Completion (COC) leading to a Covenant Not to Sue (CNTS) upon the completion of the cleanup. The chief administrator in this program views the CNTS as the key benefit to this program:

...for our participants if they successfully conclude our process they get a Covenant Not To Sue which relieves them of any environmental liability for issues that were addressed in their project. So essentially the state says we will not be coming after you for any future cleanup for anything you do in the VRP.... Covenant not to sue and Certificate of Completion essentially goes together. And when a site completes our process the agency, IDEM, issues the COC and then it is the responsibility of our participant to record that certificate onto the property deed just to show the work has been done. Then once they have done that they automatically get the covenant not to sue. It is the only thing we offer. We don't offer any other form of liability protection or different levels like some states (VRP administrator, 11/9/2006).

An additional liability abatement assurance that goes with the CNTS is the fact that Indiana possesses an MOA with the EPA for their VRP. As discussed in Chapter Four Indiana's VRP possesses a Memorandum of Agreement (MOA) with the EPA that was signed in December 1995. This MOA certifies that the federal government will not seek to intervene in sites that have successfully completed Indiana's VRP.

When a site in Indiana has been investigated or remediated in accordance with the practices and procedures of the VRP and IDEM has issued a Certificate of Completion for the site, Region $\mathrm{V}$ will not plan or anticipate any federal action under the Comprehensive Environmental Response, Compensation and Liability Act of 1980 (Brownfields and Voluntary Remediation Program MOA, 1995). 
In addition to CoC, CNTS, and the MOA the VRP in Indiana allow responsible parties to participate and allows all participants to use risk based cleanups and institutional controls:

...in fact most of them are responsible parties. They don't necessarily have to but certainly that tends to be the biggest percentage of our sites. We do [allow institutional controls]. We track them somewhat informally. One thing we do require is that they have to be formalized through an environmental restrictive covenant that gets recorded on the deed indicating which land use restrictions that property has (VRP administrator, 11/9/2006)

The VRP administrator also notes that reopeners are virtually unheard of but are allowed. "Our assumption is that we issue closure and it is final" (VRP administrator, 11/9/2006).

For sites entering the VRP a fee is required of them. In fact the VRP was designed with intent to make it almost exclusively self-funded. "We associated a fee with the program in order to help pay for, to make it almost entirely self sufficient to cover the costs of the program and not rely on departmental budgets or appropriations" (Policymaker \#1, 11/19/2006). According to the chief VRP administrator:

Our program is primarily self-funded through cost recovery. We have an agreement with all the sites in our program that they will reimburse us for our time and effort for the management of their project. That doesn't account for $100 \%$ of our time but in terms of a budget it is difficult to say exactly. We are mostly self-funded. In addition to that since it is not possible to fill $100 \%$ of your time we have an EPA grant we are part of and we get money from the EPA for our work not specifically related to a project (VRP administrator, 11/9/2006).

It is this cost recovery and lack of direct funding from the state that is cited as key to the lack of any formal oversight or reporting mechanisms to state elected or appointed officials. Both the elected officials and the administrators state that they do not have a real relationship. "As far as any reporting to the legislature, governor, or towns-we 
don't have those requirements" (VRP Administrator, 11/09/2006). Policy makers also concede a lack of oversight and influence on this program. "We don't really get involved with that program or anything on a real basis" (Policymaker \#3, 01/31/2006). In addition to no real relationships with elected officials, the VRP also reports little to no relationship or influence by appointed officials. In fact the VRP administrator reports little-or-no noticeable changes upon changes of administration in relation to their appointed commissioner of IDEM (VRP Administrator, 11/09/2006). In the hierarchy of the overall department the appointed commissioner is at least three steps above the overall office that houses the VRP.

Although the VRP seems to have little connection or oversight by Indiana policymakers or elected officials, they are somewhat more connected to and constrained by their EPA region. "We submit semi-annual reports to the EPA. We are required to report what we have done with the funds they have given us" (VRP administrator, 11/9/2006). Although the administrator of this program acknowledges reporting requirements to the EPA he also goes further to explain the relationship is not a strong one.

We have a MOU [MOA] with the EPA. For any site that completes a cleanup in our program they will essentially not consider taking any action against those sites. So essentially what that says is they have reviewed our program and like what we are doing well enough to give us free reign to run it how we see fit and they will not take any federal actions against those facilities. But they are not really involved with us directly on a day to day basis in our projects. As far as the regional office in Chicago a couple times a year we will go to a meeting. There is usually a mid year and an end year meeting that we go to and talk about issues related to brownfields and remediations projects. At the federal level we don't have any contact at all and the regional level we have a very distant relationship" (VRP administrator, 11/9/2006). 
The Indiana VRP does not provide any financial assistance within its own

program. As the VRP administrator noted: "No [we do not provide financial assistance]. There are some tax incentives for cleanups. Our only real participation advantage is to certify that the cleanup has been done. But we don't offer any sort of incentive ourselves" (VRP administrator, 11/09/2006).

To date this program has completed 190 brownfield sites with approximately 360 currently in the program (VRP administrator, 11/09/2006). The administrator reports that the most recent and biggest challenge with this program in his opinion is the prevalence of sites that are eligible for the VRP but do not fit in really well. He explains:

We do find sometimes that there are sites that are eligible to participate in our program that just don't fit in real well for one reason or another. For example, landfills. And this is not the big municipal landfills you might imagine. But there are a lot of old decades old abandoned landfills that will apply to our program. And there are really pretty difficult to manage in terms of risk related to health risks. So we just find sometimes that we have problematic sites that just don't fit real well within the framework of the intention of the program. I think that when it was first devised the legislature didn't really anticipate that we would be looking at sites like landfills. But there's nothing in our statutes or process that allows us to keep them from entering and participating in our program. So we are sort of stuck with figuring out a way to evaluate those complex sites and make sound and technical decisions on them" (VRP administrator, 11/9/2006).

\section{Indiana Brownfields Program}

Unlike Indiana's VRP, the Brownfield Program does not provide liability protections to would-be redevelopers and is primarily directed at political subdivisions and redevelopment agencies as opposed to a private developer or responsible party. Although both programs facilitate the redevelopment of brownfields, both are voluntary, both use risk based closure levels, and both issue closure documents- the mechanisms and levels of protections offered are quite different across the two programs. 
"The Indiana Brownfields Program was created by 2005 legislation that merged the brownfield technical review and financial review programs into one program" (Indiana Brownfields Program Financial Incentives, 2006). “This merger and reorganization was really aimed at making Indiana more responsive, efficient, and customer friendly. Now one place has control over most of our financial programs. Rather than go to multiple places and have competing offices, we have one" (Policy Maker $\# 2,10 / 20 / 2006$ ). Before this merger several small brownfield related programs existed in IDEM. The new organization took all debt issuing programs and placed them under one organization called the Indiana Finance Authority (IFA). Indiana's Public Finance Director is appointed by the governor and is the chief of the IFA.

In the 2005 General Assembly, the Public Finance Director was given statutory oversight of all state debt issuance and is the chief executive of the Indiana Finance Authority (IFA), leading a staff of 50 and reporting to the IFA Board. The IFA is the successor entity to the former Indiana Transportation Finance Authority, the State Office Building Commission, the Recreational Development Commission, the Indiana Development Finance Authority and the State Revolving Fund Loan Programs (Biography of the Public Finance Director of the State of Indiana, nd).

In addition to the Public Finance Director's role in the management of the IFA, it is also managed by a board of five statutory individuals. These “...members are the Director of the Office of Management and Budget, the Treasurer of the State, and three other members appointed by the Governor. No more than two of the Governor's appointees may be members of the same political party, and they all must be residents of the State" (Indiana About IFA, 2006).

The legislation creating the Indiana Brownfields Program is much more detailed than the VRP laws. Under the new legislation procedures for debt issuing are outlined in great detail, explicitly who will serve on IFA's board of directors, and what funds can be 
used for what purpose. Administrative procedures are still being worked out for the new organization in terms of the brownfields program. According to brownfield program employees the IFA board provides some oversight but hasn't really impacted the day-today operations of the program as of yet. "...there are monthly board meetings where sometimes the brownfields program will present information or present grants to be approved and things like that. But other than that we do not really have any real relationship" (Brownfield Program Coordinator, 11/06/2006). To the individuals working in the Brownfields Program this reorganization is seen as a good thing. "...it's been mostly positive. It helps make it a more efficient program. And with everyone working together and in one location it is more unified and easier for people on the outside to contact us and everyone seems to really like it" (Brownfield Coordinator, 11/06/2006). As of November 2006 the Brownfields Program employs twelve individuals ranging from attorneys to geologists to biological scientists (brownfield program coordinator, 11/06/2006). The program does not yet maintain a solid tracking system of sites going through the program but it is estimated that over 400 separate sites have entered the Brownfields Program through the history of the technical assistance and financial granting programs that existed before IFA was formed in 2005 .

...we have recently started to try and go out and get all of that information but it is still in progress. So our problem is that a lot of times when people come to us, they are coming to us looking for assessment money. Or sometimes some cleanup money. But then we don't really know what they don't really keep in touch with us as to when the project is redeveloped" (brownfield program coordinator, 11/06/2006).

Probably one of the biggest differences in the two programs comes with the type of closure documents offered. While the VRP offers the CNTS, the Brownfields 
Program offers Comfort Letters and Site Status letters. These comfort and site status letters do not actually offer any liability release-just a statement defining or easing the concerns surrounding contamination at a site. Oftentimes the Brownfields Program is a first stop for brownfield sites in Indiana. An individual working in the Indiana Brownfields program notes that, “...a lot of times sites will start in our programs and they will find out that either through their bank or through the developer that wants a property that they need a higher level of liability protection than what we offer in this program. So then they go over to the Voluntary Remediation Program" (brownfields program coordinator, 11/06/2006).

The brownfield program's guidance indicates that the Brownfields Program is more geared towards redevelopment while the VRP is geared towards environmental remediation. "Brownfields Program's main goal is to provide government guidance assistance for the assessment, cleanup and redevelopment or reuse of properties to revitalize communities. VRP's main goal is to provide government oversight of privately conducted remediation projects" (Crosswalk Brownfields Program Document, 2006). Unlike the VRP which had no direct financial aspect, Indiana's Brownfield Program has a number of financial incentives.

Most of the financial incentives offered by the Brownfields Program are reserved for municipalities, counties, or redevelopment agencies. In some cases a private party can be a co-applicant, but a public entity must be part of the application. Financial incentives noted include: Site assessment grants, remediation grants, petroleum remediation grants, low-interest loans, and tax credits. The low-interest loan program allows for a municipality, county, or redevelopment agency to re-lend to a private 
individual. In whole the Brownfield Program individuals indicate that the reorganization and merger's details are still being worked out. "...we are constantly reevaluating our new program and structure and how we respond to the needs of the public since we are still newly reorganized and still in that stage of constantly evaluating how we are doing" (brownfields program coordinator, 11/06/2006). However, they feel that they are able to offer more streamlined services to Indiana's communities.

Although program officials and political officials interviewed do not indicate a strong monitoring of this program, the EPA regional office does require reporting concerning the grants that the program receives from them. This program indicates a strong relationship with the region in terms of communication. "...we communicate with them for many things. For example, we had a workshop on November $2^{\text {nd }}$ to help send the applicants to the federal grant round that is going on right now and our Region $\mathrm{V}$ person Deborah Orr came down and gave a presentation" (brownfields program coordinator, 11/06/2006).

Overall the Brownfields Program's goals are to get publicly held brownfields remediated and ultimately redeveloped. However, they have not yet been able to determine the impact they are having in Indiana. With the newly organized program the impacts and day to day operations are still in flux and program employees are still working out the kinks from the reorganization.

\section{RCRA in Indiana}

Given the logical connection between RCRA inspections and enforcements and brownfields interviews in all states included officials in that state's RCRA program. Indiana's RCRA program's duties are located within the Office of Land Quality of 
IDEM, the same office where the VRP is located. Within the Office of Land Quality is a multimedia office with four sections: air enforcement; water enforcement; solid waste, underground storage tanks, leaking underground storage tanks, and confined feedings; and a section that does hazardous waste and industrial waste enforcement (RCRA enforcement, 10/14/2006).

Indiana has an Environmental Performance Partnership Agreement (EnPPA) with the EPA concerning its RCRA program. "It is an agreement we have in order to get funding grants from the EPA. A certain percentage of our program is actually funded by the EnPPA grant. It has some fairly specific measures we have agreed to" (RCRA compliance, 12/05/2006). Basically this agreement requires a specific percentage of the various RCRA regulated facilities be inspected annually. This percentage is determined through negotiations and agreements between the EPA Region and the State. Although the percentage of facilities to be inspected is detailed in this agreement, the staff selects which of the actual facilities will be inspected. For the negotiated percentage the employees look back at what previous inspections have been done and choose facilities that have gone the longest without an inspection. It usually comes to a five year frequency (RCRA compliance, 12/05/2006). The inspections are not announced in advance to the facilities being inspected.

If the inspectors find a violation they have some discretion in what the enforcement route will be. "When they [the inspectors] find violations if they are pretty minor they will not refer them to my office. They will take care of it on site or in a follow up inspection" (RCRA enforcement, 10/14/2006). However, if the inspector finds a violation that he or she feels is serious enough to warrant a more formal enforcement 
measure they will be referred to the enforcement office within the Office of Land Quality.

The enforcement office in Indiana has six case managers. When a violation is referred to them the case manager will take over.

We have pretty much two enforcement routes that we do. We can do a violation letter. Which all it is, is a letter that says there are the violations that we found and generally you have thirty days to make corrections and submit documentation showing it has been corrected. There's no civil penalty or anything. That is really the minority of our cases. Most of those kinds of things are handled with the inspector themselves. We do some of those that we feel are a little more severe but don't really warrant a penalty. If a problem is not corrected after a violation letter or if the violation is more severe to begin with, we can issue a notice of violation. At this point we are trying to reach an agreed order that would include injunctive relief and civil penalty (RCRA Enforcement, 10/14/2006).

During the enforcement process it is possible that the appointed head of IDEM can be involved. "...most of our cases are done through the notice of violation and agreed order process that the commissioner does not get involved with. However, sometimes a respondent or their attorney will want to discuss it with the commissioner and so the commissioner would meet with them. That does happen fairly often" (RCRA enforcement, 10/14/2006).

The RCRA enforcement process in Indiana frequently involves elected and appointed officials. In addition to the likelihood that the commissioner will be called upon to discuss a case with a violator after receiving a notice of violation, one of the biggest penalties in the enforcement process is called a Commissioner's Order.

We have a fairly successful rate in getting agreed orders negotiated. However, if we can't get it resolved we go to what is called a Commissioner's Order. This basically recites the issues in the notice of violation. However, there have been 
different administrations when it is difficult to issue those commissioner's orders. So when we tell a company that they need to enter into an agreed order and they are refusing and we make the threat that we will go to the next step of the commissioner's order. It is kinda frustrating when we can't get those issued. And there's been a real difference across administrations in their willingness to issue commissioner's orders. I think the word gets out that all the people outside know we won't issue a commissioner's order (RCRA enforcement, 10/14/2006).

Although it is very apparent that political influences exist in the enforcement or penalty process of RCRA, the inspection to ensure compliance side of RCRA does not note such strong influences. RCRA compliance officials note that: "It is not unusual to get requests or complaints that are funneled through different politicians. But we don't have any functional relationship" (RCRA compliance, 12/05/2006).

In addition to the involvement by the commissioner acting on behalf of the governor, the EPA has some level of involvement in the enforcement process of RCRA in Indiana. However, this involvement is fairly minimal. “...if there's some case that for some reason we would prefer EPA to do the enforcement we will refer it to them. That rarely happens though. EPA also does a small number of inspections annually, I think six. If they find a violation in one of those inspections they would also do the enforcement" (RCRA enforcement, 10/14/2006).

RCRA enforcement officers note that the EPA provides guidance and a definition concerning what constitutes a significant non-complier but they are in charge of doing the actual determination of whether a violator falls into that category. "There's some guidance on significant non-compliance status that requires a certain penalty. However, we have actually do most of the determination of what level of violation we consider the offense to be" (RCRA enforcement, 10/14/2006). 
RCRA officials note that they are involved in determining financial assurance and post closure inspections. "...we do some post closure inspections... we have an individual on staff that we call our financial assurance officer and he is dedicated to financial assurance reviews" (RCRA compliance, 12/05/2006). The financial assurance and closure aspects of RCRA are connected to brownfields and some level of discretion is involved in this aspect of RCRA.

\section{Indiana Overall}

Indiana's brownfield remediation and redevelopment efforts are channeled through two different programs. The VRP is the standard voluntary cleanup type program offering investors, developers, and responsible parties' liability relief in return for participation. This liability relief includes relief from both further cleanups and from $3^{\text {rd }}$ Party lawsuits ( $3^{\text {rd }}$ Party relief only for non-responsible parties). The program is funded through EPA grants and cost recovery. Although they are statutorily constrained in that they cannot deny certain sites entry even when they do not fit well into the program they indicate they are pretty autonomous in their functioning. The Indiana Brownfields Program declares itself an economic development program, however, its primary function seems to be providing funds to public entities in order to assess and cleanup some sites in Indiana. The Brownfields Programs, in theory is subject to a great amount of oversight by state officials on how they spend money and operate; however, the program is still very new and underdeveloped.

RCRA in Indiana is far more impacted by political officials than are the brownfield programs. In fact in terms of RCRA enforcement, a politically appointed official can actually prevent RCRA administrators from issuing the highest enforcement 
order. A key connection from RCRA to the brownfields programs is that a RCRA facility can complete a RCRA corrective action order under the VRP. This is not the case in every state.

\section{Florida}

Florida's brownfield program was created in 1997 with the passage of the Brownfields Redevelopment Act. Elected officials involved in the creation of this legislation cited two primary concerns that led them to believe Florida needed such a program: cost of cleanup and environmental justice issues. "You know we wanted some incentive system that would help or I guess keep Florida from having to pay the bill for these cleanups. We figured it would be less expensive to give incentives than it would be to just pay for the cleanup. You know also there is a real racial aspect to brownfields. So many of them are in minority areas that the state really has a duty to do something to help that to remedy that" (Policymaker $\# 2,10 / 21 / 2006$ ). News articles at the time also reflect an environmental justice aspect to the program's creation. "The Florida proposal was sparked by a report that showed nine of every 10 of 9,000 known Brownfield sites were in low-income and minority communities" (Christenson, 1997). In fact these same justice sentiments are echoed in the legislative intent aspect of the Act along with several other issues related to brownfields.

The statute is very specific about the intent. The key legislative intentions in the statute are as follows: to reduce public health and environmental hazards on existing commercial and industrial sites; alleviate blight; to encourage voluntary cleanup through incentives; to provide clear and predictable remediation standards; to allow risk based cleanups; to address the prevalence of environmental hazards in low income and minority 
areas; to potentially reduce neighborhood decline; and to provide for cooperation across governments and organizations (Florida's Brownfield Redevelopment Act, 1997). The statute is also very specific about the roles, duties, and requirements of the program explicitly outlining the processes and methods for entering into and completing the program.

One interesting and potentially unique aspect of Florida's Brownfield Program was created within the statute itself by then-elected policymakers.

A local government with jurisdiction over the brownfield area must notify the department of its decision to designate a brownfield area for rehabilitation for the purposes of ss. 376.77-376.85. The notification must include a resolution, by the local government body, to which is attached a map adequate to clearly delineate exactly which parcels are to be included in the brownfield area or alternatively a less-detailed map accompanied by a detailed legal description of the brownfield area. If a property owner within the area proposed for designation by the local government requests in writing to have his or her property removed from the proposed designation, the local government shall grant the request (Florida's Brownfield Redevelopment Act, 1997).

As of the writing of this dissertation this is the only state where participation by the local government is statutorily required to designate a brownfield area as a precursor to participation in the program. Both elected officials and non-elected administrators concur on the purpose of this designation. "We didn't want the local governments to feel like the state was interfering in their rights and responsibilities" (Policymaker \#1, 09/15/2006). "The local government designation is very interesting. But I think that was very intentional on the legislature's part at the time. There was a big concern that there was, well there was a lot of voices down there at the time it was being developed that said we want to make sure that the local government doesn't have this shoved down their 
throats" (brownfields program administrator, 09/20/2006). As of February 5, 2007 there were approximately 145 designated areas in the state of Florida encompassing a total of 78,198 acres of designated brownfield area (Florida Brownfield Areas, 2007). This entire acreage is not necessarily brownfields given the fact that many Florida localities designate blocks, census tracts, or other larger areas that encompass both brownfields and uncontaminated land. As of February 6, 2007 a total of 85 sites had executed remediation agreements with the program with a total of 1,827 acres being included (Florida's Sites with executed BSRA's). The sites with remediation agreements actually encompass the brownfields part of the property in the designated areas making this an accurate acreage of brownfields, unlike the previous measure.

This requirement of local government participation has not been without conflicts. In fact brownfield program officials and news articles demonstrate one interesting and recent conflict concerning the program and the designation.

It's all over the paper in St. Augustine. They just designated one in St. Augustine. It was a historic golf course that the city was not able to purchase and the folks in the area wanted it to stay a golf course. But it turns out that there was some arsenic contamination that required cleanup. But there was some issue about whether the developer should be able to use cleanup tax credits. Really, it appeared that there were some people who just didn't want it to become a housing development and they were using many different types of ways to try and block it. I fielded a lot of calls on that one. It just got designated on November thirteenth I think" (brownfields program manager, 11/15/2006).

Now, Stokes [developer] is trying to join the state's Brownfields Redevelopment Program, an initiative to encourage development as a way to clean polluted grounds. He could generate up to $\$ 500,000$ in tax credits for a cleanup many people feel he should do without the financial assistance. Mayor George Gardner is one of them. "He went in knowing that it was an area that needed to be cleaned up. He started cleaning it up," Gardner said. "The Brownfields act, which is an excellent act, is meant for cleanup of industrial land that no developer wants to touch. This could be used as a golf course. It's not a gas plant or an oil refinery." A local resolution supporting Stokes' Brownfields request is required before the 
state Department of Environmental Protection considers designating the former Ponce de Leon, a Brownfields site (Hunt, 2006)

However contentious this particular situation was most officials in elected and bureaucratic positions associated with the brownfields program feel that the designation is a good thing that encourages and fosters local participation. In fact “....an individual can request an individual property be designated a brownfield area and for most of the ones that have occurred this year they have been for individual properties rather than a specific part of town" (brownfields program manager, 09/20/2006). Public participation was a key consideration when the program was created. "We wanted to encourage people to have a say in the process. You know to get involved. We wrote it so that at least one public comment session was required for a site or area to be designated" (Policy Maker \#1, 09/15/2006).

After the creation of this program in 1997 the Florida Department of Environmental Protection (DEP) was charged with implementing the program. The DEP has a very vertical organization. The office that controls the Brownfields Program is at least 6 levels away from the appointed Secretary of the DEP. Specifically, within the DEP the Bureau of Waste Cleanup oversees the program. The Bureau of Waste Management is located under the regulatory programs branch of the Department-the same branch that oversees the RCRA program. Within that Bureau the program has three individuals working directly in the program. There is also one person who oversees the Voluntary Cleanup Tax Credit program.

All programs located in the regulatory branch of the DEP have what are termed regulatory districts. There are six of these districts across the state. Each district has its own office that deals with brownfield issues in their designated areas. "We are organized 
into six districts and there is a brownfields coordinator in each district. Their

responsibilities have to do with technical implementation once sites enter the program, assessment, and remediation. They are there to help the properties get through the process" (brownfields program manager, 09/20/2006).

\section{Liability Provisions}

Florida's brownfield program is similar to other states' voluntary cleanup programs, although it is not formally called that. Upon the completion of an agreed upon cleanup a voluntary participant receives a No Further Action letter indicating that:

Based upon the information provided by (property owner) concerning property located at (address), it is the opinion of (the Florida Department of Environmental Protection or approved local pollution control program) that (party) has successfully and satisfactorily implemented the approved brownfield site rehabilitation agreement schedule and, accordingly, no further action is required to assure that any land use identified in the brownfield site rehabilitation agreement is consistent with existing and proposed uses (Florida's Brownfield Redevelopment Act, 1997)

This liability protection does not extend to $3^{\text {rd }}$ Party lawsuits. The only $3^{\text {rd }}$ party protection Florida offers is an assurance that $3^{\text {rd }}$ Parties cannot litigate to force additional cleanup. However, participants in the Florida Brownfields Program do also enjoy the added liability protections associated with an EPA MOA for the program. Florida's MOA was originally signed in December 1999 and was renegotiated to allow for a wider eligibility in sites participating in the program in November 2005 . Florida does not allow a responsible party to enter into the Brownfields Program and receive any liability protections or incentives if the contamination was caused after 1997.

The state of Florida allows and encourages risk based cleanups and the use of institutional controls. “...originally when the brownfields rule was passed in 1997 it was 
one of the few ways a site could use RBCA in Florida. Since that we have passed a RBCA rule that pretty much encompasses all sites in Florida. Yes [we allow Institutional Controls] and we have a registry that is available online and it tracks any of these controls that might be used" (Brownfields Manager, 09/20/2006).

Although the statute creating the program includes a lengthy list of possible incentives to be created for the remediation and redevelopment of brownfields under this program, the actual state level incentives stemming from the Brownfield Program itself are very few. There are not any real grants associated with the program:

We do not offer any grants. We do have one through an EPA grant and we offer grants in services to successful applicants. For example, we are working with a mission over in Jacksonville that is trying to build a group home and they need soil removal done. We are going to be conducting the soil removal with one of our own contractors so we don't actually give grants but provide services sometimes (brownfields program manager, 09/20/2006).

Additionally the state does not have a revolving loan fund. Although it is noted that several Florida cities have their own revolving loan fund capitalized by the EPA. The one major financial incentive that Florida does offer is a Voluntary Cleanup Tax Credit Program (VCTC). Both sites in the brownfields program as well as certain dry cleaning sites that cannot participate in the state dry cleaning program are eligible for these tax credits. In 2006 these tax credits were increased substantially to provide for up to $\$ 500,000$ in tax credits as well as enable responsible parties to access the benefit (Florida's Voluntary Cleanup Tax Credit). Department guidance is still being worked on and little can be said yet about these changes. “...we are all working on rule changes based on legislative activity this year" (brownfields program manager, 09/20/2006). 
Although the actual Brownfield Program as located in the Department of Environmental Protection a separate agency called the Florida Department of Tourism, Trade, and Economic Development offers several brownfield related economic development incentives. Brownfield properties are eligible for: Loan Guarantees and bonuses for jobs created through the aforementioned economic development agency. Additionally, brownfields are eligible for sales and use tax exemptions for building materials through the Department of Revenue in Florida. Virtually all of these incentives located in other agencies are incentives that existed without reference to brownfields and have subsequently been altered or have decided to allow and to include brownfield redevelopments in their potential beneficiaries.

Unlike all of the other states with voluntary cleanup programs, there is no fee to enter the Florida Brownfields Program. "There is not a fee to the department. We don't charge a fee to enter the program or to review documents. The only fee associated with brownfields in Florida is a $\$ 250$ application fee for the tax credits" (brownfields program manager, 09/20/2006). This program is instead funded partially by the state and partially by EPA funds.

Brownfield program administrators indicate that they are quite impacted by appointed officials following guidance from the governor. "The department has an agenda that is spelled out very specifically by the secretary and we just had a change of administration and we are getting a new governor so we will likely get a new agenda next year. Our primary job is to implement what we are given by the legislature and we make changes when we get new rules from them" (brownfields program manager, 09/20/2006). The program officials also indicate that as administrations change so does their 
involvement with elected officials. In addition to having strict guidance about how the program is to be administered, the program also is required to file an annual report with the state. In this report they are required to detail all their activities for the year including cleanup agreements, economic impacts, economic expenditures, and designated sites.

In addition to oversight and monitoring relationships with elected officials the program also reports to the EPA.

We talk to them [EPA] quite a bit. We have one brownfields grant and we have one of the state tribal response grants and we have chosen to keep this separate from administering the program so I talk to them a lot about that grant. You know some states use the state tribal response grants to actually administer their programs, we don't do that. We do have a MOA for CERCLA and RCRA so they don't really override what we do, but we interface with them a lot concerning the money they give us (brownfields program manager, 09/20/2006).

\section{Florida's RCRA}

Florida's RCRA program is also located in the regulatory branch of the DEP. This program is divided into six districts just like all the other programs in the regulatory branch of the DEP. Brownfield program officials acknowledge a connection between the two programs. "I just sent an email to them [RCRA employees] about a site that is under RCRA cleanup that entered our program. That is sort of a new thing that is something that was added to our MOA during the revision. You didn't used to be able to use the Brownfields program if you were in RCRA cleanup, now you can" (brownfields program manager, 09/20/2006).

Florida's RCRA program does not have a PPA with the EPA. As a result the

RCRA manager explains how sites are selected for inspection:

We negotiate a work plan with EPA Region IV to outline minimum inspections for the year. If you look at the OECA guidance [EPA guidance on inspections] we follow the suggested usual drill of about half of the permitted facilities are 
inspected in any year and a percentage of the other facilities (RCRA manager, 11/02/2006).

In addition to the negotiated work plan with the EPA region the EPA conducts a small number of inspections in the state.

An interesting aspect, with potential ramifications, is the abilities and duties of the six districts in Florida. Each of the six districts in Florida have the power to enforce and sign enforcement letters in the field (RCRA Field Manager, 11/03/2006). "Each of the five major environmental programs we have out there each of the DDMs [field managers] are authorized by the secretary to manage the day to day compliance enforcement. If it is a big enough issue or concern, like the Everglades, it is actually handled out of the Secretary's Office" (RCRA manager, 11/02/2006). It is also noted that the central RCRA office does very few enforcements in the field-with each of the six districts handling most of the RCRA processes on actual facilities.

Funding in the RCRA program is cited as the biggest concern. "...well the biggest thing is dollars to run the program. We are on a combination of EPA grants and general revenue. The EPA grants just have not increased in the last several years and our share of the program has gone up. So where before we may have only been paying for $55 \%$ of the program now it's crept up towards $60 \%$ " (RCRA manager, 11/02/2006).

Although the program reports to and works closely with the EPA regional office, the program officials site very little interaction with elected or appointed officials. "The secretary's office has reporting requirements, but not for the RCRA program per se. Sometimes something might get passed by the legislation that says they want a report in $\mathrm{x}$ 
months. Then we will compile that report and submit it but we have to coordinate with a legislative office the department has" (RCRA manager, 11/02/2006).

\section{Florida Overall}

Florida has only one brownfield program that follows the typical voluntary cleanup structure seen across the United States. Brownfield exclusive financial incentives are very minimal, but the program has adopted a number of economic development incentives for their own program. The brownfields program and the elected officials in Florida both indicate that the program has specific guidance both written in statute and given to them by the Secretary on an annual basis.

Both the brownfields program and the RCRA program are organized into six districts with powers delegated to each district over various aspects of the programs. In the case of the brownfields program the districts only guide participants through the process. However, in the RCRA program the districts actually perform inspections and enforcements of facilities. These RCRA districts then report back to the central RCRA office in Tallahassee which in turn handles any EPA, EPA region, or state involvement. Additionally, the Secretary's office handles all of the big environmental concerns, like the Everglades-thereby bringing certain properties closer to appointed and elected officials.

The Brownfields Program's requirement of a local government delegation of a brownfield area facilitates a greater level of public participation than might otherwise be achieved. This greater level of public participation has contributed to some pretty contentious issues in the recent past. This requirement not only encourages public participation but it also allows local officials a say in the brownfield process. 


\section{$\underline{\text { Nevada }}$}

Nevada's efforts at brownfield remediation and redevelopment started in earnest in 1999 and include two separate programs: The Nevada Brownfields Program also called the Land Recycling Program, and the Nevada Voluntary Cleanup Program (VCP). Both programs are located within the Bureau of Corrective Actions within the Nevada Department of Environmental Protection. The bureau of corrective action:

...oversees cleanup of releases of regulated substances using a multi-media (air, water, soil, and ecological resources) approach. The bureau also administers the environmental response program, superfund and brownfields programs, a reimbursement fund for petroleum claims, and a certification program for environmental consultants" (Nevada Bureau of Corrective Actions Home).

Nevada's RCRA program is located in the Bureau of Waste Management in the Nevada Department of Environmental Protection. These programs were once in the same bureau.

"We used to be in the same bureau. I believe ten years ago the bureau of waste management and the bureau of corrective action were the same. Now the bureau of waste management does primarily RCRA" (VCP Manager, 01/24/2007). Both of Nevada's brownfield programs are very small and underdeveloped in many ways.

\section{The Land Recycling Program/Brownfields Program}

Although program officials in both brownfield related programs admit the programs are small, the Nevada Land Recycling Program (LRP) is the more active program of the two. This program is also called the Nevada Brownfields Program. The program was created in 1999 as grant program for Nevada public entities (Brownfields Coordinator, 01/03/2007). This program relies solely on funding from the EPA and does not receive any support from the state of Nevada. "The State of Nevada has received federal funds intended for use in encouraging brownfields redevelopment; the Nevada's 
Land Recycling Program manages these funds for use in a holistic approach to redevelopment where environmental concerns may be present as a barrier" (Nevada Land Recycling Program). To date this program has helped cleanup 25 sites in the state of Nevada and employs only one individual directly for all oversight and administration of the program.

The LRP receives approximately $\$ 600,000$ annually from the EPA in the form of CERCLA 128a funding to administer the program and give out grants to public entities. Each year Nevada has up to $\$ 400,000$ of that total to award to grant seekers for brownfield projects. The main goal of this program is to just give out as much of that money as possible (brownfields coordinator, 01/03/2007). The grants they award pay for everything for site assessments to the actual cleanup of contamination (brownfields coordinator, 01/03/2007). The LRP also has a revolving loan fund capitalized with EPA funds. To date the RLF has not completed any loans. “...we have not had any success with the revolving loan fund. As of yet we have not given out even one loan in the life of the grant" (Brownfields Coordinator, 01/03/2007)

The program official and policymakers alike do not report a substantial connection by elected or appointed officials on this program. "Our department head is appointed, but he oversees the entire department.... he is way up there. He doesn't have any day to day conflicts or participation in our program.... My program is a grant program and I do not run off of state funding so they do not really involve themselves with my program" (brownfields coordinator, 01/03/2007). "The EPA handles most of the oversight and monitoring of that program. It's their money you know" (Policymaker \#1, January 24, 2007). 
As was the case in the other two states, this program reports an oversight and reporting relationship with their EPA region. "We have quarterly reports and quarterly meetings. We get along quite well" (brownfields coordinator, 01/03/2007).

\section{Nevada Voluntary Cleanup Program}

Nevada's Voluntary Cleanup Program was created in 1999 through the state legislature. This program offers a similar structure as compared to the other state VCPs where a voluntary party can obtain a liability release from the state for completing a cleanup of a property. Nevada has:

...established cleanup requirements for soil and groundwater that has been contaminated with hazardous substances or petroleum products. Sites requiring cleanup are usually identified through property transfer assessments or reports of contamination from the owners of a property or the general public. The owners of the property are required to remediate the property to State cleanup standards until the State determines that No Further Action will be required" (Nevada Voluntary Cleanup Program Fact Sheet).

The state cleanup process that is separate from the VCP allows for an end-use appropriate cleanup level, although they do not specifically use RBCA as formally defined. A property that is cleaned up under a state required cleanup does not offer any legal release of liability. Conversely, the VCP “...provides a means of giving permanent relief of liability to owners of a property where a cleanup is conducted..." (Nevada Voluntary Cleanup Program Fact Sheet).

The Nevada VCP charges an oversight fee to participants. This fee is varied and is determined on a case by case basis. Although the program has been in place since 1999 only one site has entered the program and that site has not completed the cleanup yet. This one site is the University of Nevada at Reno-a state owned facility. The VCP supervisor reports that, "I honestly think the main reason it is part of the VCP is because 
the university has an academic interest in the program" (VCP supervisor, 01/24/2007).

The program's supervisor feels that individuals do not enter the VCP because:

The RP's do not take advantage of the program because they are happy with our regular cleanup process. Our state process. VCP gives them a little more liability protection and so far most folks don't feel like they need that. The big disadvantage of this program is that we charge for our oversight (VCP Supervisor, 01/24/2007).

The VCP program's supervisor is also in charge of the Nevada Superfund Program, the overall brownfields program, an environmental assistance program directed at outreach to rural parts of the state concerning emergency responses, and the revolving loan fund. All of these programs combined have a total of four employees. Only the environmental assistance position is funded through state appropriations, with the remaining three positions being funded through EPA grants. The brownfield programs cumulatively do not receive any appropriations from the state. "We are very proud of that" (VCP supervisor, 01/24/2007).

The VCP supervisor reports no real oversight or monitoring relationships with the state elected or appointed officials. However, he does note that, “... we have to report to the environmental response committee how many spill calls we get and how we responded. And then we have performance requirements tied to the biennial budget we do. Like we may have a question of how many brownfield sites did the program have in the last two years? Then we would answer that as a way of showing our performance, but they don't really hold us accountable for much" (VCP supervisor, 01/24/2007).

The VCP in Nevada also reports a strong tie to the EPA region.

Our relationship is really good, but overall there is some friction between the state and the federal EPA in general. But as far as the programs I work with we have a lot of programs that we grant money. We have one superfund site and the EPA 
has given us complete control over that site. We have a lot of terms and conditions with the grants we receive. We have some paperwork and bean counting that goes along with getting money" (VCP supervisor, 01/24/2007).

\section{RCRA in Nevada}

Nevada's RCRA program was noted as being exceptionally high in the number of inspections conducted as compared to the other 49 states in the overall state database. What was not able to be captured in the quantitative values in the database is an explanation for this high level of inspections. This illustrates evidence of why qualitative inquiry is necessary at times.

We have an agreement with our two largest counties by population, Washoe County which is Reno and Clark County which is Las Vegas. We basically have a contract with the local health departments to do inspections. They do the real small ones. They get paid about $\$ 250$ an inspection. They do about 75 a quarter. So that's 600 annually. They really pull up our numbers. We just don't have the staff time or resources to do that (RCRA supervisor, 02/28/2007).

Although this contractual relationship for inspecting the smaller facilities partially explains the high level of inspections in Nevada, other components of the program are pivotal to Nevada's inspection rate. The final sites to be inspected are determined through a negotiation with the EPA region. "The state has committed to inspection of all of our large quantity generators annually and all of our small quantity generators every other year. We do a lot more than the EPA holds us to. They want us to do something like $25 \%$ annually" (RCRA supervisor, 02/28/2007).

RCRA program officials and policymakers report little oversight or involvement with their program by state elected or appointed officials. "The only time we ever have a political influence is when they are asking us to look at something specific, like a 
complaint. We are not a very large state" (RCRA Supervisor, 02/28/2007). "We have little involvement there" (Policymaker \#2, 02/13/2007).

\section{Nevada Overall}

Nevada has strict requirements that any property with a known hazardous contamination on their property must clean it up to their state mandated standards. At the end of the general state cleanup process individuals are given No Further Action letters that carry no liability protections. Only one individual has accessed the VCP and only 25 public entities have received grants from the LRP-making both of these programs very small. All of Nevada's Brownfield programs are entirely funded by the EPA and as such policymakers and program officials report little connection between state elected or appointed officials and the program. Another cited reason for the lack of oversight by the state legislature is the fact that Nevada's legislature is only in session ever other year-not giving them a lot of opportunity to monitor or oversee the programs. The EPA provides oversight and monitoring requirements for all the programs. However, that oversight tends to be directly tied to the funding received.

Initially Nevada appeared to be very heavy in terms of regulatory nature by virtue of their reported inspections and enforcements in EPA's ECHO database. However, this number is inflated through a delegated process of inspections to local health departments. Although this fact explains the high level of inspection and enforcement reporting, Nevada still appears to be heavy in terms of regulation of environmental harms. In terms of RCRA the program has set the bar much higher than the EPA requires them to.

State law dictates that any release or known contamination by a hazardous substance is required to be cleaned up to state standards. The oversight for this process is 
free and funded by the state. The VCP is not free, but provides real liability relief for the contamination. It is possible that with a heavy regulatory environment and booming economy properties do not often make it to the point of brownfields to enter into these programs.

\section{All Three States}

Looking across the three case studies, we have seen a great deal of variation. We have seen a state plagued by deindustrialization with two relatively successful programs that help private and public entities. We have seen a state where the lower governments and public participation is pivotal, allowing for both public and private entities to participate. We have also seen a very small underdeveloped program that receives all of its funds from the EPA and has only helped a total of 26 sites-all public entities.

Across these three states are a multitude of financial offerings ranging from EPA grant funded assessment and cleanup money to state tax credits and loan guarantees. Two of the states show money available only to public entities, while one has money available for everyone with few restrictions on whether the entity is public or private. We have seen two programs using the entirety of its CERCLA 128a funds for grants to public entities and for administration of the program; and one where it is used to offer grants-in-services to communities and non-profits. We have seen two states with revolving loan funds and one without.

We have seen a varied RCRA environment in the three states. One with very high levels of inspection and enforcements-in fact much higher than the EPA requires them to perform. We have seen a state with an agreement with the EPA that spells out the percentages they must reach in inspections. Finally, we have seen a very 
decentralized RCRA program where six districts each have their own decision making and inspection discretion - although the percentages of each type of facility is determined at the central state level through negotiations with the EPA region. Across these three states we have seen a state who has always allowed RCRA facilities to utilize their voluntary cleanup program for RCRA corrective actions; one that has recently allowed them to do so; and one where they cannot use the VCP for RCRA corrective action.

The overall diversity, complexities, and relationships across these states is very striking and provides some interesting questions about state level brownfield efforts. The following chapter will delve into discussion of what lessons we might gain from the database and these case studies as well as provide some insights into what this data may mean in the bigger picture. 


\section{CHAPTER VI \\ CONCLUSIONS AND POLICY RECOMMENDATIONS}

The research agenda for this dissertation involved two distinct goals. The first goal was to determine what the fifty states are doing in the quest to remediate and redevelop their brownfields. Taken alone, this is a significant contribution to the literature on brownfields, because the data currently available is unreliable, underdeveloped, and incomplete. The database described in Chapter Four, and partially presented in the Appendices, is the product of this research. The size of this database prevents presentation in this printed document, however, as stated in Chapter Four, it is available online. The second research goal of this dissertation included taking a closer look at three specific state programs while adding to and expanding upon bureaucratic discretion and legislative control theories. This is accomplished through an in-depth comparative case study of three individual states. As was pointed out in Chapter Two, this dissertation seeks to use the more complex state level government as a vehicle for informing these theories, which at this time are primarily concentrated on the federal government. Part of the complexities at the state level is the interdependence between other state level programs and agencies as well as federal level programs and agencies. This chapter draws on the themes discovered in this research to critically assess the two overarching research goals of this project. First, some findings and conclusions are presented concerning the overall data on the fifty states sometimes supplemented with 
findings from the cases. Following the discussion of the fifty states, the theories of bureaucratic discretion and political control concerning the case studies are discussed. This chapter also includes some policy recommendations and overarching conclusions.

\section{What have the "laboratories of democracy" taught us?}

One potential key to the goal of remediation and redevelopment of brownfields is to enable and foster an effective public effort. Understanding the differences across the fifty laboratories of democracy and what can be learned from these differences is a valuable lesson in policy. To be sure, each state has a different set of resources, level of brownfield problem, and desires to remediate these properties—-however, with public investment into these programs growing each year, it is wise to take a moment and learn a little more about what is being done across the states and what implications these programs may have.

The database has shown that liability concerns and financial costs of redeveloping brownfields across the states have been handled in a diverse, sometimes unequal, way. The database also shows unique differences in state level RCRA program enforcement and compliance. Questions posited in Chapter One included: How, if at all, does the regulatory environment of a state influence their brownfield program? What can the states learn from each other? Are there any commonalities across the fifty states that are interesting to the quest for remediation and redevelopment of brownfields? Drawing from the themes discovered in this database enables this analysis to discuss these questions. 


\section{Regulation}

The data gathered in the fifty state database shows interesting and striking differences in the numbers of inspections at RCRA regulated facilities. As was detailed in Chapter Four an examination of the entire universe of RCRA regulated facilities reveals some states with extremely low inspection rates and some states with relatively high inspection rates. Using this data as a proxy for the environmental regulatory nature of a state reveals that, in fact, some connection may exist between the two. More specifically, if the states with higher levels of inspections and enforcements are viewed as being more environmentally protective than states that do not, then it is possible to examine the details of the brownfield programs to see if they have attributes that are equally as environmentally protective. To do this we can take a sample of states with the highest inspection rates and a sample of the states with the lowest inspection rates and compare them across their stated mission/purpose of their brownfields programs.

\begin{tabular}{|l|l|}
\cline { 2 - 2 } \multicolumn{1}{c|}{} & BF Mission \\
\hline $\begin{array}{l}\text { NV } \\
\mathbf{( 4 4 . 7 5 \% )}\end{array}$ & $\begin{array}{l}\text { "The Nevada Land Recycling Program of NDEP maintains } \\
\text { technical staff which can oversee assessments and site cleanups to } \\
\text { ensure they are consistent with Nevada laws and are protective of } \\
\text { human health and the environment". }\end{array}$ \\
\hline $\begin{array}{l}\text { MT } \\
\mathbf{( 2 4 . 9 1 \% )}\end{array}$ & $\begin{array}{l}\text { "The primary focus.....is to facilitate investigation and cleanup of } \\
\text { releases of unregulated hazardous substances". }\end{array}$ \\
\hline $\begin{array}{l}\text { VT } \\
(\mathbf{1 . 8 3} \%)\end{array}$ & "VRCPP is a road for invigorated community growth". \\
\hline $\mathbf{N H ~ ( 1 \% )}$ & $\begin{array}{l}\text { "The New Hampshire Brownfields Program encourages the } \\
\text { redevelopment of contaminated properties through a variety of } \\
\text { initiatives that address the uncertainty and liability concerns } \\
\text { associated with brownfields sites". }\end{array}$ \\
\hline
\end{tabular}

Table 6.1: RCRA Inspections and BF Missions across small sample of states 
Examining Table 6.1 shows that in the two states with the highest propensity to inspect and enforce environmental regulations, their brownfield programs have a mission that is rhetorically centered on environmental remediation. Conversely, the two states with the lowest propensity to inspect and enforce RCRA environmental regulations have a brownfield purpose/mission more centered on the economic development aspects of brownfields. Taking a look at additional specifics of these four state brownfield programs seems to lend further credence to this finding. For example, in Nevada the two brownfield programs only offer an EPA funded revolving loan fund and EPA funded grants to public entities. Comparing this to New Hampshire where that state offers nineteen separate grant programs that range from EPA grants to state funded grants drawn from various administrative agencies shows a state more focused on funding environmental remediation to facilitate the redevelopment of a brownfield. As has been stated throughout this dissertation, I am not testing a theory---but providing an exploration of the issue. These possible connections are something that further research can explore to see if states can be characterized in an environmentally protective versus economic development oriented manner. If a measure like this is possible, then future quantitative studies of brownfields can be facilitated through the use of RCRA ECHO data as a proxy for environmental regulatory versus economic development nature of the programs.

In addition to these indirect connections between RCRA and Brownfield Programs, direct connections exist that make it logical to study the two in conjunction. Certain hazardous substances being removed from brownfield sites may be regulated under RCRA, providing a direct link between the two. These substances will likely have 
at least two facility connections with RCRA: first, the act of transporting the substances will fall under RCRA's Transporters regulations; second, the end resting place for these materials will likely be a TSD (Treatment, Storage, and Disposal Facility) that is often not in the same state. Florida, for example sends RCRA hazardous waste to Alabama or North Carolina; and Kentucky sends waste to Oklahoma. Although as was discussed in Chapter Four, TSD's are the most heavily inspected and regulated facility type across the fifty states, Transporters did not receive this same consistent level of enforcement of RCRA. Referring back to the four extreme states touched on above reveals the following variation in these two types of facilities:

$\begin{array}{llll}\text { Nevada } & \text { Montana } & \text { Vermont } & \text { New Hampshire } \\ \text { TSD: } \mathbf{9 1 \%} & \text { TSD: } 100 \% & \text { TSD: } 86 \% & \text { TSD: } \mathbf{5 0 \%} \\ \text { Transporter: } 19 \% & \text { Transporter: } 90 \% & \text { Transporter: } \mathbf{1 3 \%} & \text { Transporter: } \mathbf{3 1 \%}\end{array}$

Table 6.2: Specific RCRA facility inspection rates in selected states

Even in just these four states, a wide variation exists in the transporters who get inspected under RCRA regulations. Leaks, accidents, carelessness, or even fraud in these transporters of hazardous materials being removed from brownfields can cause serious environmental harm--potentially resulting in another contaminated property somewhere new.

Another direct link to Brownfield Programs is that of RCRA corrective action. In some cases when a violation is discovered in inspections or when a facility is closing, corrective action is ordered under the RCRA regulations. This cleanup process can possibly be able to be completed in a state's Voluntary Cleanup Program. Although the database is not able to provide an exact tally of which states allow this connection, the 
three case studies provided some additional information here. In Indiana and Florida, RCRA corrective action sites are able to be cleaned up under the brownfields programs; in Nevada it is not allowed. Another state of note is Colorado, where RCRA corrective action is strictly prohibited from participation in the Brownfields Voluntary Cleanup Program. It is likely that further qualitative inquiry across the other states will reveal more states where RCRA corrective action is allowed to be completed under the brownfields program. Enabling RCRA corrective action sites to utilize a state's brownfield program has a number of implications for RCRA and for the brownfield programs. First, the allowance of an actively operating facility into a program presumably geared for inactive or abandoned sites changes the nature of the entire cleanup. The capacity of the brownfield program to accommodate these differences is unknown and can potentially be detrimental to the purpose of RCRA to the environment as a whole. A second implication comes with accountability for funding. We know from the database and details presented in Chapter Four that most brownfield programs across the fifty states utilize a combination of user fees and EPA grants to operate. The EPA grants were awarded to the states from the EPA to enable more brownfields to be remediated and redeveloped-not necessarily to enable a RCRA facility to obtain liability relief for their faults under RCRA. The accountability for these EPA grants as well as the capacity of the brownfield program to properly oversee a cleanup in an active RCRA facility is unknown.

Examining the two seemingly independent programs, RCRA and Brownfield Programs, has revealed that connections do exist, making it logical and necessary for future brownfield program studies to further investigate the connection between these 
two programs. In some cases the lines between the two programs become very blurred with accountability to the EPA, the state, and the citizens being in question. It would also seem that using RCRA inspection and enforcement data may be able to provide a reasonable indicator for the nature of that state's brownfield efforts, although further inquiry in this respect would be fruitful in future studies. In all cases across the 48 RCRA authorized states, the RCRA program is operated in the same Department as the Brownfield Program, thereby potentially working under the same institutional culture. Judging from the cases outlined above, something between the two programs seems to be connected, or at least being influenced by the same thing. Future studies could potentially use the highly quantitative RCRA inspection data to provide a measure of environmental protectiveness of a given state when studying brownfield programs. Additionally, future studies could use the implications of RCRA corrective action cleanups using the brownfields programs as an interesting inquiry into intergovernmental relations and financial accountability.

\section{Lessons Learned?}

Both the database and case studies of this dissertation enabled a look at the complexities of these programs. No two states are identical in how they handle their brownfield programs. As was pointed out in Chapter Four, brownfield literature is dominated by the premise that brownfields are not more widely developed as a result of developer's liability concerns and concerns over the financial costs of cleanup. Table 6.3 restates, in a simple form, the basic foundations of these programs that exist across the states in relation to these two aspects of brownfield remediation and redevelopment. 


\section{Liability Abatement}

-48 of 50 states have liability protections -23 of 48 states have an EPA sMOA -Approximately $50 \%$ of states allow responsible party to receive liability protections -11 States offer $3^{\text {rd }}$ Party Liability Protections
Financial Abatement

Opportunities

-EPA funded grants

-Revolving Loan Funds

-State Funded Grants

-Loan Guarantees

-Tax Incentives: Sales, Property, Income

-RBCA/Institutional Controls

\section{Table 6.3: State Liability and Financial Abatement Methods}

First, in the 47 states with a typical Voluntary Cleanup Program, liability abatement is a pivotal part of that program - in fact sometimes it is the only benefit of the program. The concept and goal of achieving voluntary cleanups in exchange for liability protections is one that is not without opponents and detractors. First, in some ways it relieves the responsible party of duties to cleanup contamination that they have created because as it is quite possible that a voluntary party will step in and cleanup the site. Second it likely allows for cherry-picking in sites. Making cleanups voluntary and providing public resources for that purpose, does create the potential for less than equitable results in what sites will be remediated. That is the sites with the most redevelopment potential, in the best markets, will likely be redeveloped using the benefits of these programs. However, there is a risk that these 'best' sites would have been redeveloped anyway, leaving all of the most undesirable sites behind. Without future and additional studies, this is not something that this dissertation can prove, however, logically from the data gathered this makes sense, and as such, it warrants future studies. 
Although some amount of cherry picking probably occurs as a result of these voluntary programs, it is certainly true that before these liability mechanisms were in place many current property owners and municipalities were at risk of being held liable under state and federal law for contamination that they may not have created or even contributed to. The liability mechanisms in the voluntary cleanup programs certainly can help get the redevelopment process started for a number of sites where the parties are all innocent. Irregardless of the benefits to be gained by providing these liability relief documents they are not without detractors and problems. With the number of states possessing EPA MOA's for their VCPs and allowing responsible parties to participate fully, have these liability protections gone too far? Have the remedies for the unanticipated consequences of the strict environmental laws of the 1980s, gone so far as to possibly recreate the potential for similar harms that prompted the original strict environmental laws?

The CERCLA strict liability that the brownfield laws were passed to relieve may very well be quite an effective incentive to prevent future contamination. By encouraging cleanup through liability relief guarantees, it is possible that liabilities for future contamination become less feared and less avoided, thereby increasing the likelihood of future problems: a sort of unanticipated consequences problem. That is, taking away the liability concerns may leave cities and states vulnerable to future contamination and problems. An additional concern with these liability protections is present in the eleven states with $3^{\text {rd }}$ Party liability protections. It is quite possible that harms to other individuals will not be able to be litigated to an acceptable solution in these states. This type of liability protection may provide little recourse to individuals 
who may have suffered as a result of contamination in a neighboring property or as a result of groundwater contamination. Although it eases the developers concerns, what implications might this have for the injured innocent party? Finally, providing a mechanism for liability relief may encourage businesses to cleanup, but may result in giving tax dollars to these businesses to perform cleanups they may have been responsible for or that they may have performed without the program at all- the socalled cherry picking problem again.

These liability relief documents in some states go further with an EPA M.O.A. Just under half of the states have a MOA for their VCP. The same implications and unanticipated consequences could result to a greater degree under the states with an EPA MOA. From a developer's point of view, a state possessing a MOA may be looked upon more favorably for the location of potential development, or in this case redevelopment. This EPA MOA can be looked at as beneficial in providing extra assurances to developers concerning their potential for future liability--- but it could also be viewed as an additional way in which the responsible party for contamination cannot be required to pay for their own cleanup. Almost thirty states allow the responsible party to participate and receive liability protections from the state. Fourteen of these states also possess an MOA with the EPA. In essence, these states are providing double liability assurance to the responsible party. Allowing the responsible parties to obtain this level of liability protections has potentially troubling implications for environmental problems that science may not yet know about, or that the state has not identified on a list of hazardous substances. As was outlined earlier in this dissertation, the states do not uniformly identify hazardous substances or require that they be cleaned up to a specific, uniform 
level. With this variation across the states, this double liability protection for responsible parties potentially leaves citizens in very unequal situations.

Some further important questions raised by the growing acceptance and use of voluntary cleanups are: is it good use of tax dollars and policy to utilize public resources to provide a voluntary party liability relief in order to clean up contaminated property if it means the entity at fault for the contamination never has to pay for it? Or, as is true in Pennsylvania, is it good policy to provide state and federal cleanup and $3^{\text {rd }}$ Party liability relief to someone who may have been partially responsible for the contamination, even though they, by former laws, should have cleaned up the contamination anyway? The answers to those questions are certainly debatable.

\section{Financial Costs}

The second often cited impediment to brownfield redevelopment is the added financial costs associated with cleaning up brownfields to ready them for redevelopment. There is a logical relationship that exists between liability relief and financial incentives in the quest to get brownfields redeveloped. Obviously, liability relief documents reduce the risk on the part of the developer. With a reduction in developer's risk, the risk premium $^{2}$ for obtaining and developing a brownfield will be lower, thereby theoretically, requiring fewer financial incentives to get the brownfield done. In states where liability protections are less comprehensive, those states may be able to compensate by offering more financial incentives to developers. The most commonly offered incentives as explained in Chapter Four were: EPA assessment and cleanup grants; loan guarantees and revolving loan funds; and various tax incentives. Some states have begun drawing from other economic development programs as a way to encourage and facilitate

\footnotetext{
${ }^{2}$ The reward for holding a risky investment rather than a risk-free one (Investorwords, 2007).
} 
redevelopment. The use of these types of financial mechanisms may be able to offer enough incentive to get developers to invest into brownfields---achieving the remediation and redevelopment of brownfields. However, much like the liability relief aspect of these programs, financial opportunities offered across the states are not without some concerning aspects.

A majority of financial incentive programs offered across the states stem from the EPA's grants to the states-although in terms of total dollars state investment is likely higher. In fact, one large (in terms of grants directly to states) grant that was created in the 2002 federal Brownfields Law, CERCLA 128a, provides up to $\$ 50$ million a year for states to expand or establish their brownfield programs. An interesting component of this funding is that the states must apply through their EPA Regions for this funding. As was seen in Chapter Four funding is quite varied across the states. For example, Montana received $\$ 976,426$ from this grant program last year while Minnesota received $\$ 753,000$. Translating this into per capita reveals that Montana received an average of $\$ 1.03$ per person living in the state while Minnesota received $\$ 0.15$ per person. This is quite a discrepancy. Most states report using these funds for administrative purposes, formulation of a database for brownfields, and for cleanup and assessment grants to public entities. This use of federal brownfield money across the states appears to be diverse and has the potential to be awarded in a discretionary manner with less than fair results. Unfortunately, as was detailed in Chapter Four, the amounts these states receive are not made readily available by the EPA or the EPA Regions and must be gathered on a state-to-state basis. Some potential policy recommendations concerning these funds include: A transparent tracking system by the EPA. Public funds provided to public 
entities should be made readily available to policy analysts and researchers. Relying on state responses to inquiry to determine amount of funding received does not enable accountability to citizens. Additionally, funding should not solely be done by grant applications by the states. Certainly, many states have been in the brownfield remediation and redevelopment process for much longer and have a potentially unfair advantage in the experience and awarding rates for grants. In fact, what is seen in the states that CERCLA 128a funding is known, is that the states with the most established programs are actually receiving more money than those with less established programs. For a grant program directed at states for the purpose of expanding brownfield effortsthis makes little sense. Certainly, future research should further expand on this tracking to determine whether discrepancies exist across regions and how the EPA regions determine which grant applications to approve.

The brownfield efforts across the fifty states have not widely offered financial incentives from their own funds---particularly direct grants. In some ways it seems that states are relying more heavily on abating the risk on the sites in order to achieve remediation and redevelopment. What grants that are offered tend to be tied to the EPA, and many of those EPA grants are awarded on the basis of grant applications. Again, this implies that those states with more experience and more persistence will likely be able to obtain greater EPA funding. This may not always be the states that need it the most. Furthermore, since brownfield policies at the state level are not directly related to any federal standards, remediation standards are left to the state decision makers who may make decisions based upon the costs and willingness of developers. Brownfield programs, in essence, are replacing environmental health with risk relatively-something 
that might result in higher cleanup standards in wealthier areas and lower standards in poorer areas (Landy, 1999). Additionally, Bullard (1993) has pointed out that poor and minority communities are oftentimes willing to accept lower levels of remediation for fear of missing all economic investment and development. The so called, "environmental blackmail".

Outside of these EPA funds, the primary state originated incentive comes in the form of tax related incentives. The use of tax incentives requires a financial commitment by the states, and sometimes by local governments. In some of these tax incentives the local government is required to take the financial burden of these incentives. More specifically, many states permit their local governments to provide property tax abatements or reductions for remediated brownfields. Although this may work to encourage remediation and redevelopment, it is at the expense of the local government, not the state. Arguably the local government is the most ill-equipped of all levels of government to absorb this cost. In some of these property tax programs, current revenue is forgone either voluntarily, or by state requirement, through a partial or full exemption of property tax on a brownfield being redeveloped. To be sure, in the poorer cities it may not be economically feasible to forgo revenue in order to get remediation done---even if in the long run the property brings in more revenue for the local government.

Some states that offer property tax incentives ask or require that the local government forgo future revenue for a specified period of time by not taxing the additional value of the remediation or redevelopment of the property. Certainly from a local government's perspective the tax incentives based on future revenue are more easily dealt with and is very similar to the process used by Tax Increment Financing (TIF) for 
other economic development projects. However, it can still pose a problem to local governments by creating an increased demand on services as a result of the redevelopment without an immediate or even near-future increase in tax revenues. For example, if a brownfield is remediated and redeveloped into a large scale housing development in a city where the property tax is frozen for several years, that city will still be forced to provide local services to that development and its residents but will receive no additional funding to do so for the period of the program. These sort of financial incentives that require the local government to either forfeit current or future revenues, has a strong likelihood of producing unfair and unequal results across localities.

Another key incentive offered across many states is income tax deductions and credits. Generally, these income tax credits and deductions allow a developer or individual to deduct (or obtain a credit) for a certain percentage of the cost of remediation, or sometimes the equipment or labor costs, from their state income tax. Credits are certainly the bigger and better incentive, as they will count as the equivalent of a payment to the state department of revenue, unlike a deduction which only counts to reduce taxable income of a business or entity. In order for this incentive to provide a substantial relief from financial costs the entity obtaining the deduction or credit would need to be a significantly large enough entity to have state tax liability or the state would need to provide for the ability of the credit or deduction to roll over to the following year if all of it is not able to be used. Some states do allow for roll over of the tax incentives, but not all. This is certainly an area where states could improve. Providing credits with roll over capacity will help alleviate some of the potential unanticipated consequences associated with these types of incentives. This form of incentive favors larger developers 
with greater tax liability, over smaller developers with less state tax liability. A business or individual with marginal state tax liability will likely not see this sort of incentive, with the exception of extremely small brownfield sites with equally as small cleanup bills, as helpful as other forms of financial assistance. Furthermore, this sort of incentive requires that the developer pay for the cost of remediation upfront and recoup a portion of the costs later through their tax deduction. Again, this favors the larger entities that have the upfront funds to conduct the cleanup. It is possible that these sorts of incentives are working to encourage big box development. Something that may not have been considered by the state administrators or policymakers creating these types of incentives.

\section{$R B C A$ and $L U C s$}

Another key financial aspect seen across the fifty states are the risk based corrective action and land use control allowance that reduces the cost of remediation of a brownfield. Almost all of the states provide a mechanism for the use of these cleanup mechanisms. By allowing for flexible cleanup standards, these programs have circumvented the whole issue of "how clean is clean" that filled environmental debates for years. Under these flexible guidelines clean enough is accepted even if that means contamination still exists in the groundwater or soil. In most states that allow for risk based cleanup levels, intuitional controls and engineering controls are attached that that particular site to provide for monitoring and public notice of the remaining contamination.

Most often the institutional controls used across the states are notations on the deed and/or a registry providing the information to the public. The public notice capacity and publicly available database for land use controls across the states is extremely varied. 
As was seen in Florida, the state has an extensive system in place to both inform the public and to allow the public complete transparency in what controls exist across the state. However, other states do not have this same level of transparency or public information availability. Overall, the process of LUCs, although it likely reduces the cost of cleanup, has some potential unanticipated consequences associated with it. First, these controls on residential property may very well not be understood by individuals purchasing the property. With the high number of states with underdeveloped and potentially ineffective land use control monitoring and reporting systems, it is quite likely that a purchaser of a property with these controls or restrictions may not fully understand what that control means. Additionally, this leaves open the possibility for controls to become completely untracked, essentially falling through the cracks, as a result of administrative negligence or disorganization. Furthermore, some individuals may find the lower costs of these sites the only affordable option to them in some markets across the country possibly leading to a disproportionate number of lower income individuals and minorities living in homes, or operating businesses that were erected on sites with contamination still present.

An additional issue that is present with the use of flexible cleanup standards is that it favors industrial and commercial developments where the end-use dictates a lower level of cleanliness in the contamination. To be sure, across the states the level of cleanup is the highest for residential developments. Providing for flexible cleanup standards is certainly a disincentive to developers to invest in residential developments where the costs are going to be the highest for cleanup. In fact, by having these flexible guidelines, middle and low priced residential developments are not going to be as 
economically feasible as commercial, industrial, or high end residential. Furthermore, it is relatively few markets that high-end residential development can take the place of a brownfield- leaving developers to decide between industrial or commercial end use. Unfortunately for this situation, many of the brownfields are located in former industrial centers surrounded by residential development where the most appropriate use would likely be residential. However, the use of these flexible standards is likely discouraging the more appropriate end use in some areas. Overall, with the increased use and acceptance of flexible cleanup standards, even on residential developments, some serious environmental justice and equity implications exist.

One theme that is apparent across the state's financial offerings is that the states with heavier industrial backgrounds tend to offer incentives specifically focused on distressed urban communities. This is a stark difference from some states, such as Nevada or Iowa, where incentives and assistance are often geared towards more rural communities. Key states that have distressed or urban specific incentives are: Ohio, New Jersey, Michigan, and Massachusetts. These states specifically have a financial program restricted for use within distressed and/or urban areas. Other states, those with higher unemployment rates, have tied some brownfield incentives to the number of jobs created. Delaware and Oklahoma are two examples of this. This structuring of incentives reflects, to some degree, a state that recognizes their economic development needs and places that need onto the brownfield programs incentives. What is interesting about this so-called need oriented incentive, is that it clearly illustrates a view of brownfields as an economic development opportunity —and less of an environmental hazard. 
It is probable that financial incentives do actually encourage remediation of brownfields, however, they are not to be taken lightly and they are not without unanticipated consequences that deserve further study. Each of the various types of incentives will likely work to encourage certain types of development. For example, in Oklahoma the Quality Jobs Act will actually pay a developer quarterly incentives for locating on a minimum of a 10 acre brownfield and employ a certain number of people. This form of incentive will naturally encourage commercial or industrial use of brownfields, which create the prerequisite number of jobs required to receive the incentive.

Overall each of the primary incentives offered require both a risk and forgone revenue or explicit costs on the part of either the state or local government. Additionally, loans and loan guarantees require a level of risk that may be too great for states to take and create a problem in states with a balanced budget requirement. As the state governments are being handed more and more responsibility over federal programs, these incentives may not be accomplishing exactly what they are intended to accomplish and each state should look internally to analyze what the state's development needs are, what their environmental situation is, and redirect their scarce financial abilities to those that fit best with their states situation. They should also include general economic development tools to their brownfield efforts. In the states where economic development tools are not encouraged or allowed to be used for brownfields, the state is essentially providing yet another disincentive for investment in brownfields. 


\section{Discretion and Control of the programs?}

As was pointed out in earlier chapters, a number of issues are known from previous scholarship to impact program implementation and administration. As was discussed in Chapter Two the literature concerning bureaucratic discretion and political control theories is currently concentrated at the federal level-this study has enabled an examination of the much more complex state level with the goal of informing these theories and providing the groundwork for future studies. These case studies are not intended to test these theories, but to inform them through the examination of a more complex administrative and political environment. Several themes were uncovered in the three case study states that may offer some insights into how these programs are influenced by administrators and political officials alike. The major themes across these states were: money/funding, EPA region and lower-level government officials.

\section{Money}

All three state case studies indicated oversight and monitoring in relation to their funding. All three states receive money from the EPA and as a result are accountable to the EPA for that funding. In addition to the reporting requirements associated with this funding, political officials also indicate a lack of interest in oversight as a result of the program's non-reliance on state appropriations. For example, as was detailed in Chapter Five, a Nevada policymaker concedes that they do not get involved with the programs because it is the EPA's money funding the program. This lack of oversight has some very interesting implications for the actions of these programs. As contaminated properties increasingly move through these voluntary programs, judging from these three programs, the public seems to have little direct recourse in the programs where the state 
does not provide funding. The non-elected administrators are administering, with little oversight by state political officials, a program where the potential for human health harm is quite real. Furthermore, the level of decentralization in some of the programs likely allows administrators to become more discretionary. For example, in Florida where the brownfield program and RCRA program both are divided into six separate districts with each district having discretionary abilities, these programs are further removed from political oversight and monitoring. This is not something that has been accounted for in bureaucratic discretion or political control theories. Certainly, these and other state level programs influence the daily lives of citizens, and they are perhaps offered less political oversight, and thereby popular control, than the federal program analyses that demonstrate political control. In many ways these state level programs are more influential to citizens than are some of the federal programs--making discretionary and control issues much more relevant and important. These three cases seem to be showing that the level of direct political control is associated with the funding, not the results or operation of the program. RCRA is an exception to this in Indiana where the political officials have actually exerted direct control over the program, but not for the purpose of protection the environment. This has very real implications for popular control of these programs.

A commonality across found in two of the states was that a fee was made part of the program so that the program would not have to rely on appropriations. Both Nevada and Indiana policymakers indicated this was a key consideration when determining how to design the program. Florida, is an exception and policymakers indicated that other issues were more important to them rather than impose a fee on participants. More 
specifically, policymaker \#2 indicated, "We had a pretty significant situation with the racial report that I mentioned. Attaching a fee to this program would have certainly impeded participation and the goal was to help and encourage participation, not prevent it" (Florida Policymaker \#2, 10/21/2006). Important to note here is that Florida is the only program of the three that does not impose a fee, and is the only voluntary program that doesn't at least allow for a charge across the entire United States-thereby relying upon state appropriations. As a result of these appropriations it is also the only program of the three to indicate a significant political oversight and monitoring from the state level.

It is possible, perhaps even likely judging from lessons of these three states, that states which offer state-funded financial incentives are faced with more oversight than the states that do not have such programs. Again, this would be oversight tied to financial contributions at the state level. Future research should certainly pursue this form and level of oversight. Popular control of the government relies on accountability to the citizens. However, if oversight and monitoring is tied to funding and budgets in these programs, then the utility of oversight is questionable for the accountability to the public and purposes of the program.

Overall, judging from these three states, it would seem that oversight and monitoring in these programs is tied strongly to funding and money. At the state level state policymaker interest is highly centered on accountability for funds provided. In essence these policymakers want to know exactly what have they gotten in return for their investment? In Nevada, where no funds are provided by the state, very little oversight and interest was reported. However, in Florida, where state funds are being 
used, policymakers took a much more keen interest in monitoring the program's actions and successes. It seems that on some level, the discretion ability of administrators may be, in part, determined by who they get the funding from. This implies that in discretionary terms, the administrators who are funded by federal grants may have oversight and monitoring by federal officials but not state officials. This, too, has real implications for a democracy that rests upon the popular control of the government. If these administrators are not being held accountable to the citizens of the state they operate in, what control do the citizens have over how they operate? While federal oversight appears present, the reality is that there will be less detailed scrutiny than would be possible - or possibly expected - if a state were monitoring its own internal programs and activities.

With discretion and control being tightly related to who is funding the programs, some interesting implications for discretion and political control questions emerge from the relationships with the EPA and the EPA Regions. Specifically, with state programs reporting to federal EPA administrators, not elected officials, how do the citizens of that state ensure representation in something that likely impacts them? How does political control manifest itself in these programs when it comes from a few steps above? To be sure, EPA headquarters and EPA regional staff have oversight by Congress and the President; however how that oversight gets channeled down to the lower level state administrator is yet to be seen and cannot be answered in this dissertation.

A further consideration concerning funding and discretion, is when the EPA provides funds to the states to use in administration and granting--- how those funds are being distributed in the state is left to the state level administrators. It is quite possible 
that in order to be able to show results the state level administrators use these funds to facilitate the easiest redevelopments, again leaving the less than marketable sites unremediated.

EPA Region

The EPA is a highly complex administrative body. Decisions, influence, and control is channeled down from Washington to the Regions and then on to the States. Implementation of brownfield programs is likely impacted by decisions made at the federal level, regional level, and the state levels all working together in some manner. Due to this complexity, coupled with the highly administrative and vertical organization of the EPA, political control of the state level programs are not as clear or as easily identified as is in the federal studies of this topic. All programs, including the RCRA programs, noted that their respective EPA region was pivotal and key in their relationship with the EPA. In fact all reported little-to-no contact with the headquarters of EPA at all.

What is interesting about the EPA region in relation to discretion and political control theories is that the EPA regions are a set of administrators acting on behalf of the EPA. This provides an interesting funnel of political control. How CERCLA and the brownfields legislation are being funneled down the set of non-elected administrators is again something which is being missed in current political control and bureaucratic discretion theories. What level of discretion exists at the EPA Region may well impact what level of discretion the state level administrators, and perhaps even local administrators, possess in determining how to implement and administer a program. Although most states have passed enabling legislation for their brownfield programs, the state programs are all still relying, in whole or in part, on federal EPA dollars to operate 
their program, including administrative expenses. When the EPA funds state programs in some capacity and level, the programs are faced with oversight and monitoring from the individual EPA regions. EPA regions are comprised of non-elected administrators which may have varying levels of discretion across them. How EPA regional officials respond to their non-elected administrator bosses, who in turn are responding to appointed and elected officials at the national level illustrates a very complex discretionary and political control environment. Even in Florida where state officials are overseeing and monitoring the program more acutely than in Nevada and Indiana, the program is also responsive and accountable to the EPA region.

\section{Lower Level Government Involvement}

An interesting theme that came from these three case studies is the role lower level governments sometimes play in the state brownfield programs. Although the exact role varied across the three cases, the fact is that the lower level governments were still involved, making it worth noting. This relationship can be purely informational or for communications like in Indiana. However, the relationship can also be more controlling like in Florida where a local government and its elected officials must approve a brownfields area in order for individuals to participate. To be sure, an aspect of the various programs that either require or encourage local government participation is subject to many of the problems associated with local government implementation. That is corruption and poverty may often act as an impediment, or leave some local communities prone to excess influence from wealthy outsiders, to any measure that requires local level participation. Furthermore, in the states where grants are provided to the local governments for assessments and remediations, it is likely the cities who need 
the funds the most are also the most ill-equipped to be persistent in the application for these grants from the state. This is a fact that is also likely true at the state level. That is the poorer a state is, the more likely it is to be less able to be persistent to their respective EPA region in the application for grants and funds. If a state or local government is strapped for funds, they may quite likely not have the funds for an employee to become educated and persistent in grant applications to their EPA region or EPA headquarters.

In terms of local government participation, Florida is likely the most unique in that it both allows and requires local government participation. However, in many state programs the customer of the brownfields programs are local governments. For example, as was seen in Nevada- the only participants in any of the programs are public or nonprofit entities. Local government participation in the state brownfield programs, whether through direct participation as in Florida or through indirect participation as the customer, is fundamentally shaped by their political coalitions and economic abilities, something not accounted for in current brownfield literature or in current political control and bureaucratic discretion theories.

\section{Overall}

Not so long ago the fears of red ice and purple dogs associated with contaminated sites struck fear in citizens and businesses. Stemming from these fears harsh federal legislation aimed at punishing those responsible for the contamination and preventing it from happening again were created. Certainly, this harsh outlook on contaminated properties provides a very real incentive for industry to avoid future contamination. However, as a result of a complex set of circumstances, many sites remained 
unremediated and undeveloped years after industry left. Many cities are in decline and liability and financial cost concerns keep developers away from these sites.

However, in the past fifteen years or so, we have seen a shift in the public response to contaminated properties that is quite striking. Gone are the days of wide public support for Superfund and strict liability. With New Jersey, Minnesota, and Illinois leading the way in the 1980's states began to develop ways to help get these properties developed. Some states started the process with legislation, others with agencies creating administrative codes. Throughout the nineties the remaining states began to create similar redevelopment programs. The Federal government came on board in 2002 and the last state, South Dakota, created a program in 2004.

State efforts at remediation and redevelopment of brownfields rely heavily on the private sector to do the remediation and redevelopment. Most states provide market incentives in the form of liability relief, flexible cleanup, and financial opportunities to try and help developers see brownfields as a marketable, viable alternative to Greenfield development. In essence these programs are seeking for the private sector to voluntarily remediate and redevelop properties that were already, for whatever reason, unmarketable. Cities are in distress because industry moved out and left behind contaminated, unusable land. These programs are offering financial opportunities and liability relief, but it very well may not be enough to address the reasons why the industry left in the first place. Some of the communities that have the most brownfields are faced with real estate market conditions that exhibit low marketability on even the cleanest property. Adding contamination to an already bad market only further exacerbates the problem. These voluntary brownfield programs focus on making sites profitable to a developer so that 
these sites will be invested in. Any time profit is a key consideration, discrepancies across states and localities will ensue. To be sure, states and localities do not have equal economic capacities, political willingness, and market conditions. In states like Florida, Nevada, and Arizona where market conditions are extremely favorable, brownfields become more competitive with greenfields for development. However, in states like Mississippi, Kentucky, and West Virginia where market forces are not so strong, the properties are not going to be so successfully or easily dealt with. Unfortunately, some of the states with the most brownfields, are also the states with the least capacity to address them. The states with the biggest problems and least capacity to address them will require more creative mechanisms and more federal assistance to successfully redevelop their brownfields.

The movement to invest public funds into voluntary brownfield remediation and redevelopment programs has spurred a plethora of mechanisms and variations across the fifty states. The database and the case studies have shown just how diverse these programs truly are. With this diversity come a number of significant questions and implications that only future research will provide insights into.

Findings from this research include:

- The States have very diverse, unequal mechanisms to promote brownfield remediation and redevelopment. A variety of balance between risk abatement and financial incentive mechanisms are distributed across the states. Some states are providing extensive, far reaching liability abatements, while others are providing the barest. 
- State political officials are minimally providing oversight. That oversight is often tied to funding. The EPA Regions play a pivotal role in oversight. Popular control of these programs can be seriously questioned judging from the three states examined in this dissertation.

- Bureaucratic discretion seems to be, in some ways shaped by other non-elected administrators as well as political officials. The discretionary ability of the EPA regions and states answering to these regions is a logical next step for research.

- Political control of environmental programs, particularly RCRA, can sometimes be contrary to the political goals of the program.

- Environmental protection and regulation has gone through a dramatic transformation in the last fifteen years, with yet to be seen consequences.

- Understanding Brownfield programs requires understanding RCRA programsThey are undeniably connected.

- RCRA program activity may be able to reflect and measure the regulatory nature of a state in terms of their brownfield programs.

Some policy implications for these findings are:

- State political officials should tie oversight and monitoring of these programs more closely to the potential impact they can have on the public instead of strictly controlling and asking for accountability for funds allocated.

- The balance between liability and financial incentives should be determined by an individual states level of resources. However, unanticipated consequences of flexible cleanup standards need to be thoroughly understood and recognized 
across the states. Environmental Justice issues are likely under these flexible cleanup standards.

- Land Use Controls should have greater consistency and states should pass the Uniform Environmental Covenants Act. LUCS have the potential for great public harm if not tracked or monitored effectively. States need to make this a priority.

- Brownfields have lost some of the stigma previously associated with them. States are increasingly moving to more flexible, less controlling, perspectives on these properties. Policymakers should critically assess whether the current trend and level of flexibility is appropriate. 


\section{REFERENCES}

Aberbach, Joel D., Keeping a Watchful Eve. Washington: The Brookings Institution, 1990.

Adler, J. H. (1998). A New Environmental Federalism: Environmental Policymakers are increasingly turning to the states for solutions to today's environmental problems. Forum for Applied Research and Public Policy, 13(4), 55-61.

Agger, Robert and Goldrich, Daniel and Swanson, Bert (1964). The Rulers and the Ruled-Political Power and impotence in American Communities. London: John Wiley and Sons, Inc.

Alaska Department of Environmental Conservation (2007). Alaska's Brownfields Program. Retrieved 01/02/2007, from http://www.dec.state.ak.us/SPAR/csp/brownfields.htm\#tools

American Society for Testing and Materials (2007). Standard Guide for Risk-Based Corrective Action. Retrieved 01/02/2007, from http://www. astm.org/cgibin/SoftCart.exe/DATABASE.CART/REDLINE_PAGES/E2081.htm?E+mystore

Appleby, Paul Henson. Policy and Administration. Tuscaloosa, Ala.: University of Alabama Press, 1949.

Arizona Department of Environmental Quality (2007). Voluntary Cleanups: Brownfields Assistance. (02/27/2007). Retrieved 03/13/2007, from

http://www.azdeq.gov/environ/waste/cleanup/brownfields.html\#target

Balla, Steven. (1998). Administrative Procedures and Political Control of the Bureaucracy. The American Political Science Review, 92(3), 663-673.

Banks, Jeffrey and Weingast, Barry (1992). The Political Control of Bureaucracies under Asymmetric Information. American Journal of Political Science, Vol. 36, No. 2, pp. 509-524

Bardach, Eugene. (2005). A Practical Guide for Policy Analysis. Washington DC: CQ Press.

Barnett, Harold. (1994). Toxic Debts. Chapel Hill, NC: University of North Carolina Press. 
Bartsch, C. and Wells, B. (April 2005). State Brownfield Financing Tools and Strategies. Washington DC: Northeast Midwest Institute.

Bartsch, C., \& Dorfman, B. (2000). Brownfields and Housing: How are state VCPS encouraging residential development? Washington DC: Northeast Midwest Institute.

Bartsch, C. and Pepper, and Collaton. (1996). Coming Clean for Economic Development: A Resource Book on Environmental Cleanup and Economic Development Opportunities. Northeast-Midwest Institute.

Barzelay, Michael. (1992). Breaking Through Bureaucracy A New Vision for Managing in Government. Berkeley: University of California Press.

Bawn, Kathleen. 1995. "Political Control Versus Expertise: Congressional Choices About Administrative Procedures." American Political Science Review 89: 62-73.

Bendor, Jonathan and Taylor, Serge and Van Gallen, Roland. (1985). Bureaucratic Expertise vs. Legislative Authority: A Model of Deception and Monitoring in Budgeting. American Political Science Review. 79: 1041-60.

---. (1987). Politicians, Bureaucrats and Assymetric Information. American Political Science Review. 31: 796-828.

Berejikian, Jeffrey. (1992). Revolutionary Collective Action and the Agent-Structure Problem. The American Political Science Review. 86(3), 647-657.

Bernstein, M. H. (1955). Regulating Business By Independent Commission, Princeton: Princeton University Press.

Berry, William D. and Ringquist, Evan and Fording, Richard and Hanson, Russell. (2002). Ideology Measures, Study number 1208. Available from: http://webapp.icpsr.umich.edu/cocoon/ICPSR-STUDY/01208.xml

Brownfields Center. Glossary of Terms. Retrieved 01/20/2007, from $\mathrm{http}: / / \mathrm{www}$. brownfieldscenter.org/big/glossary.shtml\#r

Brownfield Redevelopment Incentives (2006). Retrieved 01/02/2007, from http://www.newtonchamber.com/default.aspx?scid=EagAPNfw3vU=

Buchanan, James M. and Tullock, Gordon. (1965). The Calculus of Consent. Ann Arbor: University of Michigan Press.

Bullard, Robert D. (1993). Confronting Environmental Racism: Voices for the Grassroots. Boston: South End Press. 
Cahn, Matthew and O'Brien, Rory. (1996). Thinking about the Environment. Armonk, New York: M.E. Sharpe.

Calcott, P., \& Hutton, S. (2006). The Choice of a liability regime when there is a regulatory gatekeeper. Journal of Environmental Economics and Management, $51,153-164$.

Calvert, Randall L. and Moran, Mark J. and Weingast, Barry R. (1989). Congressional Influence Over Policymaking: The Case of the Federal Trade Commission. St. Louis: Washington University.

Chang, RR (2003). CERCLA: The Problems of Limiting Contribution Claims For Potentially Responsible Parties. Loyola Of Los Angeles Review. 35, 1107-1130.

Christenson, S. (1997). Bill aids development of contaminated sites. Florida Times -Union.

Clark, William. (1998). Agents and Structures: Two Views of Preferences, Two Views of Institutions. International Studies Quarterly. 42(2), 245-270.

Clinton, Bill. (1993, March 3). National Performance Review Speech. Available online: http://govinfo.library.unt.edu/npr/library/speeches $/ 030393 . \mathrm{html}$

Coffin, S. L. and A. Shepherd (1998). Barriers to Brownfield Redevelopment: Lessons Learned from Two Great Lakes States. Journal of Public Works Management and Policy 2(3): 258-266.

Collins, F. P. (2003). The Small Business Liability Relief and Brownfields Revitalization Act: A Critique. Duke Environmental Law and Policy Forum, 13, 303-328.

Colorado Brownfields Tax Credit. Retrieved 01/02/2007, from http://www.cdphe.state.co.us/HM/bftaxhowto.htm

Connolly, Kathleen and Daddrio, David (1995). "How to Find Green in your City's Brownfields" American City and County. Vol 110: no 12. pp. 28-32.

Council of State Governments. (2004). The Book of the States. Lexington, KY: Council of State Governments.

Cresswell, J. (1998) Qualitative inquiry and research design: Choosing among five traditions. Thousand Oaks, CA: Sage.

Cronin, T. E. (1980). The State of the Presidency. Boston: Little Brown.

Dana, D. A. (2006). State Brownfields Programs as Laboratories of Democracy? NYU Environmental Law Journal, 14(1), 86-107. 
Davis, Kenneth. (1976). Discretionary Justice. Chicago: University of Illinois Press.

DePass, Michelle (2006). Brownfields as a tool for the rejuvenation of land and community. Local Environment. Vol 11, No 5.

De Sousa, Christopher A. (2003). Turning Brownfields into Green Space in the City of Toronto, Landscape and Urban Planning, 62(4), 2003, pp. 181-198.

Delaware Hazardous Substance Cleanup Act Mixed Funding and Brownfields Retrieved 01/02/2007, from

http://www.dnrec.state.de.us/dnrec2000/Divisions/AWM/sirb/misc/bfapp.doc

Demsetz, H. (1967). Toward a Theory of Property Rights. American Economic Review, 57.

Denhardt, Robert and Barry, Hammond (1992). Public Administration in Action. Fort Worth, TX: Harcourt Brace College Publishers.

Dente, Bruno and Fareri, Paolo and Ligteringen, Josee (1998). The Waste and the Backyard. The Netherlands: Kiluwer Publishers.

Downs, A. (1967). Inside Bureaucracy. Boston: Little, Brown, and Company.

Drezner, Daniel. (2000). Ideas, Bureaucratic Politics, and the Crafting of Foreign Policy. American Journal of Political Science.

ECOS. (2006). Delegation by Environmental Act. Retrieved November 15, 2005, 2005, from http://www.ecos.org/section/states/enviro_actlist

EPA's history. (2004) Retrieved November 8, 2004, from http://www.epa.gov/history/timeline/index.htm

Eisinger, C. (2001). Brownfields Legislation: Making the Grass Greener on the Other Side. Retrieved 11/15/2006, 2006, from http://www.agiweb.org/gap/legis107/tpg_ce.html

Eisner, M. A., Worsham, J., \& Ringquist, E. J. (1999). Contemporary regulatory policy. Boulder, Colo.: Lynne Rienner Publishers.

Ellerbusch, Fred and Gute, David and Desmarais, Anne and Woodin, Mark (2006). Community engagement as a component of revitalization: Lessons learned from the Technical Outreach Services to Communities programme. Local Environment. 11,5: 515-535.

Ennist, Larry (2006). Brownfields: New Life New Uses. New York State Conservationist. 
Environmental Law Institute (2002). Available at: http://www2,eli.org/index.cfm

Epstein, David and O' Halloran, Sharyn. (1994). Administrative Procedures, Information, and Agency Discretion. American Journal of Political Science. 38: 697-722.

Etsy, Daniel C. (1996). Revitalizing Environmental Federalism. Michigan Law Review, 95(3).

Farber, D. A. (2005). The Story of Boomer: Pollution and the Common Law. Ecology Law Quarterly, 32(1), 37.

Fenno, Richard. (1978). Home Style. Boston: Little, Brown.

Fesler, J. W., \& Kettl, D. F. (1991). The politics of the administrative process. Chatham, N.J.: Chatham House.

--.-. (1996). The politics of the administrative process (2nd ed.). Chatham, N.J.:

Chatham House Publishers.

Florida Brownfield Redevelopment (1997). State Statutes: 376.77

Florida Department of Environmental Protection (2007). Brownfield Areas. Retrieved 03/02/2007, from

http://www.dep.state.fl.us/waste/quick_topics/publications/wc/brownfields/proces ses/Areas.pdf

--.-. (2007). Sites with executed BSRA's. (Febuary 06, 2007). Retrieved March 2, 2007, from

http://www.dep.state.fl.us/waste/quick_topics/publications/wc/brownfields/proces ses/Agreements.pdf

-.-. (2006). Voluntary Cleanup Tax Credit. (November 17, 2006). Retrieved 03/02/2007, from http://www.dep.state.fl.us/waste/categories/vctc/default.htm

----. (2007). Florida Regulatory District Offices. Retrieved 03/02/2007, from http://www.dep.state.fl.us/secretary/dist/default.htm

----. (2006). Florida Voluntary Cleanup Tax Credit. Retrieved 01/04/2007, from http://www.dep.state.fl.us/waste/categories/vctc/default.htm

Frederickson, H. G., \& Smith, K. B. (2003). Public Administration Theory Primer. Boulder: Westview Press.

Gilmour, Robert and Halley, Alexis. (1994). Who Makes Public Policy: The Struggle for Control between Congress and the Executive. New York: Seven Bridges Press. 
Goodnow, Frank. (1900). Politics and Administration. A Study in Government. New York: Russell and Russell.

Grayson, E. Lynn. (1995). The Brownfields Phenomenon, Environmental Law Reporter, 25 (10337).

Handler, J. (1992). "Discretion: Power, Quiescence, and Trust." 33160 in The Uses of Discretion, edited by Keith Hawkins. Oxford: Clarendon.

Hawkins, Keith ed. (1992). The Uses of Discretion. Oxford: Clarendon Press.

Heclo, Hugh (1977). A government of strangers : executive politics in Washington. Washington DC: The Brookings Institute.

Howard, R. and Nixon, D. (2003). Local Control of the Bureaucracy: Federal Appeals Courts, Ideology, and the Internal Revenue Service. Journal of Law and Policy. 13: 233-256.

Higgs, R., \& Close, C. P. (Eds.). (2004). Re-Thinking Green Alternatives to Environmental Bureaucracy: The Independent Institute.

Hill, Carolyn and Lynn, Laurence. (2004). Governance and Public Management, an Introduction. Journal of Policy Analysis and Management, 23(1), 3-11.

Hoepfl, M. C. (1997). Choosing qualitative research: A primer for technology education researchers. Journal of Technology Education, 9(1), 47-63. Retrieved 10/10/2006, from http://scholar.lib.vt.edu/ejournals/JTE/v9n1/pdf/hoepfl.pdf

Hodge, J. A.(1996, Spring). Protecting Owners and Prospective Owners of Contaminated Property from Environmental Liability. South Carolina Law Journal, 5(1), 1-32.

Huber, J.D. and Shipan, C.R. (2000). "The Costs of Control: Legislators, Agencies and Transaction Costs" Legislative Studies Quarterly. XXV, 1: 25-52.

Huber, J. D., \& Shipan, C. R. (2002). Deliberate Discretion? The Institutional Foundations of Bureaucratic Autonomy. New York: Cambridge University Press.

Huber, John D., Charles R. Shipan, and Madelaine Pfahler. (2001). Legislatures and Statutory Control of Bureaucracy. American Journal of Political Science 45:330345.

Hunt, D. (2006). Cleanup yes, but who will pay cost? Developer raises ire in St. Augustine by seeking state funds, tax credits. Florida Times-Union, pp. A-1.

Huntington, Samuel. (1952). "The marasmus of ICC: The Commission, the railroads, and 
the public interest." Yale Law Journal 61: 467-509

Idaho State Statutes, Title 63 Chapter 6 Exemptions from Taxation.

Imbroscio, David. (1999). Stucture, Agency, and Democratic Theory. Polity. 32(1),45-66.

Indiana Department of Environmental Management (2007). IDEM Office of Land

Quality. Retrieved 02/28/2007, from

http://www.in.gov/idem/programs/land/index.html

---. (2006). Indiana Voluntary Remediation Program Fact Sheet. (2006). Retrieved 11/10/2006, from

http://www.in.gov/idem/programs/land/vrp/factsheet/vrpfactsht.pdf

-..-. (2007). VRP Site Status List.

Indiana Finance Authority (2006) About IFA. Retrieved 03/01/2007, from http://www.in.gov/ifa/about/

----. Biography of the Public Finance Director of the State of Indiana. Retrieved 03/01/2007, from http://www.in.gov/ifa/about/Kitchellbio.htm

----. (2006). Crosswalk between the Indiana Brownfields Program and IDEM's

Voluntary Remediation Program (VRP).

-.-.. (2006). Indiana Brownfields Program Financial Incentives.

Investorwords. (2007). Retrieved 03/18/2007 from:

http://www. investorwords.com/4306/risk premium.html

Katzman, Robert A. (1980). Regulatory bureaucracy: the Federal Trade Commission and antitrust policy. Cambridge MA: MIT Press.

Kaufman, Herbert. (1956). Emerging Conflicts in the Doctrines of Public Administration. The American Political Science Review, 50(4):1057-1073

Kaufman, Herbert. (1981). The administrative behavior of federal bureau chiefs. Washington DC: The Brookings Institute.

Keiser, Lael R. and Soss, Joe. (1998). With Good Cause: Bureaucratic Discretion and the Politics of Child Support. American Journal of Political Science, 42,4: 1133 -1156 .

Kettl, D. F. (1993). Sharing Power: Public Governance and Private Markets. Washington DC: The Brookings Institution.

---.-. (2002). The Transformation of Governance: Public Administration for 
Twenty-First Century America. Baltimore: The John Hopkins University Press.

----. (2005). The global public management revolution (2nd ed.). Washington,

D.C.: Brookings Institution Press.

Kettl, Donald F. (ed.) (2002). Environmental Governance: A Report on the Next

Generation of Environmental Policy. Washington DC: The Brookings Institution Press.

Kettl, Donald F. and Fesler, James W. (2005). The Politics of the Administrative Process. Washington DC: CQ Press.

Kingdon, John. (1995). Agendas, Alternatives, and Public Policy. New York: Harper Collins.

Land Use Controls. (2007). Retrieved 01/02/2007, from http://lucs.org/

Landy, Mark. (1999). "Local Government and Environmental Policy," in Dilemmas of Scale in America's Federal Democracy. In Martha Derthick, ed., Cambridge. UK: Woodrow Wilson Center Press, 227-260.

Layzer, J. A. (2006). The Environmental Case. Washington DC: CQ Press.

Lipsky, Michael. (1980). Street Level Bureaucracy. New York: Russel Sage Foundation.

Long, Norton. (1949). Power and Administration. Public Administration Review 9:257264.

Louisiana Department of Environmental Quality. Louisiana Voluntary Remediation Program Description. Retrieved 01/02/2007, from http://www.deq.louisiana.gov/portal/Default.aspx?tabid=1667

Lowi, T. J. (1969) The End of Liberalism: Ideology, Policy, and the Crises of Public Authority. New York: W. W. Norton.

Maine Statutes, Title 38 Chapter 2, Subchapter 1, 343-E

Manning, G. S. (2006). 3rd Party Liability Relief in Kentucky. Brownfield News.

March, James and Olsen, Johan (1989). Rediscovering Institutions The Organizational Basis of Politics. New York: The Free Press.

Maryland. Maryland Brownfields Tax Incentive. Retrieved 01/02/2007, from http://www.choosemaryland.org/businessservices/taxincentives/brownfields.html

Mayhew, David R. (1974). Congress : the electoral connection. New Haven: Yale 
University Press.

McAnnulla, Stuart. (1998). The Structure-Agency Debate and its Historiographical Utility. Contemporary Political Studies 1998: Volume 1-2 Proceedings of the Annual Conference held at the University of Keele.

McCubbins, Matthew D. (1985). Legislative Design of Regulatory Structure. American Journal of Political Science. 29: 721-48.

McCubbins, M. D., Noll, R. G., \& Weingast, B. R. (1987). Administrative Procedures as Instruments of Political Control. Journal of Law, Economics, and Organization, $3(2), 243-277$.

McCubbins, Matthew D. and Scwartz, Thomas. (1984). Congressional Oversight Overlooked: Policy Patrols versus Fire Alarms. American Journal of Political Science. 28: 167-179.

Meier, Kenneth. (1993). Politics and the Bureaucracy: Policymaking in the Fourth Branch of Government. Pacific Grove, California: Brooks/Cole.

Melosi, M. V. (1981). Garbage in the Cities: Refuse, Reform, and the Environment: 1880-1980 (1st ed. Vol. 4). College Station, TX: Texas A\&M University Press.

Merrill, T. W. (1985). Trespass, Nuisance, and the Costs of Determining Property Rights. Journal of Legal Studies, 13.

Meyer, Peter B. and Williams, R.H. and Yount, K. R. (1995). Contaminated Land, Reclamation, Redevelopment, and Reuse in the United States and the European Union. Aldershot, UK: Edward Elgar Publishing Ltd.

Meyer, P.B. and Van Landingham, H. Wade. (2000). Reclamation and Regeneration of Brownfields: US Economic Development Administration.

Meyer, P. B., \& Yount, K. (2006). State Brownfield Insurance Programs, 2006:

Environmental Protection Agency.

Michigan Department of Environmental Quality (2006). CMI Brownfield Redevelopment Grants (BRG). Retrieved 01/02/2007, from http://www.michigan.gov/deq/0,1607,7-135-3311_4110_29262-151085--,00.html

-----. (2006). Brownfields Grants and Loans. Retrieved 01/02/2007, from http://www.michigan.gov/deq/0,1607,7-135-3311_4110_29262-9307--,00.html

Moe, Terry (1989). In Can the Government Govern? ed. Chubb, John and Peterson, Paul. Washington DC: The Brookings Institute. 
Nevada Bureau of Corrective Actions (2007). Bureau of Corrective Actions Home.

Retrieved 03/02/2007, from http://ndep.nv.gov/BCA/bca01.htm

(2007). Nevada Brownfield Program Role. (2006). Retrieved 09/05/2006, from

http://ndep.nv.gov/BCA/brown6.htm

----. (2007). Nevada Land Recycling Program. Retrieved 03/03/2007, from

http://ndep.nv.gov/BCA/brownfld.htm

----. (2007). Nevada Voluntary Cleanup Program Fact Sheet. Retrieved 03/02/2007, from $h t t p: / / n d e p . n v . g o v / B C A / v c p f c t s h t . p d f$

New Hampshire's Brownfields Covenant Program. (2005). Retrieved 01/03/2007, from http://www.des.state.nh.us/factsheets/rem/rem-8.htm

New Jersey Administrative Codes (2006). Chapter 26C Department Oversight of the Remediation of Contaminated Sites.

New Jersey Department of Environmental Protection (2006). HDSRF Fact Sheet.

Retrieved 01/02/2007, from

http://www.state.nj.us/dep/srp/finance/hdsrf/factsheet.htm

New Mexico Department of Environment (2006). Ground Water Quality BureauVoluntary Remediation Program. Retrieved 01/02/2007, from http://www.nmenv.state.nm.us/gwb/New_Pages/ros_files/vrp_new/how_to_enter _vrp.htm

New State Ice Co. v. Liebmann, 285 (US Supreme Court 1932).

Niskanen, William A. (1971). Bureaucracy and representative government. Chicago: Atherton.

Noll, R. G. (1971). Reforming Regulation, an Evaluation of the Ash Council Proposals. Washington DC: The Brookings Institution.

North, Douglas (1990). Institutions, institutional change, and economic Performance. Cambridge: Cambridge University Press.

North Carolina. Program FAQ. Retrieved 10/31/2006, from http://www.ncbrownfields.org/program_faq.asp\#7

Northeast-Midwest (n.d) Brownfields Basics: An Issue Primer Retrieved November 8, 2004, from http:/www.nemw.org/BFprimer.pdf

O' Reilly, M., \& Brink, R. (2006). Initial Risk-Based Screening of Potential Brownfield 
Development SItes. Soil and Sediment Contamination, 15, 463-470.

Oates, W. E. (2001). A Reconsideration of Environmental Federalism. Washington DC: Resources for the Future.

Ogul, M. (1976). Congress Oversees the Bureaucracy. Pittsburg: University of Pittsburg Press.

Ogus, A. I. (1994). Regulation: Legal Form and Economic Theory. New York: Oxford University Press.

Oklahoma Department of Environmental Quality (2004). Oklahoma Brownfields Financial Incentives Fact Sheet. Retrieved 01/02/2007, from http://www.deq.state.ok.us/lpdnew/Brownfields/taxincennew2004.pdf

Oregon's Brownfield Program-An Overview. Retrieved 01/02/2007, from http://www.nga.org/cda/files/ORBFIELDPROFILE.pdf

Osborne, David. (1990). Laboratories of Democracy: A New Breed of Governor Creates Models for National Growth. Boston, MA: Harvard Business School Press.

Palumbo, Dennis J. and Calista, Donald J. (1990). Opening up the Black Box: Implementation and the Policy Process. In "Implementation and the Policy Process Opening up the Black Box. Ed. Dennis J. Palumbo and Donald J. Calista. New York: Greenwood Press.

Patton, M. Q. (2002). Qualitative Research and Evaluation Methods. Thousand Oaks: Sage Publications Ltd.

Pennsylvania Land Recycling and Remediations Standards Act. (1995). Available online at: http:/www.palrb.us/pamphletlaws/19001999/1995/0/act/0002.pdf

Percival, R. V., Miller, A. S., Schroeder, C. H., \& Leape, J. P. (2006). Environmental Regulation: Law, Science, and Policy (5th ed.). Aspen: Aspen Law and Business.

President's Management Agenda. (2002). Executive Office of the President, Office of Management and Budget. Available online: http://www.whitehouse.gov/omb/hudget/fy $2002 / \mathrm{mgmt}$.pdf

Pressman, J. L., \& Wildavsky, A. (1984). Implementation: How Great Expectations are in Washington are dashed in Oakland (3rd ed.). Los Angeles: University of California Press.

Reitze, A. W. J. (1991). A Century of Air Pollution Control Laws: What's Worked; What's Failed; What Might Work. Environmental Law, 21, 1550-1646. 
Revesz, R. L. (1992). Rehabilitating Interstate Competition: Rethinking the Race to the Bottom Rationale for Federal Environmental Regulation. New York Law University Law Review, 1210, 1210-1254.

----. (2000). Federalism and Regulation: Extrapolating from the analysis of Environmental Regulation in the United States. Journal of International Economic Law, 3(2), 219-233.

Ringquist, Evan. (1993) Environmental Protection at the State Level. Armonk, New York: ME Sharpe.

Ritchie, J., \& Lewis, J. (2003). Qualitative Research Practice: A Guide for Social Science Students and Researchers. Thousand Oaks: Sage Publications Ltd.

Roddewig, R. (1996). Stigma, Environmental Risk, and Property Value. Appraisal Journal vol 64, no 4.

Rose-Ackerman, S. (1995). Controlling Environmental Policy: The Limits of public law in Germany and the United States. New Haven: Yale University Press.

Rosen, Bernard (1998). Holding Government Bureaucracies Accountable. Greenwood: Praeger.

Rosenbaum, W. A. (2005). Environmental Politics and Policy. Washington DC: CQ Press.

Rosenbloom, D. H., Kravchuck, R., \& Rosenbloom, D. D. (2005). Public administration: understanding management, politics, and law in the public sector (5th ed.). Boston: McGraw-Hill.

Rourke, Francis E. (1976). Bureaucracy and Public Policy. Little Brown.

Scheberle, D. (1997). Federalism and environmental policy : trust and the politics of implementation. Washington, D.C.: Georgetown University Press.

---. (2005). The Evolving Matrix of Environmental Federalism and Intergovernmental Relationships Publius, 35(1), 69-86.

Seidman, Harold and Gilmour, Robert. (1986). Politics, Position, and Power: From the Positive to the Regulatory State. New York: Oxford University Press.

Sheldon, I. (2006). Trade and Environmental Policy: A Race to the Bottom? Journal of Agricultural Economics, 57(3), 365-392.

Simon, Herbert. (1947). Administrative Behavior. New York: The Free Press. 
Small Business Liability Relief and Brownfields Revitalization Act, (2002).

Smith, K. B., Greenblatt, A., \& Buntin, J. (2004). Governing States and Localities. Washington DC: CQ Press.

Stake, R. E. (1995). The Art of Case Study Research. Thousand Oaks: Sage Publications.

Stone, Clarence. (2005). Rethinking the Policy-Politics Connection. Policy Studies. 26, 3/4:241-260.

Stewart, R. B. (1977). Pyramids of Sacrifice? Problems of Federalism in Mandating State Implementation of National Environmental Policy. Yale Law Journal, 86.

Stigler, George J. (1971). The Theory of Economic Regulation. The Bell Journal of Economics and Management Science, Vol. 2, No. 1, pp. 3-21

Svara, J. H. (2006). Complexity in Political-Administrative Relations and the Limits of the Dichotomy Concept. Administrative Theory \& Praxis, 28(1), 121.

----. (1994). Dichotomy and Duality: "Reconceptualizing the Relationships Between Policy and Administration in Council-Manager Cities". In Ideal and Practice in Council-Manager Government, edited by H. George Frederickson. Washington D.C.: International City/County Management Association.

Syms, Paul. (2004). Previously developed land: industrial activities and contamination Oxford: Blackwell Publishers.

Theodoulou, S. Z., \& Kofinis, C. (2004). The art of the game : understanding American public policy making. Belmont, CA: Wadsworth/Thomson Learning.

Tullock, G. (1965). The Politics of Bureaucracy. Washington DC: Public Affairs Press.

Uniform Environmental Covenants Act, (10/31/2006). Retrieved 02/01/2007, from http://www.environmentalcovenants.org/ueca/UECAnews/UECA_colormap.pdf

United States Census Bureau. 1990 Census of Population and Housing. (1990).

Retrieved 02/27/2007, 2007, from www.census.gov

--.-. (1970). Labor Force Characteristics of the Population. From http://www2.census.gov/prod2/decennial/documents/31679801n1-40ch03.pdf

United States Environmental Protection Agency, US EPA. (1997). Guidance for Developing Superfund Memoranda of Agreement (MOA) Language Concerning State Voluntary Cleanup Programs. Retrieved 01/20/2007, from http://www.epa.gov/swerosps/bf/html-doc/sfmoagid.htm 
----. (2003). Targeted Brownfields Assessments Fact Sheets. Retrieved 01/02/2007, from http://www.epa.gov/brownfields/facts/tba_0403.htm

---. (2005). State Brownfields and Voluntary Response Programs: An Update from the States.

---.. (2006). Land Use and Institutional Controls. Retrieved 01/02/2007, from http://www.epa.gov/brownfields/tools/tti_lucs.htm

----. (2006) Brownfields Cleanup Revolving Loan Fund Pilot Program.

Retrieved 01/03/2007, from http://www.epa.gov/brownfields/html-doc/bcrlffs.htm

-.--. (2006) Environmental and Compliance History Online (ECHO). Retrieved from: http://63.160.3.204/echo/index.html

--.. (2006). RBDM FAQ 6: What is RBCA, or Rebecca? Retrieved 01/21/2007, from http://www.epa.gov/oust/rbdm/rbdmfaq6.htm

----. (2006). RCRA Orientation Manual. Retrieved 11/01/2006 from:

http:/www.epa.gov/epaoswer/general/orientat/

-.-.. (2006). State Authorization Tracking System (StATS). Retrieved 07/10/2006 from: http://www.epa.gov/epaoswer/hazwaste/state/stats/stats.htm

-.-.-. (2007). Grant Funding Guidance for State and Tribal Response Programs.

Retrieved 03/02/2007, from

http://www.epa.gov/swerosps/bf/pg/fy06state_guidelines.htm

----. (2007). National Environmental Performance Partnership System. Retrieved 03/02/2007, from http://www.epa.gov/ocirpage/nepps/

---. (2007) About Performance Partnership Agreements. Retrieved 03/01/2007, from http://www.epa.gov/ocir/nepps/about.htm

United States Environmental Protection Agency Region V (1995). Brownfields and Voluntary Remediation Program Superfund Memorandum of Agreement.

Utah Department of Environmental Quality. Voluntary Cleanup Program. Retrieved 01/02/2007, from http://www.superfund.utah.gov/docs/vcp-sum.pdf

Volden, Craig. (2002). A Formal Model of the Politics of Delegation in a Separation of Powers System. American Journal of Political Science. 46, 1: 111-133. 
Walcott, Charles and Hult, Karen M. (1987). Organizing the White House: Structure, Environment, and Organizational Governance. American Journal of Political Science. 31, 1: 109-125.

Waldo, Dwight. (1946). The Administrative State. San Francisco: Chandler.

Walker, C., Boxall, P., Bartsch, C., Collaton, E., Meyer, P. B., \& Yount, K. (1997). The Effects of Environmental Hazards and Regulation on Urban Redevelopment. Washington DC: US Department of Urban Development.

Wamsley, G. L., \& Zald, M. N. (1973). The Political Economy of Public Organizations. Public Administration Review, 33(1), 62-73.

Waste, Robert. (1987). Power and Pluralism in American Cities. New York: Greenwood Press.

Weber, Max. (1952). "The Essentials of Bureaucratic Organization: An Ideal-Type Construction". In Reader in Bureaucracy, edited by Rober K Merton, Ailsa P. Gray, Barbara Hockey, and Hanan C. Selvin. Glencoe, Il: The Free Press.

Welborn, D. M. (1998). Conjoint Federalism and Environmental Regulation in the United States. Publius, 18.

Welch, David. (1992). The Organizational Process and Bureaucratic Politics Paradigm. International Security. 17(2). 112-146.

Wendt, Alexander. (1987). The Agent-Structure Problem in International Relations Theory. International Organization. 41(3), 335-370.

Wernstedt, Kris, Peter B. Meyer, Anna Alberini, and Lauren Heberle. 2006: "Incentives for Private Residential Brownfields Development in US Urban Areas." Journal of Environmental Planning and Management, 49(1). 101-119.

Whitney, H. (2003). "Cities and superfund: Encouraging brownfield redevelopment." Ecology Law Quarterly 30 (1): 59-112 2003

Williams, Daniel. (2000). Reinventing the Proverbs of Government. Public Administration Review. 60(6), 522-534.

Wilson, James Q. (1989). Bureaucracy: What Government Agencies do and why they do it. United States: Basic Books, INC

Wilson, Woodrow. (1887). The Study of Public Administration. Reprinted in Political Science Quarterly December 1941: 197-222.

Wood, B. D., \& Waterman, R. W. (1994). The Dynamics of Political Control of the 
Bureaucracy. American Political Science Review, 85(3), 801.

Wood, B. D., \& Waterman, R. W. (1994). The dynamics of political-bureaucratic adaptation. American Journal of Political Science, 37(2), 497.

Wyoming Department of Environmental Quality (2003). Fact Sheet \#15, Liability Assurances. Retrieved 03/12/2007, from http://deq.state.wy.us/volremedi/

Yin, R. K. (2003). Case study research, design and methods, 3rd ed. Newbury Park: Sage Publications.

Yount, K. R., \& Meyer, P. B. (1999). Project Scale and private sector environmental decision making: Factors affecting investments in small- and large- scale brownfields projects. Urban Ecosystems, 3, 179-193. 


\section{APPENDIX A \\ CONTENTS OF DATABASE}

\section{Brownfield Specific}

Year Initial Legislation Passed

Administrative Organization

Citizens Ideology Measure of Program

Inception Year

Government Ideology Measure of Program Inception Year

Citizen Ideology Measure most recent year

Government Ideology Measure most recent year.

Employees in Overall Agency

Employees in Program(s)

Status of Head of Agency

Name of Program(s)

Additional Names?

\# of Liability Provisions

CNTS

$N F A$

COC

Other $/ 3^{\text {rd }}$ Party Liability

Re-openers?

\# of Spinoff Programs

EPA Approved UST Program?

Non-approved UST Program

Drycleaner Program

Others

\# of Financial Incentives

Grants

-Types

-Notes

Loans

-Types

Tax Incentives

-Types

PRP Participate?

Restrictions on PRP Participation?

128a Funding most previous year

128a Funding Cumulative

RBCA?

Other Risk Based Standards?

Institutional Controls?

Tracking System?

Costs to enter program?

\section{RCRA Related}

Base Program: RCRA Authorized State?

Number of key RCRA rules authorized?

RCRA Corrective Action?

RCRA Land Disposal Restrictions?

RCRA Closure Standards

RCRA Remediation Waste Management

Requirements?

Number of RCRA regulated facilities (July 2006)

Absolute number of facilities with inspections

Percentage of facilities with inspections

Absolute number of NOV/Informal enforcements

Percentage of Facilities with Informal

Enforcements/NOV

Number of Facilities with inspections and informal enforcements

Percentage of inspected facilities with informal enforcements

Absolute Number of Formal Enforcements

Number of formal enforcements in

facilities with inspections

Percentage of inspected facilities with

formal enforcements

Percentage of facilities with formal

enforcements

Number of facilities in SNC

Percentage of facilities in SNC

Number of NOV done by EPA

Percentage of NOV done by EPA

Total LQG facilities

Inspections at LQG

Percentage of LQG with inspections

Total SQG

Inspections at SQG

Percentage of SQG with inspections

Number of CESQG

Inspections at CESQG

Percentage of CESQG with inspections

Number of TSD

Inspections at TSD 
VCP MOA?

Works with other agencies in state?

Economic Development

Environmental

Other

Location relative to RCRA?
Percentage of TSD with inspections

Number of Transporters

Inspections at Transporters

Percentage of Inspections at Transporters PPA for RCRA 


\section{APPENDIX B}

\section{THREE STATE EXAMPLES}

Of note: RCRA data in this appendix was updated in March 2007 to provide the most upto-date information. However, as a result the exact percentages may not match some of the examples in the text of this dissertation. However, all implications taken from these examples remain the same with the new calculations as the percentages are not extremely deviant after being updated.

\section{INDIANA}

Year Initial Legislation Passed

\section{Brownfield Programs Specific}

Administrative Organization

\section{Citizens Ideology Measure of Program Inception Year \\ Government Ideology Measure of \\ Program \\ Inception Year}

Citizen Ideology Most Recent Year

Government Ideology Most Recent Year

Employees in Overall Agency

Employees in Program(s)

Status of Head of Agency

\section{Name of Program(s)}

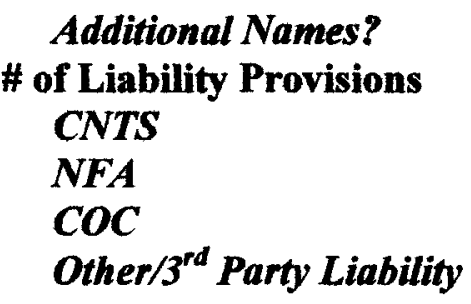

\# of Spinoff Programs
1993; 2005 technical and many financial components moved to IFA

VRP: Indiana Department of

Environmental Management $\rightarrow$ Office of Land Quality

62.788

46.36168

43

63

934

8 in VRP; 12 in Brownfields Program Commissioner appointed by Governor heads IDEM; Board of appointed officials heads IFA.

1. Voluntary Remediation Program (VRP)

2. The Indiana Brownfields Programs

NA

2

Yes

No

Yes

3rd Party protections for Non-Responsible Parties.

Brownfield program offers Site Status Letters, Prospective Purchaser Agreements, and Comfort Letters - however, they do not protect from liabilities.

$3+$ 
EPA Approved UST Program?

Non-approved UST Program

Drycleaner Program

Others
\# of Financial Incentives
Grants
-Types

-Notes

Loans

-Types

Tax Incentives

-Types

\section{PRP Participate?}

\section{Restrictions on PRP Participation?}

\section{Re-Openers}

128a Funding most previous year

\section{8a Funding Cumulative RBCA?}

Other Risk Based Standards?
No

Yes

Not a cleanup program; Voluntary certification program, and compliance assistance program

Confined Feedings; Auto Salvage Program 3+

Yes, in Brownfields Program only Assessment grants, cleanup grants, petroleum remediation grants, CDBG grants, revitalization grants.

VRP has no funding available specifically through their program. The brownfield program handles all the financial components offered by the state of Indiana and the EPA in the state.

Yes.

EPA funded RLF awarded in 1999. Local governments are eligible for a low interest loan program offered through IFA. Amounts above $\$ 750,000$ require approval by IFA board.

Yes.

Cleanup tax credit: Lesser of $\$ 200,000$ or sum of $100 \%$ of first $\$ 100,000$ of qualified investment plus $50 \%$ of the amount of the qualified investment over $\$ 100,000$.

Yes, in most cases the VRP participant is the responsible party. RP cannot get $3^{\text {rd }}$ party liability protections.

Cannot receive $3^{\text {rd }}$ party liability protections. Many of the financial incentives are for public entities. Allowed, but never happened. VRP staff reports that closure means closure to them. $\$ 751,117$ (since IFA created- shares small percentage with IDEM, but IFA actually receives the funds).

$\$ 2,726,705$

Similar

State RISC (Risk Integrated System of Closure) standards are in effect for VRP and brownfields program. Does not have force of law and must be used in conjunction with existing laws. Provides 
Institutional Controls?

Tracking System?

Costs to enter program?

VCP MOA?

Works with other agencies in state?

Economic Development

Environmental

Other

Location relative to RCRA? guidance on how to identify contamination and what level it should be cleaned to for final development.

IC's are viewed as acceptable to cleanups. VRP has a database and an inter-office database is under development. VRP has internal database, office wide database under development. VRP has public notice requirement that 'advertises' the use of IC. However, no online or publicly accessible database exists. Required to be recorded on deed of property.

Brownfield Program is Free.

VRP has $\$ 1000$ application fee. Cost recovery of oversight and time for participants in VRP. Municipalities are exempt from application fee of VRP.

Yes, December 1995

Yes

IFA is a quasi governmental authority that houses all financial mechanisms for the brownfield effort in Indiana.

IFA has some environmental components to it.

Governor's office issues the CNTS.

VRP and RCRA are both in Office of Land Quality of IDEM.

\section{INDIANA RCRA}

\section{RCRA Program Information}

Base Program: RCRA Authorized Yes

State?

Number of key RCRA rules authorized? 11/12

RCRA Corrective Action? Yes

RCRA Land Disposal Restrictions? 3 of 3

RCRA Closure Standards Yes

RCRA Remediation Waste Management Yes

Requirements?

Number of RCRA regulated facilities $\quad 7644$

(March 2007)

Absolute number of facilities with

1283

inspections

Percentage of facilities with inspections $\quad 16.78 \%$ 


\begin{tabular}{|c|c|}
\hline $\begin{array}{l}\text { Absolute number of NOV/Informal } \\
\text { enforcements }\end{array}$ & 488 \\
\hline $\begin{array}{l}\text { Percentage of Facilities with Informal } \\
\text { Enforcements/NOV }\end{array}$ & $6.4 \%$ \\
\hline $\begin{array}{l}\text { Number of Facilities with inspections } \\
\text { and informal enforcements }\end{array}$ & 478 \\
\hline $\begin{array}{l}\text { Percentage of inspected facilities with } \\
\text { informal enforcements }\end{array}$ & $37.25 \%$ \\
\hline $\begin{array}{l}\text { Absolute Number of Formal } \\
\text { Enforcements }\end{array}$ & 136 \\
\hline $\begin{array}{l}\text { Number of formal enforcements in } \\
\text { facilities with inspections }\end{array}$ & 122 \\
\hline $\begin{array}{l}\text { Percentage of inspected facilities with } \\
\text { formal enforcements }\end{array}$ & $9.50 \%$ \\
\hline $\begin{array}{l}\text { Percentage of facilities with formal } \\
\text { enforcements }\end{array}$ & $1.77 \%$ \\
\hline Number of facilities in SNC & 28 \\
\hline Percentage of facilities in SNC & $0.366 \%$ \\
\hline Number of NOV done by EPA & 2 \\
\hline $\begin{array}{l}\text { Percentage of NOV done by EPA } \\
\text { Total LQG facilities }\end{array}$ & $\begin{array}{l}0.41 \% \\
552\end{array}$ \\
\hline $\begin{array}{l}\text { Inspections at LQG } \\
\text { Percentage of LQG with inspections }\end{array}$ & $\begin{array}{l}420 \\
76 \%\end{array}$ \\
\hline Total SQG & 1108 \\
\hline $\begin{array}{l}\text { Inspections at SQG } \\
\text { Percentage of SQG with inspections }\end{array}$ & $\begin{array}{l}389 \\
35 \%\end{array}$ \\
\hline $\begin{array}{l}\text { Number of CESQG } \\
\text { Inspections at CESQG }\end{array}$ & $\begin{array}{l}5363 \\
356\end{array}$ \\
\hline $\begin{array}{l}\text { Percentage of CESQG with inspections } \\
\text { Number of TSD }\end{array}$ & $\begin{array}{l}7 \% \\
96\end{array}$ \\
\hline $\begin{array}{l}\text { Inspections at TSD } \\
\text { Percentage of TSD with inspections }\end{array}$ & $\begin{array}{l}65 \\
68 \%\end{array}$ \\
\hline $\begin{array}{l}\text { Number of Transporters } \\
\text { Inspections at Transporters }\end{array}$ & $\begin{array}{l}525 \\
53\end{array}$ \\
\hline $\begin{array}{l}\text { Percentage of Inspections at } \\
\text { Transporters } \\
\text { PPA for RCRA }\end{array}$ & $10 \%$ \\
\hline
\end{tabular}




\section{FLORIDA}

\begin{tabular}{|c|c|}
\hline \multicolumn{2}{|c|}{ Brownfield Programs Specific } \\
\hline Year Initial Legislation Passed & 1997 \\
\hline Administrative Organization & Department of Environmental \\
\hline & $\begin{array}{l}\text { Protection } \rightarrow \text { Regulatory Branch } \rightarrow \text { Division } \\
\text { of Waste Management } \rightarrow \text { Bureau of Waste } \\
\text { Cleanup }\end{array}$ \\
\hline $\begin{array}{l}\text { Citizens Ideology Measure of Program } \\
\text { Inception Year }\end{array}$ & 55.268 \\
\hline Government Ideology Measure of & 44.602 \\
\hline $\begin{array}{l}\text { Program } \\
\text { Inception Year }\end{array}$ & \\
\hline Citizen Measure of Ideology Most recent & 46 \\
\hline Year & \\
\hline $\begin{array}{l}\text { Government Measure of Ideology Most } \\
\text { recent year }\end{array}$ & 7 \\
\hline Employees in Overall Agency & 3599 \\
\hline Employees in Program(s) & $\begin{array}{l}3 \text { in the central Tallahassee office; } 14+ \\
\text { across regions. }\end{array}$ \\
\hline Status of Head of Agency & Secretary Appointed by Governor \\
\hline Name of Program(s) & Brownfields Redevelopment Program \\
\hline Additional Names? & Voluntary Cleanup Tax Credit (VCTC) \\
\hline \# of Liability Provisions & 1 \\
\hline CNTS & No \\
\hline NFA & Yes \\
\hline $\mathrm{COC}$ & No \\
\hline Other $/ 3^{\text {rd }}$ Party Liability & No $3^{\text {rd }}$ Party Liability Protections. \\
\hline & $\begin{array}{l}\text { Participants must have a brownfield area } \\
\text { designated by the local government before }\end{array}$ \\
\hline & accessing any liability protections or \\
\hline & financial benefits of the program. \\
\hline \# of Spinoff Programs & 3 \\
\hline EPA Approved UST Program? & No \\
\hline Non-approved UST Program & Yes \\
\hline Drycleaner Program & $\begin{array}{l}\text { Yes. Drycleaner Solvent Cleanup } \\
\text { Program. }\end{array}$ \\
\hline Others & Cattle Dip Vat program \\
\hline \# of Financial Incentives & 2 \\
\hline Grants & Not grant money specific in the \\
\hline & environmental department. However the \\
\hline & Development has a brownfield specific \\
\hline & grant program. \\
\hline -Types & 1. Environmental department will provide \\
\hline
\end{tabular}


-Notes

Loans

-Types

Tax Incentives

-Types

\section{PRP Participate?}

Restrictions on PRP Participation? grants-in-services to eligible nonprofit or public entities. Usually in the form of soil removal or assessment using state and EPA funds.

2. Office of Tourism, Trade, and Economic Development has a brownfield bonus. This brownfield bonus is designed to work with other job creation programs and provide an additional $\$ 2,500$ per job created over the other job programs minimum requirements. It was expanded in 2000 to allow brownfield sites to get the $\$ 2,500$ per job bonus even without participating in other job creation programs. This is a refund on taxes paid and only $25 \%$ can be taken each year.

State does not offer any typical cleanup grants or grants in money to entities.

Yes

Loan Guarantees. State revolving loan funds.

Yes.

1. The brownfield Program itself has a Voluntary Cleanup Tax Credit program (VCTC). This was initially created for and used by the drycleaners program.

However, the brownfield program has utilized the program more routinely and has become the primary user. The VCTC is only good for corporate income tax and provides up to a $\$ 500,000$ credit on corporate income tax. This is allowed to be rolled over to following years.

2. The Governor's Office of Trade, Tourism, and Economic Development has a number of incentives that are noted as being for brownfields (among others).

Notable brownfield relevant tax incentives are: Sales tax refund, target industry tax refund, and job tax credits.

3. Department of revenue has sales tax exemption on building materials for brownfield redevelopment.

Yes

In order for a responsible party to participate the contamination must have 


\section{Re-Openers}

128a Funding most previous year

128a Funding Cumulative

RBCA?

Other Risk Based Standards?

Institutional Controls?

Tracking System?

Costs to enter program?

VCP MOA?

Works with other agencies in state?

Economic Development

\section{Environmental}

Other

Location relative to $R C R A$ ? occurred before 1997 to be eligible. Any person responsible for contamination after 1997 cannot participate.

Technically yes. However, it is reserved for fraud in most cases.

Approximately $\$ 1.2$ million

$\$ 3,491,000$

Similar

Has set of risk based priciples written in statute and in administrative code. Will allow them in most cleanups.

Yes

The program has an extensive tracking system. It is online and publicly available. http://ca.dep.state.fl.us/imf/?focus=icr Brownfield Program is Free.

Tax credit requires an annual fee of $\$ 250$ to apply.

December 1999; Revised in November 2005 to expand eligibility including RCRA cleanup sites.

Yes

Governor's Office of Tourism, Trade, and Economic Development houses a number of brownfield related grants, loans, and tax incentives.

RCRA is allowed to do cleanups under The Brownfield Redevelopment Program--both are in the DEP, but in different bureaus within that agency.

Department of Revenue administers the sales tax refund and exemption.

Both are in the Department of Environmental Protection- $\rightarrow$ Regulatory Branch- $\rightarrow$ Division of Waste Management.. However, RCRA Is the Bureau of Solid and Hazardous Waste; Brownfield Program is in the Bureau of Waste Cleanup

\section{FLORIDA RCRA}

RCRA Program Information

Base Program: RCRA Authorized Yes

State? 
Number of key RCRA rules authorized?

$12 / 12$

RCRA Corrective Action?

Yes

RCRA Land Disposal Restrictions? 3 of 3

RCRA Closure Standards Yes

RCRA Remediation Waste Management Yes

Requirements?

Number of RCRA regulated facilities $\quad 26,272$

(March 2007)

Absolute number of facilities with $\quad 2106$

inspections

Percentage of facilities with inspections

$8.01 \%$

Absolute number of NOV/Informal $\quad 916$

enforcements

Percentage of Facilities with Informal $\quad 3.5 \%$

Enforcements/NOV

Number of Facilities with inspections

and informal enforcements

Percentage of inspected facilities with

informal enforcements

Absolute Number of Formal

Enforcements

Number of formal enforcements in

244

facilities with inspections

Percentage of inspected facilities with $\quad 11.6 \%$

formal enforcements

Percentage of facilities with formal

$1.14 \%$

enforcements

Number of facilities in SNC

Percentage of facilities in SNC

$0.16 \%$

Number of NOV done by EPA

0

Percentage of NOV done by EPA $\quad 0 \%$

Total LQG facilities

422

Inspections at LQG

Percentage of LQG with inspections

$50.7 \%$

Total SQG

15,148

Inspections at SQG

419

Percentage of SQG with inspections

$2.8 \%$

Number of CESQG

10,351

Inspections at CESQG

1324

Percentage of CESQG with inspections

$12.8 \%$

Number of TSD

Inspections at TSD

Percentage of TSD with inspections

$94 \%$ 


\section{NEVADA}

Year Initial Legislation Passed

\section{Brownfield Programs Specific}

Administrative Organization

Citizens Ideology Measure of Program Inception Year

Government Ideology Measure of

Program

Inception Year

Citizen Ideology most recent year $\quad 46$

Government Ideology most recent year 37

Employees in Overall Agency 207

Employees in Program(s)

Status of Head of Agency

Name of Program(s)

Additional Names?

\# of Liability Provisions

CNTS

$N F A$

COC

Other $/ 3^{\text {rd }}$ Party Liability

\# of Spinoff Programs

EPA Approved UST Program?

Non-approved UST Program

Drycleaner Program

Others
1999

Division of Environmental Protection $\rightarrow$

Bureau of Corrective Actions

46.63

57.26

1 in Land Recycling Program; 2 in VCP; 4 total in environmental cleanups.

Governor appointed Administrator

Land Recycling Program (LRP)

Voluntary Cleanup Program

LRP also called Brownfields Program 1

No

Yes-can only receive this through VCP.

No

No $3^{\text {rd }}$ Party Liability Protections.

1

Yes- 1998

NA

1. Environmental assistance program that provides outreach to rural communities concerning emergency responses to accidents or leaks or 
\# of Financial Incentives

Grants

-Types

-Notes

Loans

-Types

Tax Incentives

-Types

PRP Participate?

Restrictions on PRP Participation?

Re-Openers

128a Funding most previous year

128a Funding Cumulative

RBCA?

Other Risk Based Standards?

Institutional Controls?

Tracking System?

Costs to enter program?

VCP MOA?

Works with other agencies in state?

Economic Development

Environmental

Other

Location relative to RCRA? contamination.

2. MTBE (Methyl Tertiary Butyl

Ether) corrective action guidance.

2

Yes

CERCLA 128a Funds are granted to public entities for all aspects of brownfield remediation from assessments to cleanups. No private entity funding available.

Yes

Revolving Loan Fund

No

NA

Yes

No

Yes, however no one has completed the VCP-so unsure about how this would actually apply in real situations

$\$ 600,000$

Approximately $\$ 1.8$ million

Similar

State specified end use appropriate cleanup levels are used.

No

No

Brownfield Program is Free.

VCP has oversight costs determined on a case by case basis.

No

No

NA

NA

NA

Both are in the Division of Environmental Protection. RCRA Is in the Bureau of Waste Management. Was in the same bureau many years ago - but were separated into two different bureaus. 


\section{NEVADA RCRA}

RCRA Program Information

Base Program: RCRA Authorized Yes

State?

Number of key RCRA rules authorized? $\quad 12 / 12$

RCRA Corrective Action? Yes

RCRA Land Disposal Restrictions? 3 of 3

RCRA Closure Standards Yes

RCRA Remediation Waste Management Yes

Requirements?

Number of RCRA regulated facilities $\quad 1950$

(MARCH 2007)

Absolute number of facilities with $\quad 1212$

inspections

Percentage of facilities with inspections $\quad 62 \%$

Absolute number of NOV/Informal $\quad 254$

enforcements

Percentage of Facilities with Informal 13\%

Enforcements/NOV

Number of Facilities with inspections 253

and informal enforcements

Percentage of inspected facilities with $\quad 21 \%$

informal enforcements

Absolute Number of Formal 39

Enforcements

Number of formal enforcements in

facilities with inspections

Percentage of inspected facilities with $\quad 3.1 \%$

formal enforcements

Percentage of facilities with formal $\quad 2 \%$

enforcements

Number of facilities in SNC $\quad 0$

Percentage of facilities in SNC 0

Number of NOV done by EPA 12

Percentage of NOV done by EPA $\quad 4.7 \%$

Total LQG facilities 91

Inspections at LQG 84

Percentage of LQG with inspections $\quad$ 92\%

Total SQG 486

Inspections at SQG $\quad 409$

Percentage of SQG with inspections $\quad 84 \%$

Number of CESQG $\quad 1246$ 
Inspections at CESQG

Percentage of CESQG with inspections Number of TSD

Inspections at TSD

Percentage of TSD with inspections

Number of Transporters

Inspections at Transporters

Percentage of Inspections at

Transporters

PPA for RCRA
687

$55 \%$

11

10

$91 \%$

116

22

$19 \%$

No 


\section{CURRICULUM VITAE}

Name: Jaclyn Susan Marie Opp

Office: USI 218, Urban Studies Institute

University of Louisville, Louisville, KY 40208

ACADEMIC PREPARATION:

Ph.D. in Urban and Public Affairs, University of Louisville, May 2007.

Concentration: Policy and Administration

M.P.A, Department of Political Science, Western Kentucky University, 2003

B.A. in Economics, University of Colorado, Boulder, CO, 2001

\section{PUBLICATIONS:}

Heberle, Lauren C. and Opp, Susan M. (eds) (Forthcoming in 2007). Local Pursuit of Sustainability in the Face of Globalization. Aldershot, UK: Ashgate Publishing.

Opp, Susan M. (Forthcoming in 2007). Roles and Realities: The Future of Sustainable Development. In L. Heberle and S. Opp (Ed), Local Pursuit of Sustainability in the Face of Globalization. Aldershot, UK: Ashgate Publishing.

Five Encyclopedia Entries on State Government in Kurian, George T.(ed) (forthcoming). International Encyclopedia of Political Science. CQ Press.

Opp, Susan M. (2005). Brownfield Redevelopment: Make it Possible! Center for Environmental Policy and Management, US EPA Practice Guide Series. Available online at: http://cepm.louisville.edu/publications/publications.htm\#PG10

Opp, Susan M. (2005). Brownfields Program Placement in Local Governments. Center for Environmental Policy and Management, US EPA Practice Guide Series. Available online at: http://cepm.louisville.edu/publications/publications.htm\#PG11 
Opp, Susan M. and Hollis, Sarah (2005). Contaminated Properties: History, Regulations, and Resources for Community Members. Center for Environmental Policy and Management, US EPA Practice Guide Series. Available online at: http://cepm.louisville.edu/publications/publications.htm\#PG9

Opp, Susan M. (Forthcoming in 2007). Impact Fees as a Planning Tool and a Revenue Generator. Center for Environmental Policy and Management, US EPA Practice Guide Series.

\section{PROFESSIONAL EXPERIENCE:}

Assistant Professor Tenure Track, 2007

Texas Tech University, Department of Political Science

Research Assistant, 2004-present

Center for Environmental Policy and Management, University of Louisville

Research Associate, 2005-2006

Institute for Public Leadership and Public Affairs, Northern Kentucky University

Program Committee, 2004

The Sixth Symposium of the International Urban Planning and Environment Association, 2004

TEACHING EXPERIENCE:

Instructor, Fall 2005

Political Science Department, University of Louisville

\section{CONFERENCE ACTIVITY:}

Regulatory Administration and Brownfield Programs, Midwest Political Science Association. Chicago, IL. April 2007.

Bureaucratic Discretion and Legislative Control of the State Brownfield Programs, Southern Political Science Association. New Orleans, LA. January 2007.

Regulatory Administration: The Case of Brownfields. Georgia Political Science Association. Savannah, Georgia. November 2006.

Moderator: MPA Student Panel, Kentucky Political Science Association, March 2005

Brownfield Programs and Organizational Outcomes, Kentucky Political Science Association. Bowling Green, KY. March 2005.

Moderator: Economics of Sustainable Development, International Urban Planning and Environment Association, September 2004. 
PROFESSIONAL SERVICE:

- President, Ph.D. Student Association, 2005-2006

- Vice President, Ph.D. Student Association, 2004-2005

- Colonel, Honorable Order of Kentucky Colonels, 2004-2007 